\title{
THE ECONOMICS OF MENTAL HEALTH CARE IN IRELAND
}

Eamon O'Shea and Brendan Kennelly Irish Centre for Social Gerontology and Department of Economics, NUI Galway 


\section{THE ECONOMICS OF MENTAL HEALTH CARE IN IRELAND}

Eamon O'Shea and Brendan Kennelly

Irish Centre for Social Gerontology and Department of Economics, NUI Galway 



\section{Contents}

Foreword - Mental Health Commission v

Acknowledgements vii

Executive Summary viii

A Note on Terminology Used in and Coverage of This Study xiii

CHAPTER 1

Economics of Mental Health Care in Ireland 2

Introduction 2

Context and Background 2

Expenditure on Mental Health Care in Ireland 4

Balance of Care in Ireland 8

Economic Evaluation of Mental Health Services

Social Inclusion and Equity $\quad 16$

Conclusion $\quad 19$

CHAPTER 2

The Economic and Social Costs of Mental Health Problems in Ireland 22 Introduction 22

Limitations of Cost-of-Illness Studies 23

Methodological Cost Issues $\quad 25$

Prevalence Data 27

Activity and Cost Sources 32

Health and Social Care Cost Estimates 35

Other Direct Care Cost Estimates 37

Cost Estimates for Output Losses 38

Conclusion $\quad 41$

CHAPTER 3

Preferences for Resource Allocation in Mental Health Care in Ireland $\quad 46$ Introduction $\quad 46$

$\begin{array}{ll}\text { Contingent Valuation } & 47\end{array}$

Methodology 50

The Questionnaire 50 
The Scenarios $\quad 51$

Eliciting Willingness to Pay 51

Descriptive Statistics

Interval regression $\quad 54$

Rankings $\quad 55$

Willingness to Pay $\quad 56$

Reasons for Contributing and Not Contributing 59

Discussion $\quad 62$

$\begin{array}{ll}\text { Conclusion } & 65\end{array}$

$\begin{array}{ll}\text { CHAPTER } 4 & 67\end{array}$

Balance of Care in the Community and at Work 68

Introduction 68

Balance of Care Issues $\quad 68$

Cost-Effectiveness of Community Care Models 70

Cost-Effectiveness of Case Management 71

Cost-Effectiveness of Home Treatment $\quad 72$

Cost-Effectiveness of Re-Settlement Studies $\quad 73$

Cost-Effectiveness of Crisis Intervention 73

Cost-Effectiveness of Day Hospital Provision 75

Evaluation of Family Support within Community-Based Care 76

Factors Affecting Care Givers' Burden $\quad 76$

Work and Mental Health $\quad 78$

Vocational Rehabilitation Schemes $\quad 79$

Lessons for Ireland $\quad 83$

$\begin{array}{ll}\text { CHAPTER } 5 & 87\end{array}$

$\begin{array}{ll}\text { Conclusions } & 88\end{array}$

Bibliography 95

Appendix 1: Questionnaire 110 


\section{Foreword}

Since 2001 the World Health Organisation set out and refined a roadmap towards the protection and improvement of mental health. The publication of this report marks the reaching of another important milestone on that road.

The WHO report of 2001, Mental Health: New Understanding, New Hope identified a number of elements that are essential for the protection and improvement of the mental health of the population. Two of these elements were a national policy on mental health, and legislative provisions that protect the human rights and dignity of people with a mental disorder.

Since then, the Government has moved on both. It announced details of national mental health policy with the publication of 'A Vision for Change' in 2006, and later that year, the Mental Health Act 2001 was commenced in full.

In January 2005, the World Health Organisation produced a Mental Health Action Plan for Europe which specified further actions to be taken by member states in twelve areas over a five to ten year period. These include mental health promotion, tackling stigma and discrimination, making specialist community based mental health services available and establishing partnerships across sectors. This action plan - the Helsinki Declaration - also advocates that governments demonstrate the centrality of mental health as "mental health is central in building a healthy, inclusive and productive society".

This report is an attempt to do that, detailing as it does the positive economic case for investment in mental health services. Of course the reasons to invest in mental health services - indeed in health services in general - are much more than economic. A society's decision on the extent to which it will provide services and support to its more vulnerable members, including those with health difficulties, springs from its social and moral values rather than from rigorous cost/benefit analysis. This report does not say that mental health services should be provided only because this is economically advantageous - there are much more fundamental reasons behind society's decisions on how it allocates it resources.

However the report does make show that aside from the moral and social arguments, there is a powerful economic case for investment in mental health services. It estimates that the overall cost of poor mental health in Ireland was just over $€ 3$ billion in 2006, or 2 per cent of GNP. The 
economic evidence examined here suggests that the individual and social returns from judicious investment in mental health in Ireland are likely to be high and sustained.

This report is the result of the decision of the Mental Health Commission in 2005 to commission the National University of Ireland, Galway to conduct research on the economics of mental health care in Ireland. Key questions to be addressed in this study were to assess the economic burden of mental illness in Ireland and to review the cost effectiveness of treatment programmes. Economic evaluations on mental health treatment programmes have been conducted in some other countries but there is a serious dearth of such studies in Ireland.

The report "The Economics of Mental Health Care in Ireland" makes an important contribution to the discussion and debate on investment in mental health services and how to ensure provision of efficient and effective mental health services. The report also raises a number of issues that must be addressed. These include the immediate requirement for accurate and comprehensive mental health information systems, (this is also advocated in the Mental Health Commission's Research Strategy 2005 and Mental Health Commission's Quality Framework for Mental Health Services in Ireland 2007) and the further application of economic analysis to mental health care in Ireland.

The Mental Health Commission wishes to thank Eamon O'Shea and Brendan Kennelly and all those who contributed to this report.

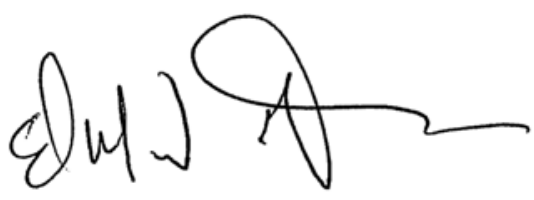

\section{Dr. Edmond O'Dea}

Chairman 


\section{Acknowledgements}

We are very grateful to a number of people for their help and support during the research for this report, particularly to Brid Clarke, Chief Executive Officer of the Mental Health Commission and Dr Fiona Keogh also of the Commission. Special thanks to Valerie Moran who provided research assistance for this report. We are grateful to Pat Brosnan and Siobhán O'Reilly from the HSE in Limerick who provided data on unit costs. Thanks to Dorothy Watson in the ESRI for facilitating the data collection for the contingent valuation study.

Dr Brenda Gannon co-authored Chapter 3 of the report. 


\section{Executive Summary}

Recent years have finally seen mental health become more important in global health policy agendas, particularly within Europe. All 52 member states of the WHO European Region, as well as the European Union and the Council of Europe, endorsed a Declaration and Action Plan on mental health in 2005 at a meeting in Helsinki in 2005. The European Union issued a Green Paper on developing strategies to improve mental health in the European Union in 2005. In Ireland, the publication of $A$ Vision for Change in 2006 raised the importance attached to mental health issues in this country. After years of relative neglect, mental health has finally begun to receive the attention it deserves. Yet much remains to be done. The annual reports of the Inspector of Mental Health Services have highlighted serious deficiencies in the quality of the mental health services. Stigma continues to be a major issue for people with mental health problems. The proportion of total health care expenditure devoted to mental health care in Ireland, at just over 6 per cent, is low relative to many other countries. There is significant disability associated with mental health problems relative to other health problems, as relatively large numbers of people acquire disorders early in life and have them for life. According to the World Health Organization, mental health problems account for approximately 20 per cent of the total disability burden of ill health across Europe.

There are economic, social and individual gains to be had from increasing expenditure on mental health care services. This report concentrates on the economic case for increased investment in mental health services. We believe this is an opportune time for policy makers and service providers to consider this case. Our research in the following chapters can be summarized as follows: policy makers cannot afford not to invest in mental health; service providers and researchers in Ireland need better data for any extra investment to yield the maximum returns for individuals, society and the economy; advocacy groups and researchers need to increase their efforts to persuade the public that increased investment in mental health services represents a wise and just use of resources.

The reasons that policy makers should invest more in mental health are: (1) the economic cost of poor mental health in Ireland is very significant; (2) the Irish public has expressed a willingness to pay extra taxation for a mental health programme that would enable more people to live in the community; (3) there is a burgeoning economic base of evidence about particular interventions which have a positive effect on the quality of life of people with mental health problems. 
While it is difficult to be precise about the economic cost of poor mental health in Ireland, we provide baseline estimates which suggest that the overall economic cost of mental health problems was just over $€ 3$ billion in 2006, which is equivalent to 2 per cent of GNP. The health care system accounts for less than one quarter of overall costs. The main economic costs of mental health problems are located in the labour market as a result of lost employment, absenteeism, lost productivity and premature retirement. The significant human and social costs associated with mental health problems, including pain, suffering, stigma, reduction in quality of life and suicide are not included in the baseline estimates.

Given the multi-faceted impact of mental health problems and the many and damaging consequences of poor mental health, it is surprising how little attention has been focused in Ireland on the economic and social returns to greater investment in mental health. The evidence suggests that it is possible to impact on many of the elements that contribute to the development of mental health problems if the political will exists to direct more resources towards mental health. Although per capita expenditure on mental health care has increased in recent decades in Ireland, spending as a proportion of CNP remains low in comparison with similarly developed countries in Europe. Clearly, we have not yet made the connection between increased public spending on mental health care and individual and societal gains. Making mental health a national health priority in Ireland would be an important first step in realising the potential gains associated with increased spending on mental health. As part of that prioritisation, we should set a target of 10 per cent for mental health care expenditure as a proportion of overall health expenditure, to be realised over a five year period.

Our research clearly shows that citizens do value spending on mental health care. We used a well-known technique in economics - a contingent valuation survey - to estimate how much people would be willing to pay in extra taxation for a particular improvement in mental health services. The results from the survey demonstrated that people would be willing to make significant tax contributions to new community-based services for people with mental health problems, counteracting the view sometimes expressed that people do not care at all about mental health care provision. However, the survey also found that people tend to value spending on cancer and ageing programmes more than they do mental health care. One of the main reasons for this is that many people have little knowledge about mental health problems, leading them to underestimate the negative consequences arising from such problems. In addition, some people may have negative attitudes about people with mental health problems which influence their subsequent judgements on resource allocation and prioritisation, especially if they are asked to compare spending on mental health with spending on more 
recognisable and socially acceptable illnesses and conditions such as cancer or age-related disabilities.

Increasing expenditure on mental health care is a necessary but not sufficient condition for realising the potential of people with mental health problems. Expenditure needs to be increased, but money needs to be spent fairly and efficiently. It is now accepted generally that resource allocation for mental health is not simply a dichotomous choice between spending on institutional care and spending on community care. Instead, a balanced care approach is required, where frontline services are based in the community but hospitals and other related care settings play important roles as specialist providers. The emphasis should be on developing an integrated continuum of care where resources follow people, thereby allowing them to receive the best possible care in the most optimal setting.

Addressing questions of efficiency in relation to the continuum of care in Ireland will require specific domestic research funding to support the development of an evaluative framework for the analysis of all types of mental health care spending. We have shown in this report the benefits of systematic evaluation of mental health care services. New funding initiatives are now required to encourage the development of dedicated multi-disciplinary mental health research units across the country, including the establishment of a National Centre for Mental Health Economics Research, to examine how well current monies are spent. This could be done through the Health Research Board granting system or through initiatives within the Mental Health Commission.

We need much more information on the need for and provision of mental health services in the country. A community-based analysis of need, linked to local and national prevalence studies, should be the first step in setting up new resource allocation structures. A large national morbidity survey is necessary every five years to determine the prevalence of mental health problems in the population and to find out what effect mental health problems have on work, informal activities and broader indicators of quality of life. We also need comprehensive, annual information on existing mental health services by catchment area, including information on unit costs. This would tell us where the gaps are, thereby ensuring much more equity in the allocation of resources. We already have much of the population-based data on demography and deprivation that could be used to supplement new information on prevalence. The development of performance indicators should be used to ensure greater compatibility between need and service delivery, once such information becomes available. 
Work is very important for people with mental health problems. It provides income, social status, a sense of achievement and a means of structuring one's time. The available evidence suggests that place and train models are generally more effective than pre-work training in helping people find competitive employment. Moreover, placing individuals in open employment and providing them with ongoing support seems to be more cost effective than vocational rehabilitation approaches. But even where proven interventions are available, there are many barriers that prevent people with mental health problems from taking up work. These barriers include stigma and discrimination, poorly structured social welfare systems, low expectations, fear of failure, lack of life skills and employers' lack of knowledge in dealing with mental health problems. These barriers are real, suggesting that concerted, person-centred actions are required to address work-related issues for people with mental health problems in Ireland. Interventions should concentrate on getting more people with mental health problems into the labour force and ensuring they stay there through dedicated, firm-specific mental health wellbeing programmes that cover all workers and employers.

Stigma may also explain the reluctance of citizens and governments to support new investment in mental health care. There is a prevailing tendency to exclude people with mental health problems from mainstream economic and social life. To counteract this, public interventions aimed at reducing the stigma attached to mental health problems are required. We have had national campaigns to address poverty, legislation to deal with disability, and programmes to highlight age discrimination. We now need a similar national strategy to address the stigmatisation of people with mental health problems and promote their economic and social inclusion at all levels of society. Affirmative action by government is required to harness the potential economic and social gains to be had from greater social inclusion of people with mental health problems. Political leadership may be required to bring mental health problems to the notice and attention of citizens, who may be unwilling or unable to confront such issues. Higher levels of engagement by citizens in mental health issues will, in turn, provide support and sustenance for the increase in expenditure that is required from government.

In summary, this report makes a rational economic argument for greater investment in mental health in Ireland. Additional investment is required to address the range of costs associated with mental health problems; personal, social and economic. The economic potential of the economy is being affected by a failure to invest in mental health care services. This is the central message of this report. There is public support for additional spending on mental health care in Ireland, particularly in relation to community-based initiatives. Innovative programmes to help people with mental health problems live at home and continue to work are particularly 
merited, but any new initiatives should be subject to economic and social evaluation. Negative public attitudes to mental health problems also need to be addressed through carefully structured education, training and public information campaigns. All of the economic evidence suggests that the individual and social returns from judicious investment in mental health in Ireland are likely to be high and sustained. 


\section{A Note on Terminology Used in and Coverage of This Study}

Many terms are used to describe mental health difficulties and there is much debate on the subject. The stigma associated with mental health difficulties has meant that some terms are seen as pejorative by some service users and advocacy groups.

We have used the phrase mental health problems (or poor mental health) to describe the full range of mental health difficulties that might be encountered, from the psychological distress encountered by many people, to serious mental disorders and illnesses that affect a smaller population.

The term mental illness is used to refer to specific conditions such as schizophrenia, bipolar disorder and depression.

Note that our study does not cover conditions such as Alzheimer's disease, dementia, alcohol and drug dependency, and intellectual disabilities. Data considerations have meant that we have also excluded mental health problems of children and adolescents from our study. 


\section{CHAPTER 1

in

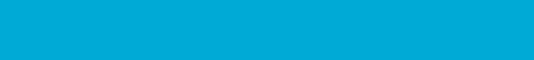

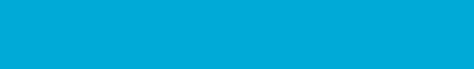
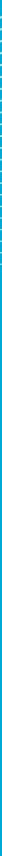


\section{Economics of Mental Health Care in Ireland}

\section{Introduction}

Our overall task in this report is to provide economic analysis and reflection on mental health care provision in Ireland, with particular emphasis on three themes: cost of illness; economic evaluation; and willingness to pay. We will devote a separate chapter to each of these topics, but prior to that we need to outline the potential role and scope of economics in relation to mental health care in Ireland. The starting point in any economic analysis is to recognize that resources are scarce and that choices therefore have to be made about the allocation of resources among competing objectives. Economics can help us to understand the processes which determine the allocation and distribution of resources to mental health care. It facilitates an analysis of costs and benefits of various forms of provision for people with mental health problems and provides guidance on who should get what services, when and where. Economic analysis is therefore a crucial aid to decision making on resource allocation and on priority setting. Economics also helps in the analysis of equity issues. Who experiences mental health problems and what are the consequences for individuals and society are important questions for policy-makers. Given the importance of economic analysis for resource allocation decision-making, it is surprising how little it has been used in studies of mental health care in Ireland. What follows is an argument for the application of economic reasoning to mental health care issues in the country.

\section{Context and Background}

One of the major constraints for undertaking any type of economic analysis of mental health care programmes is the absence of quality data. We are particularly weak in this country in respect of information on prevalence and incidence rates for every kind of mental health problem. The results from the first National Psychological Wellbeing and Distress Survey (NPWDS) have just been published by the Health Research Board (Tedstone Doherty et al, 2007). This is a very important and welcome development and we look forward to this survey being repeated in future years with hopefully larger samples. However the fact that this survey was only carried out for the first time in 2006 highlights the lack of data that has hindered any rational analysis of many aspects of mental health care in Ireland up to now. The short version of the General Health Questionnaire (CHQ12) was used as a measure of psychological distress in the NPWDS and Tedstone Doherty et al found that $12 \%$ of adults aged 18 and over were at risk of psychological distress using this measure (Tedstone Doherty et al, 2007: 33). According to the World Health Organisation, about one in four individuals in a typical society will have a mental health problem at some point in their lives. In the UK, data from the Psychiatric Morbidity 
Survey suggest that at any point in time about $16 \%$ of the population suffer from a mental health problem (Singleton et al, 2002).

The NPIRS database held by the HRB covers mental health care inpatient services provided in public and private hospitals. However, there is a lack of basic information on community-based provision for people with mental health problems, as well as an absence of data on overall need for services. Similarly, there is no comprehensive information available on housing and social care services provided to people with mental health problems. These information gaps have been recognised and criticised by the Inspector of Mental Health Services in various reports. The absence of good information makes planning difficult and undermines attempts to improve the economic efficiency and equity of services.

In 2006, the Department of Health published a report from the Expert Group on Mental Health Policy entitled A Vision for Change. This report, which sets out a comprehensive policy framework for mental health services, proposes a holistic view of mental health problems incorporating biological, psychological and social aspects. Ireland, in common with most developed countries, now recognises the need to improve the broader quality of life of people affected by mental health problems, including service users, their families and other members of society more generally. A person-centred approach to care is an important part of this philosophy. Much more attention is also now given to the process of care - for example, how are people with mental health problems involved in decision making about their care - and the locus of care, as shown by, for example, the decisions taken in many European countries to shift the balance of provision from hospital to the community, and by developing more effective ways of supporting people who live in 'ordinary' community settings. The type of mental health system envisaged in A Vision for Change reflects this broad inclusive approach to mental health as reflected in the following passage taken from the report:

The mental health system should deliver a range of activities to promote positive mental health in the community; it should intervene early when problems develop; and it should enhance the inclusion and optimal functioning of people who have severe mental health problems. Service providers should work in partnership with service users and their families, and facilitate recovery and reintegration through the provision of accessible, comprehensive and communitybased mental health services. (Department of Health and Children, 2006:14)

A Vision for Change is an important landmark for the future development of services for people with mental health problems in Ireland. It provides both the vision and the route map for a significant expansion in mental health services over the next 10 years. However, it is critical 
that information systems and economic evaluative frameworks are put in place to ensure that any additional resources are well spent and yield maximum benefits for service users and their families. Mental health problems are a major cause of disability in Europe, accounting for up to $20 \%$ of the total disability burden of ill health. Estimates from the UK suggest that the total economic cost of poor mental health amounted to around \pm 77 billion in 2002/03 (Sainsbury Centre for Mental Health, 2004: 1). However, there has been very little economic analysis of mental health problems in Ireland. This report is a first step in developing an economics framework for the rational allocation of resources for mental health in Ireland.

\section{Expenditure on Mental Health Care in Ireland}

Irish health care is financed by both public and private agencies, although the majority of resources come from public sources. While absolute spending on health care in Ireland has increased significantly in the past decade, the health care budget remains towards the middle of OECD expenditure levels. The share of total public health expenditure spent on mental health services has fallen in the past twenty years from just under $14 \%$ in 1984 to $7 \%$ in 2005 (Figure 1). Mental health care has lost out in the ongoing scramble for scarce health care resources. In absolute terms, expenditure on mental health care has risen significantly, but the increase has been below that of other components of health care expenditure in the past twenty years. $A$ Vision for Change recommended that the proportion of the overall health budget allocated to mental health should rise to $8 \%$. In the 2007 Budget, total public spending on mental health is $€ 800$ million, out of an overall health budget of $€ 14$ billion, so that the mental health share is likely to be closer to $6 \%$ than to $8 \%$.

Figure 1: Mental Health Expenditure as Percentage of Total Health Expenditure 1984-2005

\section{$\%$}

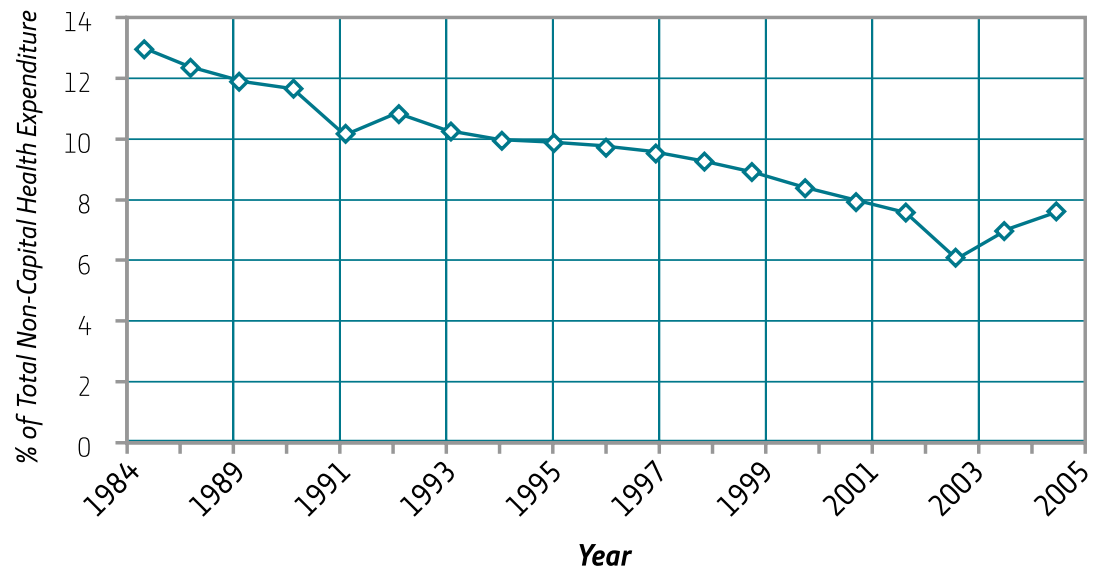

Source: Department of Health and Children, 2006 
Figure 2 shows mental health expenditure as a percentage of total health expenditure in a number of European countries. According to a European Commission report, funding below $5 \%$ of total health expenditure may indicate an inappropriate allocation of resources to mental health given that mental health problems contribute to more than $20 \%$ of disease burden in Europe (Mental Health Europe, 2002). Ireland's share is now just above the 5\% cut-off point and remains in the middle range with countries such as Belgium and the Netherlands, but significantly below countries such as the UK and Sweden.

Figure 2: Mental Health Expenditure across European Countries as a Percentage of Total Health Expenditure

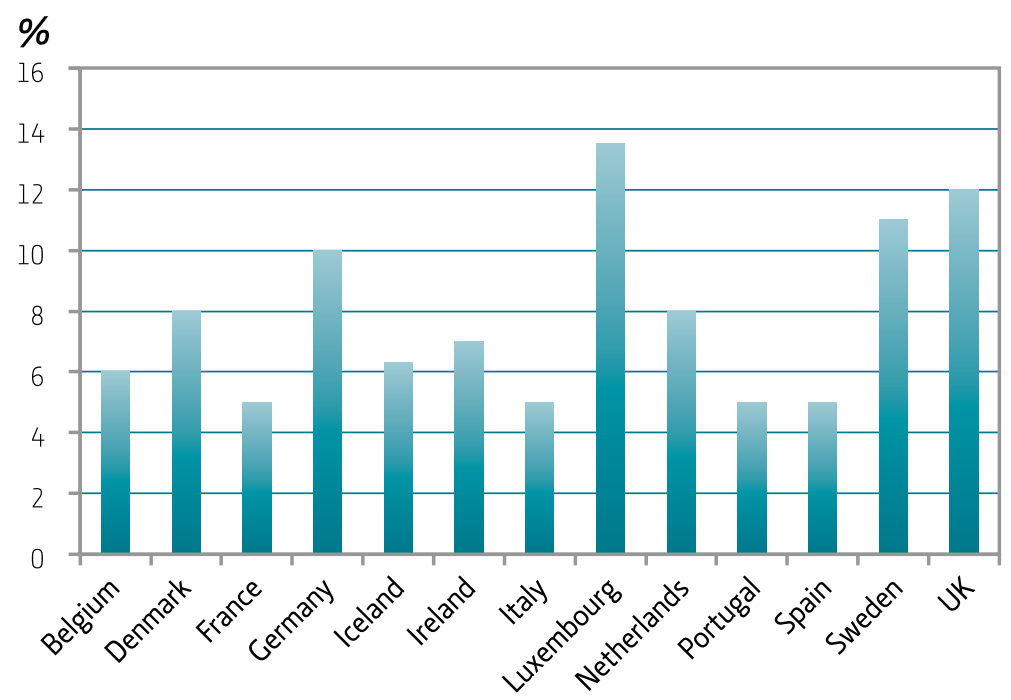

Source: Mental Health Europe, 2002

While the ratio of mental health care expenditure to total health care spending has declined, there has been a continuous rise in per capita mental health care expenditure between 1984 and 2006. There has been a four-fold increase in per capita spending over this period (Figure 3). This increase reflects more generous absolute allocations to mental health, most of which has gone on pay rather than on new services, but it also reflects some redistribution of mental health care recipients to other budgets within acute care settings and in the long-stay care sector. 
Figure 3: Mental Health Expenditure Per Capita 1984-2005

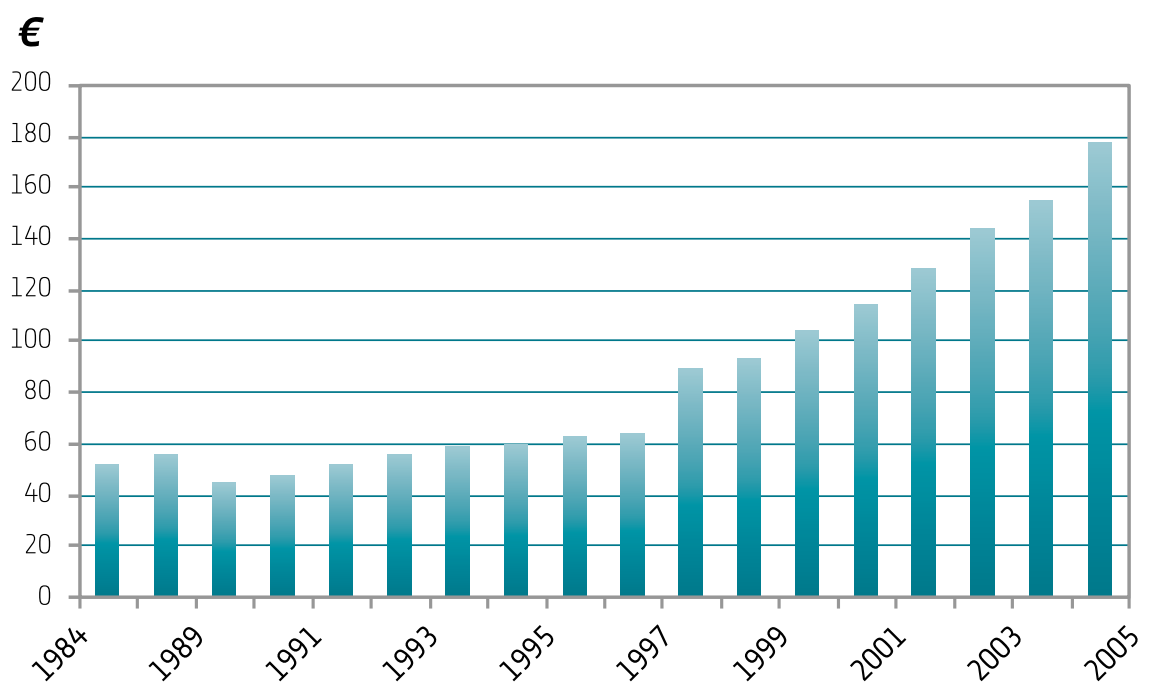

Source: Department of Health and Children, 2006

There is insufficient data available to examine with any accuracy the breakdown of expenditure within the mental health services. The geographic distribution of expenditure appears to be historically based and tends to follow the old mental hospital system rather than follow needs (Inspector of Mental Health Services, 2004; Mental Health Commission (MHC), 2005). In some areas, catchment boundaries have remained unchanged for decades, with no recognition of the enormous demographic changes that have taken place. Similarly, the number of communitybased places generally reflects the past existence of a large institution, rather than a considered response to local needs (MHC, 2005). The result is wide variability in the provision of mental health funding across current catchment areas, including no relationship between size of catchment area and the budget allocated (O'Keane et al., 2005).

This variability is confirmed by a crude analysis of funding per catchment area based on figures published in the 2004 Annual Report of the Mental Health Commission. Taking the catchment admission rate as a proxy of local need, which admittedly is not ideal, and using funding per capita as the measure of resources, the level of inequity in the allocation of resources is stark (Figure 4). Only 6 of the 32 catchments have a fund-needs difference of less than 10\%. Calway East receives two and a half times the average resources relative to its admission rate, suggesting that community care resources in this catchment area should be among the best in the country. We cannot say whether this is the case without an audit of services, but that is 
the implication from the figures. On the other hand, there is a significant gap in the opposite direction between the share of resources allocated to areas such as Wicklow and Tipperary South and the share of admissions of these areas. There are historical reasons for these differences related to staffing and institutional budgeting arrangements, but it does raise issues about the resource allocation process generally across the country and the need for better data to ensure a match between need and resource allocation.

Figure 4: Funding per capita on admission rates for catchments

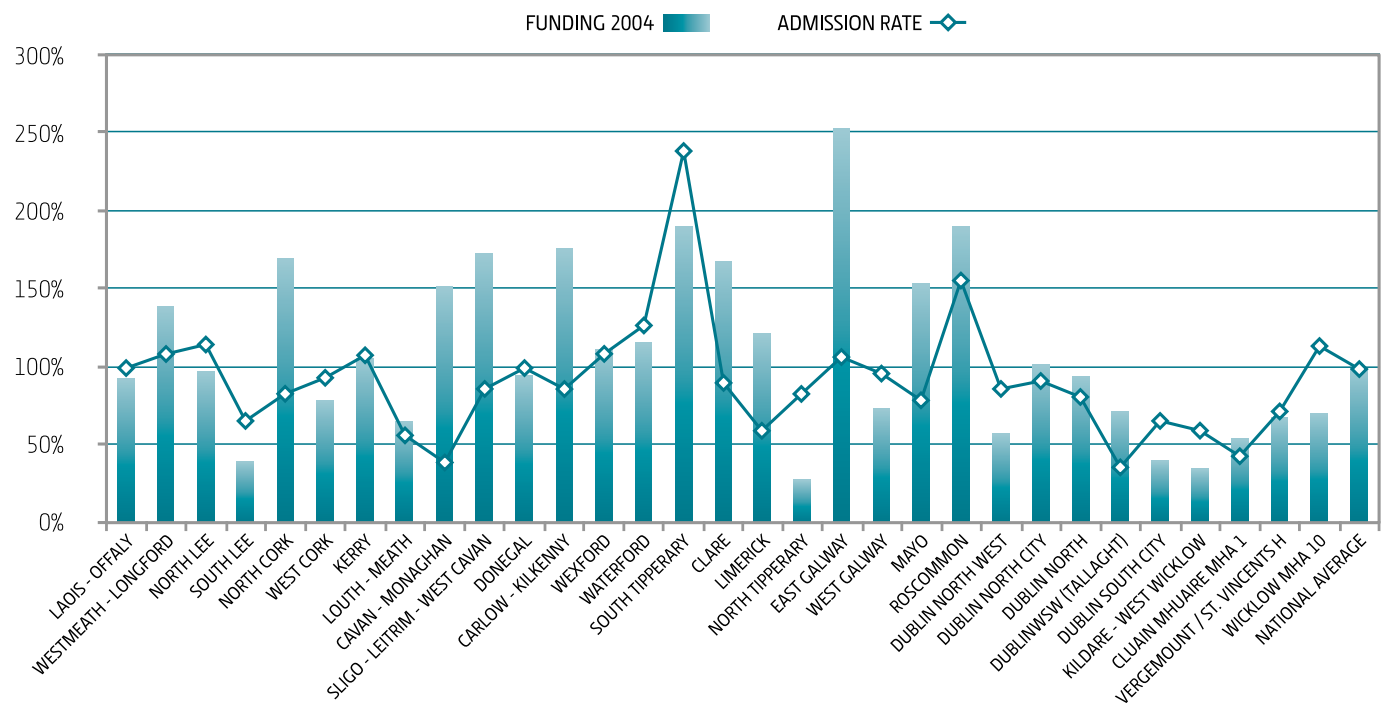

Source: data extrapolated from MHC, 2005

The ratio of inpatient beds ranges from a low of 35.0 per 100,000 in the HSE South West Area (Dublin) to a high of 235.8 per 100,000 in the HSE South Eastern Area (Dublin). The low provision in the HSE South West Area is surprising given that this area is known to have relatively high levels of deprivation. The HSE North East Area and HSE East Coast Area also have comparatively low rates of inpatient beds (MHC, 2004). People in areas suffering from high levels of social deprivation tend to have the highest rates of mental health problems and hence such areas have the greatest need for clinical resources and services. However, several studies (O'Neill et al., 2002; O'Keane et al., 2003; O'Keane et al., 2005) have found that it is the areas that are most in need of resources that are under-resourced. A Vision for Change recommended that extra funding be provided for areas that exhibit social and economic disadvantage with associated high prevalence of mental health problems. It also argued that catchment boundaries should be realigned in order to reflect the current social 
and demographic composition of the population. This should happen as a matter of urgency through the adoption of population-based resource allocation models within the HSE. There is a need for a new funding mechanism that takes social deprivation directly into account in assessing mental health need in the population.

Currently, levels of funding are not necessarily related to quality of care and some areas with high funding maintain high levels of institutional care with less than fully developed community-based alternatives. In fact, O'Keane et al. (2005: 8-9) found that there was no clear relationship between financial allocation and the provision of clinical services. They concluded that money allocated to mental health was probably being sidetracked to other areas in the health service. The allocation of funding and resources based on historical and political factors means that there continues to be high numbers of long-stay patients in catchments which are or were served by a mental hospital. This is the case in East Galway, South Tipperary, Wexford, Waterford, Carlow/Kilkenny, Longford/Westmeath, Cork and Kerry (MHC, 2004: 114). Other areas have high rates of 24-hour staffed community places in addition to high numbers of hospital beds, suggesting that the services provided in these areas are still very traditional and bed-based. In many cases 24-hour staffed community residences differ little from the traditional long-stay institutions they replaced.

When mental hospitals close in the absence of a well-developed rehabilitation service there is a high risk that people moved to 24 -hour staffed community residences are not receiving the type of rehabilitative input that is necessary. There is also the risk that people newly presenting with severe mental health problems will be placed in such residences, rather than being given the kind of treatment and support that allows them to function more independently in their own environment. The continued existence of long-stay mental hospitals means that nursing resources are not available to community mental health teams because both long-stay wards and 24 -hour staffed community places are very demanding in terms of nursing numbers. This in turn decreases the ability of services to provide true community-based care.

\section{Balance of Care in Ireland}

Since the publication in 1984 of Planning for the Future, it has been national policy to move from an institutionally-oriented psychiatric service to a community-centred one. This involves both deinstitutionalisation and the development of new community-based models of mental health service delivery. The general trend in the pattern of admissions to psychiatric facilities in Ireland has been a significant reduction in the number of admissions to public psychiatric 
hospitals and a greater reliance on community-based care. In 1966, there were 18,084 inpatients in psychiatric hospitals and units but this number had fallen to 3,332 in 2006 (Table 1). One third of these have been living in institutional care for more than 5 years.

Table 1: Number of People in Psychiatric Hospitals and Units in Ireland: 1966-2006

\begin{tabular}{ll} 
Year & Number \\
\hline 1966 & 18,084 \\
\hline 1971 & 16,661 \\
\hline 1976 & 14,473 \\
\hline 1981 & 13,984 \\
\hline 1986 & 11,643 \\
\hline 1991 & 8,207 \\
\hline 1996 & 5,212 \\
\hline 2001 & 4,321 \\
\hline 2006 & 3,332 \\
\hline
\end{tabular}

Source: Department of Health and Children, 2006

The significant reduction of people in institutional care is testimony to the desired change in the balance of care towards care in the community. Nowadays, people with mental health problems are often seen in outpatient settings, in day hospitals and day centres, and at home. Only a small proportion of these individuals are admitted to inpatient care, and when admission does occur it is often to psychiatric units in acute hospitals for relatively short periods of time. Notwithstanding changes to the balance of care, Ireland has still a relatively higher number of residential beds than other countries and more of these beds in long-stay institutional settings (WHO, 2005). Moreover, the number of psychiatric nurses in Ireland is over four times that of other high income countries, suggesting a system that remains overly institutionalised, albeit for historical reasons. While there has been progress in the development of community-based services, care tends to be centred on institutions in the community (day hospitals/day centres), with limited use being made of outreach/home care type services.

There is a desire amongst service users to see an expansion of mental health service options established in local communities so that comprehensive care can be provided. A Vision for Change recognises the need for services to become genuinely community-based, offering 
assessment and evidence-based best practice interventions as close as possible to where the user lives. It recommends that people with mental health problems should be cared for where they live and, if inpatient care is necessary, it is to be provided in the least restrictive setting (Department of Health and Children, 2006: 15). However, significant gaps continue to exist with respect to community-based provision. For example, there are only a small number of specialised rehabilitation teams in the country and there is a lack of adequate housing and accommodation options for people with mental health problems. In the absence of statutory provision, families and voluntary groups have often been forced to fill many of the gaps in community-based resource provision. Unfortunately, the current system is poorly co-ordinated. Any further development of community-based mental health services will require more resources and improved integration among statutory providers, service users, families, voluntary organisations and self-help groups.

In developing new services, the needs of particular sub-groups of the population may be greater than others and may require special attention. This is particularly the case for children, homeless people and prisoners. Services for children and adolescents have long been recognised as inadequate. In 2006, the Mental Health Commission annual report reported that basic staffing is not available in child and adolescent mental health services; waiting lists are long, and there are very few day services. Homeless people are another vulnerable group. Although data on the prevalence of mental health problems among the homeless is limited, estimates suggest that between 30 and 50 per cent of homeless people in Ireland have a mental health problem (Amnesty International, 2003: 42). A report by the Health Research Board in 1999 noted that homeless people make up approximately one third of those who were inappropriately placed in acute psychiatric beds (cited in Amnesty International, 2003, p.42.). Similarly, a number of reports have concluded that mental health services for prisoners are inadequate, particularly in relation to inpatient care (Amnesty International, 2003; MHC, 2002). Inadequate replacement of long-stay facilities with appropriate community provision of mental health care has also resulted in the increased use of forensic psychiatric services and the accumulation of those with mental health problems in Irish prisons (O'Neill et al., 2002: 48).

A Vision for Change acknowledged the need for additional funding to support increased community-based care generally and for specific at-risk groups. It recommended the closure of all mental hospitals and the re-investment of resources released by these closures in other areas of the mental health service. One of the difficulties with this approach is the absence of reliable information for Ireland on whether the arguments for the various new models for service delivery proposed in A Vision for Change are compelling. Certainly, all of the available 
evidence and accumulated clinical experience in many countries support a balanced care model that includes elements of both hospital and community care. However, community-based models of care have been shown to be sometimes as costly as the services they replace, so they cannot be considered cost-saving or cost-containing measures (WHO, 2003). They need to be judged on their impact on health and social outcomes before they can be deemed a success. The policy issue is not just about deinstitutionalisation. It is about putting in place community mental health services delivered in home care settings that result in better outcomes for people with mental health problems. Costs matter in this new approach, but only when considered in tandem with outcomes.

The problem is that there is no tradition of carrying out economic evaluation of health care services in Ireland, let alone evaluation of mental health care services. We have neither the administrative structures nor the skills set in place to routinely collect and interpret data on either costs or outcomes. This means that we often have to rely on data and economic studies from other countries on the cost effectiveness of various interventions for people with mental health problems. Extrapolation based on the experiences of other countries can be useful, but it needs to be augmented by national studies of our own. The main types of economic evaluation that might be used in such work are set out in the next section. Developing the capacity to carry out this evaluation is a separate issue, but is crucial to the development of any new culture of evaluation.

\section{Economic Evaluation of Mental Health Services}

The fact that choices have to be made on how scarce resources are allocated has led to concern about the costs of mental health problems and the pursuit of cost-effectiveness in the ways that resources are used in the treatment and support of people with mental health problems. The costs of mental health problems can be substantial, falling on service users, their families, the health and social care system, and the wider national economy. There is also growing concern about the increase in the cost of some treatments for mental health problems. Some of the the newer treatments for severe forms of depression and schizophrenia are very expensive. Not surprisingly, many people feel that there is a pressing need to determine whether the newer treatments are cost effective. The potential use of cost-effectiveness is not confined to new treatments. It is relevant for all aspects of resource allocation in mental health care, particularly in relation to balance of care decision-making along the continuum of care. Effectiveness refers not only to health outcomes but also includes: quality of life, well-being, equity and social justice. Incentive systems are also important because of their effect on access to mental health services and employment. 
However, the fundamental reason for being interested in economics is because of resource scarcity: The level of resources that can be made available - professional, pharmaceutical, technological and others - for the treatment and support for of all types of health care problems, will never be enough to meet all needs. Scarcity is a permanent and pervasive feature of all societies. In the face of such scarcity, choices have to be made between alternative uses of the same resource or service. Economics, sometimes described as the science of scarcity, aims to provide decision makers with data and analysis that can inform and assist their decisions as to how to allocate available resources. This obviously raises questions about the comparative costs and outcomes of the alternative ways to use resources, and we shall describe later the methods that economists use to evaluate cost-effectiveness.

Cost of illness studies can be used as a starting point to estimate all the resource consequences associated with a specific disease or condition. Such studies include the use of health and social care resources, premature mortality, monetary consequences of a reduction in quality of life, and the loss of ability or opportunity to earn income or engage in meaningful activities such as employment and leisure. Cost of illness studies help raise the economic profile of particular problems. They are not of themselves an argument for additional resources - evidence of cost effective interventions and strategies will be required for this - but they do signal overall resource and financial magnitudes in the field. They can be very important in highlighting the proportion of the cost burden of particular health problems in any society. This is of particular significance given the focus on linking good health to good economic wealth often spoken about by European policy makers.

The economic impacts of mental health problems are wide-ranging and in many cases long lasting, given the chronic nature of many mental health problems. As we have noted, these impacts will be felt not only by service users, but also by their families and the wider society. Individuals feel the strain of mental health problems most acutely. Depression, for example, produces a significant decrement in health compared with chronic diseases such as angina, arthritis, asthma and diabetes (Moussavi et al., 2007). Families provide care and support and may incur considerable opportunity and direct costs in so doing. The wider society is affected through the impact of mental health problems on the economic and social potential of people which can translate into higher unemployment rates, lower participation rates and higher health care costs. There may also be intangible costs for citizens stemming from the fear, mostly exaggerated and stigmatising, for personal safety among the public in relation to communitybased living for some people with mental health problems (Taylor and Gunn, 1999). 
The economic effects of mental health problems are associated with the ability to work, other productive contributions to society, personal income, and the utilisation of health care and other support services. Together, these economic impacts are considerable, as we illustrate in the next chapter. However, we need to keep these economic impacts in perspective. They stand alongside the often huge personal costs of mental health problems - symptoms that are usually very painful and distressing for the individual concerned, including psychological pain and distress, medication side-effects, co-morbid physical disorders, limitations on social functioning, stigmatisation by the rest of society, social isolation, lack of self esteem, and so on. These costs are often difficult to measure and value, but are equally important. It is important to emphasise that economics is not all about money. Certainly, money is a convenient way to value things, but money is only one part of the equation. Outcomes matter as much as costs.

There is also the question of who should be interested in the economics of mental health? A variety of stakeholders is affected by, or can affect, the economics of mental health. These include funding bodies such as governments or health insurance funds that should be looking to get the best value from their expenditure and service providers who have to plan how best to organise and use their scarce resources. Economic studies can also examine the costeffectiveness of interventions, providing information of relevance to health system decision makers, providers of services and pharmaceutical companies looking to market their products. Finally, taxpayers and contributors to insurance funds should clearly be interested in the economics of mental health to ensure, for example, that their contributions are used in efficient ways and that money is not wasted.

Economic evaluation refers to the comparative analysis of alternative courses of action in terms of both their costs and consequences (Drummond et al., 1997: 8). At its most basic level, economic evaluation involves identifying, measuring, valuing and comparing the costs and outcomes of the alternatives under consideration. Economic evaluation is necessary to make informed choices regarding the allocation of scarce resources. Due to the finite nature of healthcare resources, choices must be made about which interventions should be financed and implemented in order to get the best value for money and achieve the best outcome i.e. the greatest health gain to society. In general, the application of economic evaluation to mental health is becoming increasingly common. For example, reviews exist for depression (Rosenbaum and Hylan, 2002), for dementia (Jönsson et al., 2002), for schizophrenia (Knapp et al., 2002), and for child and adolescent mental health problems (Romeo et al., 2004). 
There are three main types of economic evaluation: cost-effectiveness analysis, cost-utility analysis, and cost-benefit analysis.

Cost-effectiveness analysis (CEA) involves the systematic comparison of the costs and outcomes of alternative interventions in which the outcomes are measured in terms of health units. Outcomes may be assessed in terms of the number of lives saved or the number of life-years gained. Intermediate health outcomes may also be used for this type of analysis, for example, cases found or patients appropriately treated. However, if intermediate health outcomes are used, it is important that a firm link is established between these and the final health output, or to demonstrate the inherent value of the intermediate health outcome itself. The cost-effectiveness of a programme or intervention is then expressed as a ratio in which the costs are divided by the relevant health outcomes. In general, an incremental cost-effectiveness ratio (ICER) is utilised to compare alternatives. This involves calculating the difference in costs and outcomes of two interventions and expressing this as a ratio. A limitation of CEA is that it facilitates comparison only between programmes that produce the same health outcome. Cost effectiveness studies dominate the evaluation landscape (Byford et al., 2003).

Cost-utility analysis (CUA) is a subset of cost-effectiveness analysis in which health outcomes are measured in terms of quality adjusted life-years (QALYs). Therefore, cost-utility analysis takes into account the changes in the quality of life as well as prolongation of life achieved by a programme or intervention. The quality of a programme is determined by a set of values or weights called utilities, one for each possible health state, that reflect the relative desirability of the health state (Drummond et al., 1997:140). Programmes are then assessed according to the cost per QALY gained. CUA is particularly relevant in cases where an illness or disease does not necessarily impact on mortality but may reduce the quality of one's life, for example in the case of depression. It is also useful to consider treatments which may positively affect mortality but have a negative short-term impact on quality of life, for example, in the case of certain cancer treatments like chemotherapy.

Cost-benefit analysis (CBA) refers to a type of economic evaluation in which the relevant outcomes are measured in monetary units. Hence, the incremental costs of a programme can be directly compared to its incremental monetary benefits. The comparison of costs and benefits of a programme or intervention can be expressed as either a net benefit or a benefitcost ratio. A programme's net benefit is calculated by subtracting its costs from its benefits. A benefit-cost ratio is calculated by dividing the benefits of a programme by its costs. In general, if net benefits are positive (i.e. greater than zero) and the benefit-cost ratio is greater than one, a programme is worth implementing. 
Cost-benefit analysis has its theoretical foundations in a branch of economics known as welfare economics. Two key value judgements of welfare economics are (1) social welfare is comprised of the individual welfare of each member of society and (2) individuals are the best judges of their own welfare. Taking these two assumptions and applying them to resource allocation, economists assume that a policy should be implemented if it can make at least one person better off without simultaneously making another worse off (this is known as a Pareto improvement). In practice, strict application of this principle proves impossible as nearly all policy changes have adverse effects on at least one member of society. Instead, policy changes are more commonly evaluated in accordance with the Kaldor-Hicks criterion which advocates a potential Pareto improvement i.e. if the gainers of a programme can compensate the losers and remain better off than they were before the change, the policy or programme under consideration should be implemented.

There are three main methods of assigning money values to health outcomes which are rooted in the welfare economics framework. The human capital approach values a gain in healthy time using market wage rates and the value of a programme is measured by the present value of future earnings. The rationale for this approach is that the consumption of health care can be seen as an investment in a person's human capital and the return on this investment is measured by a person's productivity as reflected in his/her wage rate. Revealed preference refers to the observation of actual consumer choices involving health versus money. Individual preferences regarding the value of increased health risk in exchange for increased income (which represents all other goods and services a person might consume) is reflected in a person's wage rate (Drummond et al., 1997). Therefore, a person's wage can be taken as a measure of the value he/she places on health. Willingness-to-pay/contingent valuation uses survey methods to present consumers with hypothetical scenarios about the programme or problem under evaluation (Drummond et al., 1997: 213). Respondents are asked to consider the contingency of an actual market existing for the programme or health intervention and to state the maximum amount they would be willing to pay for the benefits of this programme or intervention. We use a contingent valuation approach to explore the willingness to pay for a new mental health programme in Chapter 3. An advantage of CBA as opposed to CEA or CUA is that it facilitates the comparison of healthcare programmes not only with each other but also with programmes in other sectors of the economy. Therefore, it can be used to aid priority setting and resource allocation in a wider economic context.

There is no tradition of applying economic evaluation to mental health care in Ireland. Instead, we have to rely on the international literature for pointers and guidelines as to the economic effectiveness of various programmes. This can lead to difficulties as the results and conclusions 
of a study produced in one context or setting may not always fit other contexts or settings, particularly in another country. However, a prior problem exists for Ireland. There is no evidence that decision-makers in this country take a systematic approach to learning from evaluations carried out elsewhere. Until we are sure this happens, we should, perhaps, not worry about the dangers of making generalisations from elsewhere. Nevertheless, well-conducted economic evaluations can make significant contributions to our understanding of almost every aspect of policy and practice development in the mental health field. They can support decisions relating to the funding and provision of services and can help to improve the efficiency with which scarce mental health resources are allocated. Unfortunately, this message has not yet permeated through to policy-makers in Ireland.

\section{Social Inclusion and Equity}

In Ireland, a great deal of evidence suggests that there is a range of health inequalities by socio-economic group. The poor and the excluded get sick more and die younger than people who are better off. In addition, adults in the poorest socio-economic groups are twice as likely to report a long-standing illness as those in the richest socio-economic group (O'Shea and Cillespie, 2006). A similar social gradient applies in relation to mental health problems. International studies consistently show a relationship between poverty and/or economic inequality and poorer mental health and well-being. Populations living in poor socioeconomic circumstances are at increased risk of poor mental health, depression and lower subjective wellbeing (Patel and Jane-Llopis, 2005). Across the UK, both men and women in the poorest fifth of the population are twice as likely to be at risk of developing mental health problems as those on average incomes (Palmer et al., 2003).

According to the WHO, the burden of mental health problems falls disproportionately on certain groups, such as women, people living in extreme poverty, people traumatized by conflicts and wars, migrants, children and adolescents with disrupted nurturing, and indigenous populations in many parts of the world. People in these groups are more likely to be unemployed, to face stigmatization, and to suffer violations of their human rights than people not in these groups. They may also face considerable access barriers, e.g. the cost of satisfactory treatment for their mental disorders (WHO, 2003). The causality between poverty and mental health is likely to work in both directions; poverty is both a major cause of poor mental health and a potential consequence of it.

Table 2 shows a significant social gradient in relation to admission to psychiatric hospitals and units in Ireland. Overall admission rates per 100,000 people are just over 700, but the range 
lies between approximately 100 for own-account workers to over 1,200 for unskilled workers, a twelve-fold difference. The unspecified group which contains people who could not be assigned to any particular socio-economic group has the highest admission rate. This group is likely to contain a disproportionate share of low income and socially deprived individuals who are detached from conventional economic and social relationships. There is also evidence of a link between unemployment, poverty and psychological distress in Ireland, with the unemployed in poor households being five times more likely to have psychiatric symptoms (Whelan et al., 2001). While the evidence on the social gradient in mental health in Ireland is small, all of it points in the same direction. Poor mental health is more prevalent among poorer people in this country, leaving aside the question of whether poverty directly causes mental health problems or not.

Table 2: Admission Rates by Socio-Economic Group per 100,000 Population Aged 16 Years and Over

\section{Socio-Economic Group}

\begin{tabular}{lr}
\hline Own Account Workers & 104.60 \\
\hline Employers and Managers & 160.20 \\
\hline Higher Professionals & 362.50 \\
\hline Farmers & 418.10 \\
\hline Lower Professionals & 458.10 \\
\hline Semi-skilled & 595.50 \\
\hline Non-manual & 607.40 \\
\hline Manual Skilled & 626.50 \\
\hline Agricultural Workers & 716.00 \\
\hline Unskilled & $1,249.70$ \\
\hline Unspecified & $1,625.90$ \\
\hline Total & 701.70 \\
\hline
\end{tabular}

Source: Activities of Irish Psychiatric Services 2005

People with mental health problems are particularly vulnerable to social exclusion arising from absences from the labour force. Work is a key aspect of people's attachment to economic, social and civic life. Work involves all types of commitment and engagement, both paid and non-paid, that provides both meaning and dignity to people's lives. Participating in work for people with poor mental health has a therapeutic value, as well as indicating a successful outcome (Boardman, 2003). People with mental health problems see work as helping them recover an ordinary life (Rankin, 2005). Absence from work impacts on both economic 
security and social connectedness. The weakening of economic and social ties may erode self confidence and self esteem in people with mental health problems, which further exacerbates their vulnerability to further bouts of ill health. People may become trapped in a cycle of exclusion that leads to recurring despair and hopelessness outside the mainstream of economic and social life.

People with mental health problems have extremely low rates of labour force participation compared to the general population. In the USA, overall estimates of employment rates among people with psychiatric disabilities range from 15\% to 30\% (Tsang et al., 2000). The unemployment rate among people with mental disorders in the USA is three to five times that among those with no disorders (Sturm et al., 1999). In Australia, the employment rate among people with schizophrenia is $16 \%$ compared to $74 \%$ for healthy working age people (King et al., 2006). Non-participation and unemployment characterises the population of people with mental health problems in Australia. The situation is similar in the UK. Layard (2004) suggests that the economic cost of lost output associated with poor mental health for the UK economy is \pm 13 billion.

The 2006 Census included several questions on disability and the report on this section of the census was published in November 2007. The 2002 Census also included a section on disability but it is not possible to compare the 2006 results with the 2002 results as there were only six types of disability included in the 2002 Census and these did not include 'psychological or emotional condition'. It is not clear at all what disability, if any, would have been chosen by people in the 2002 Census who identified themselves as having a psychological or emotional condition in the 2006 Census. A total of 61,499 people aged 15 or over identified one of their disabilities as being a psychological or emotional condition. Of these 25,803 people 13,105 males and 12,698 females) stated that they were unable to work due to permanent sickness or disability. In addition, 4,627 people (2,734 males and 1,893 females) with this disability were unemployed. The unemployment rate for people with this disability was $28 \%$ which was much higher than the national unemployment rate of $8.5 \%$. The Quarterly National Household Survey (QNHS) published by the CSO included a module on disability in the labour force for the first quarter of 2004 and found that the number of hours worked by persons suffering from a "mental, nervous or emotional" disability was 29.5 hours per week compared to the average in the country of 36.8 hours. As noted earlier, Tedstone Doherty et al. found that the $12 \%$ of the respondents in the National Psychological Wellbeing and Distress Survey showed symptoms of psychological distress (Tedstone Doherty et al, 2007: 33). Extrapolating the survey findings would suggest that 348,500 adults aged 18 years or older are experiencing symptoms 
of psychological distress. Evidence from other countries suggests a significant gap between people's aspirations to work and their opportunities to do so (Bond et al, 2001; Stanley and Maxwell, 2004). That gap is also likely to exist in Ireland.

The majority of countries in Europe are in the process of adopting novel schemes to improve employment opportunities for people with severe mental health problems, while maintaining some of the more traditional sheltered working environments (Knapp et al., 2006). These policies include pro-inclusion strategies, job brokerage schemes, anti-discrimination measures, directives on employment conditions and public health information. More attention needs to be given to informal work as the latter can also provide people with an opportunity to be involved in meaningful activity of some sort. Participation does not always have to be within the formal labour market. Any new schemes designed to improve employment opportunities for people with mental health problems should take a holistic approach to participation, incorporating engagement with both community and voluntary activity along a continuum towards full competitive paid employment.

\section{Conclusion}

Changes in policy as set out in the Vision for Change document are necessary but not sufficient to improve services and conditions for people with mental health problems in Ireland. A Vision for Change must be accompanied by an economic analysis that examines the financial and resource allocation implications of mental health problems on individuals and societies. Decision makers in Ireland are facing both challenges and opportunities in the mental health field and economic studies can help in the formulation and implementation of policy. Economic evaluation is necessary to identify the costs and benefits of various options in health and social care provision for people with mental health problems. Economics can also provide insights into the individual and social consequences of unemployment for people with poor mental health. Similarly, economic analysis contributes to our understanding of equity and social inclusion issues, both of which are fundamental to reform in the mental health sector in Ireland.

Ireland is not unique in its lack of attention to economic aspects of poor mental health. Many European countries have difficulty in both undertaking and facilitating the use of economic evidence in mental health care decision-making and there is little evidence that the findings of mental health economic studies has had an impact on policy and practice in Europe (Knapp et al., 2006). Even in countries where economic criteria exist, as in the UK through NICE guidelines, progress has been slow in implementing recommendations (Sheldon et al., 2004). 
The rest of this report focuses on three potential pathways to expand the use of economic analysis in Ireland in the area of mental health. In Chapter 2 we provide an overall estimate of the economic cost of poor mental health through a cost-of-illness study for Ireland. This estimate should make it easier to justify the application of economic evaluation to the various components of resource use in the system in the future. In Chapter 3 we report on a unique contingent valuation study for Ireland which asked a randomly selected sample of people to demonstrate their willingness to pay for mental health programmes relative to two other health care programmes - cancer and elderly care. This is the first study, to our knowledge, that explores preferences for mental health care spending among citizens relative to other programmes. This should tell us more about how people value such programmes, both for themselves and for others. In Chapter 4 we bring together some of the published literature on evaluation from other countries on the balance of mental health care resource allocation in relation to care provision and work. The insights generated from the literature can aid decisionmaking with respect to identifying potential priority areas for expenditure in Ireland. The final chapter contains the main conclusions and recommendations. 


\title{
The Economic and Social Costs of Mental Health Problems in Ireland
}

\author{
Introduction
}

Poor mental health imposes a great variety of consequences on individuals, families and caregivers, and society. The most obvious and important consequence of poor mental health is the pain (physical, emotional, mental and existential) experienced by individuals whose mental health is poor. Other consequences include the effects on physical health, personal relationships, access to employment and housing, ability to participate in society, and a higher risk of being incarcerated in prison. In addition, the vast majority of families and care givers devote considerable amounts of time and resources to helping loved ones cope with the effects of mental health problems. Finally, the wider society provides health and other services to people with mental health problems and these services must be resourced.

With such a variety of negative effects, it is hardly surprising that the economic consequences of poor mental health are also great. Over the past forty years economists have developed various techniques for measuring the economic burden of an illness or health problem. This chapter presents the first estimates of the economic cost of mental health problems in Ireland The primary aim of any cost-of-illness study is to draw attention to the economic burden of a particular illness or condition, where economic burden refers to the value of all resources used in the prevention, diagnosis and treatment of that condition, as well as the productivity and welfare losses incurred as a result of the condition. Some people have suggested that the economic costs of an illness also represents the economic benefits of implementing a health care intervention that would reduce the burden of the disease in question, although we will see later that there is disagreement on this issue. At a minimum, cost-of-illness studies can inform policy-makers in priority-setting by highlighting those areas where burdens are greatest.

In relation to mental health problems in Ireland, a cost-of-illness study can act as an important information gathering exercise and serves to highlight the scale of the problem. Currently, there is little conclusive evidence on many aspects of mental health problems in Ireland. Ambiguity surrounds the prevalence of many kinds of mental health problems in this country partly due to the hidden nature and the stigma that surrounds these problems. While the numbers of people utilising health and social care services for mental health issues are quantifiable to some degree, there is a dearth of information about the costs of such services. Furthermore, while we have a figure for the overall proportion of the health budget allocated to psychiatric services, there is no breakdown of this budget to indicate which services consume most of the resources. Finally, 
there is considerable suspicion that all the money allocated to mental health services is not in fact spent on these services. This chapter addresses some of these issues through a careful estimation of the economic burden of mental health problems for 2006, using less than perfect information. Our estimates are confined to adults as we did not have any reliable data at all for children. We also excluded people with dementia from our analysis.

\section{Limitations of Cost-of-Illness Studies}

Cost-of-illness studies have been the subject of much debate by economists and health scientists many of whom have questioned the inherent usefulness of such studies (see, for example, Tarricone, 2006 and Hu, 2004). Cost-of-illness estimates are a useful measure of the potential cost savings to society only in the case where preventative interventions that could completely prevent the illness in question were known. As this is rarely the case, decisions are more likely to be made about whether to implement various prevention or treatment programmes. In this situation, economic efficiency is important i.e. whether the benefits of implementing a programme exceed the costs. If there are two or more programmes available, then marginal analysis is necessary where the incremental benefits and costs of both interventions are compared. From this perspective, the total cost of an illness does not matter; what is important is the cost and benefit of an intervention at the margin as this will determine the efficient use of existing resources.

Drummond (1992) argued that cost-of-illness studies by themselves do not provide adequate information to policy-makers about the need to devote more resources to a particular illness. An illness with a large economic burden may already have vast amounts of resources devoted to its alleviation. If past resource allocation decisions have been made in an irrational or uninformed manner, then subsequent policy decisions made on the evidence of the cost-ofillness study will only proliferate and intensify initial mistakes (Shiell et al., 1987; Currie et al., 2000). Therefore, decisions regarding the allocation of scarce health care resources should be based on the social impact of the disease as well as the availability of treatment options and their costs and effectiveness. However, Tarricone (2006) asserts that economic evaluations such as cost benefit analyses or cost-effectiveness analyses are only one of many inputs into the decision-making process regarding resource allocation. She notes the findings of Hoffman and von der Schulenburg (2000) that indicate that the results of economic evaluations are not widely used in decision-making by policy-makers. 
Cost-of-illness studies are also criticised because of the use of the Human Capital Approach (HCA) to measure economic losses due to morbidity and mortality. The HCA estimates costs due to morbidity by applying average earnings to time off work due to the illness. Mortality costs are calculated using the present value of future earnings. It has been suggested that the use of the HCA will overestimate indirect costs as it measures the value of potential lost production, whereas the actual loss may be much smaller (Currie et al., 2000; Drummond, 1992). In the case of absenteeism due to an illness, it can be argued that a person's work will be handled by others or done by the sick person when s/he returns to work, while long-term absences due to illness or mortality will be covered by a person drawn from the pool of unemployed. Therefore, there is little loss to society overall.

In the light of these debates what is the potential worth of such studies and can they make a useful contribution to the policy-making process? The Scottish Association for Mental Health (SAMH) point to three potential uses of cost-of-illness estimates of mental health problems: they highlight the scale of the problem; they can inform health and social care spending decisions; and they can show the distribution of costs (SAMH, 2006). The information contained in a cost-of-illness study certainly provides a useful framework for considering the scale of the problem. The cost exercise offers information about the amount of resources consumed due to a particular illness, as well as identifying where these resources are being employed. This helps decision-makers to become knowledgeable about actual resource allocation. This is particularly important in the case of mental health care in Ireland where data on mental health care expenditure is confined to one single figure, showing overall expenditure. In identifying the main cost components of a disease, and determining their incidence over total costs it is possible to identify what cost categories consume most resources and where resources need to be directed in order to ensure their most efficient use. Having knowledge of the factors that influence the consumption patterns of services is helpful for planning the provision of health-care services (Tarricone, 2006).

A cost-of-illness exercise may also reveal how the impact of mental illness is distributed across different population cohorts and what services are responsible for most of the burden. For example, O'Shea and O'Reilly (2000) found that informal care accounted for almost half of the total economic burden of dementia in Ireland. It may not be immediately obvious that certain cost components consume such a disproportionate amount of resources meaning that the resources currently devoted to these areas may not reflect their relative importance. Therefore, a cost-of-illness study indicates where resources need to be directed in order to maximise equity and efficiency. Similarly, it may be necessary to get some indication of the indirect 
effects that poor mental health has on the economy and society in general in order to assess its full impact. Mental health problems may place huge burdens on informal care givers through its impact on financial resources, as well on carers' physical and mental health.

\section{Methodological Cost Issues}

Most cost-of-illness studies adopt a prevalence based approach. A prevalence based approach estimates the cost burden to society during a given time period, such as a given year. The underlying principle of the prevalence based method is that costs should be allocated to the year in which they occur. Lost future earnings due to premature death are assigned to the year of death. Therefore, prevalence data is a mixture of annual figures and expected future figures (Ament and Evers, 1993). We use a prevalence based approach in this study. By contrast, an incidence-based cost study estimates the cost of an illness from the time of first diagnosis until recovery or death, which is a lifetime cost estimate. This approach is based on the rationale that the flow of costs associated with a disease should be assigned to the year in which that flow starts. Direct and indirect costs are discounted to their present value and then assigned to the year in which the disease first emerges (Ament and Evers, 1993). This approach requires much more information and is even more challenging to perform due to the availability of necessary data.

In order to conduct a cost-of-illness study, the first step is to identify all the relevant costs. Direct costs refer to the value of resources used in the treatment of a problem e.g. costs for inpatients/outpatients, medication, community services etc. Direct costs relate to actual treatment expenditures; thus, it is useful to compare these expenditures with total national health care expenditures. In general, direct costs are more reliable since these costs are estimated from treatment costs, obtained by type of health care service, amount of services, and cost per unit of services. It is useful to distinguish the separate components of direct costs as this helps to identify what areas bear the largest proportion of the economic burden of the illness (Drummond, 1993).

Indirect costs refer to the value of resources lost as a result of mental health problems. These estimates are used to address the question of the magnitude of the negative economic consequences of illness to society. Indirect costs due to lost productivity are commonly estimated using a human capital approach. This approach is based on the assumption that a person's productivity in the workplace is reflected in the wages they receive. Indirect costs due to informal care provided by family and friends can be measured using an opportunity cost 
method or a replacement cost method. Opportunity cost refers to the benefits or activities forgone by the informal carer due to the provision of informal care. In general, the opportunity cost of informal care is measured using the market wage rate as it is assumed that the informal carer would be actively participating in the labour force if $s /$ he were not providing informal care. If the analyst considers that informal care involves the sacrifice of unpaid work or leisure time, then it is necessary to estimate the value of these types of forgone time in order to accurately assess the cost of informal care. Where possible an opportunity costs methodology is used in this paper.

In contrast to the opportunity cost method, the replacement good method values a commodity using the market price of the nearest substitute. Therefore, if this valuation method is used it implicitly assumes that the commodity being valued has a close market substitute which is almost perfect. In the case of informal care, the value of the care tasks provided would be estimated by identifying how much it would cost in the open market to hire someone to perform that care task. For example, personal care would be valued using the market wage of a professional nurse or personal aide, while household tasks would be estimated using the wage rate of a professional cleaner. However, the proxy good method has several limitations. This methodology assumes that formal and informal care are perfect substitutes and hence fails to take into account differences in quality and efficiency. Also, due to market imperfections and trade union power, the wage rates of formal caregivers may not reflect labour scarcity, implying that informal care may be overvalued (Van der Berg et al., 2004).

Human costs refer to all the effects that mental illness has on an individual lother than the effect of not being able to work as productively as $s$ /he would in the absence of the illness). Human costs are always difficult to measure in cost-of-illness studies. The human cost approach tries to put a monetary measure on the suffering, pain and distress that results from mental illness. There are varying views on the inclusion of such costs in cost-of-illness estimates. It is clearly wrong to claim that the only cost of mental illness for an individual is the output that is not produced. Yet at the same time it is very difficult to imagine how we could get accurate measures of the monetary value of the reduction in the quality of life for the large diverse group of people in a society who may be experiencing mental health problems at any particular time. Most previous studies in this area have concluded that quantifying the human cost of mental illness is too difficult an issue. We have also done so in order to be able to compare our results with those found in other countries. 
Data on each of these cost categories can be extracted by employing either a top-down or bottom-up approach. The latter examines the records of a sample of service users or follows a sample of service users' health services to estimate and project the national cost of illness. The bottom-up method requires a representative sample and is often more costly to undertake. Moreover, as the bottom-up method uses smaller available sample or case studies, it may not always be representative of entire populations. A top-down approach relies on available aggregate or national figures of health services utilization or morbidity/mortality information by identifying particular disease codes. Therefore, studies employing this approach tend to be representative of national populations and less costly to undertake. The national survey data provide not only prevalence rates but also access rates, thus resulting in more reliable data from the top-down method. However, a limitation of the top-down approach is that it does not encompass certain components of direct costs such as out-of-pocket expenditures, which are not recorded at an aggregate level. It may also be biased towards costs that are easy to record at a national level such as hospital and drug costs (Tarricone et al., 2000). We use a top-down approach in our work.

\section{Prevalence Data}

The extent of any problem is usually described as its prevalence - that is the rate at which it occurs in a population. Obtaining accurate information on the prevalence of mental health problems is critical to the calculation of the output losses that are a major component of any cost-of-illness study. Prevalence rates are usually expressed as a rate of the population such as per cent (i.e. rate per 100 people), or as rates per 1,000, 10,000 and so on. The time period over which prevalence is measured is also important as it can influence the size of the rate. One useful model to understand the prevalence of mental health problems in the population is that put forward by Coldberg and Huxley (1992). This model can be presented as a pyramid which represents the mental health problems in the total population (Figure 2.1). The pyramid shows that the greatest number of problems exist in the general community, mostly at a mild level, with more severe mental illness present at the top of the pyramid. An illustrative example is the continuum of symptoms of depression in the population. There is a relatively high level of the milder signs of depression in the population. These encompass the normal fluctuations of mood experienced by most people. When a number of symptoms are present for longer periods of time an episode of depression may be experienced which has a significant impact on the life of the individual and prevents them from partaking in their everyday activities. The number of such individuals is much lower than those with one or two mild symptoms of depression. A third category would include people who experience chronic depression for long periods of their lives. 
Coldberg and Huxley (1992) combine estimates from a number of community surveys with similar methodology to give an annual period prevalence for mental disorders of 260-315 per 1,000 of the population at risk per year. That is, the proportion of people who will suffer an episode of mental disorder lasting at least two weeks in a year is between 26 and 31 per cent. For individuals attending primary care, the estimated prevalence is 230 per 1,000 per year. However, it is estimated that only about half of those with mental health problems in primary care are detected or diagnosed - giving a detected population rate of approximately 115 per 1,000 per year. Mental health problems are not detected by CPs for a variety of reasons, the simplest being that individuals choose not to disclose symptoms to their CP or that CPs do not have sufficient skills and training to diagnose mental health problems. A small proportion of the population attends specialist mental health services (approximately 2.5\%) and an even smaller proportion is admitted to a psychiatric hospital or unit (approximately $0.5 \%$ ). This model gives a useful perspective on the mental health needs of a total population and enables us to plan and organise services based on this information

Figure 2.7: Total population model showing estimates of annual period prevalence of mental health problems

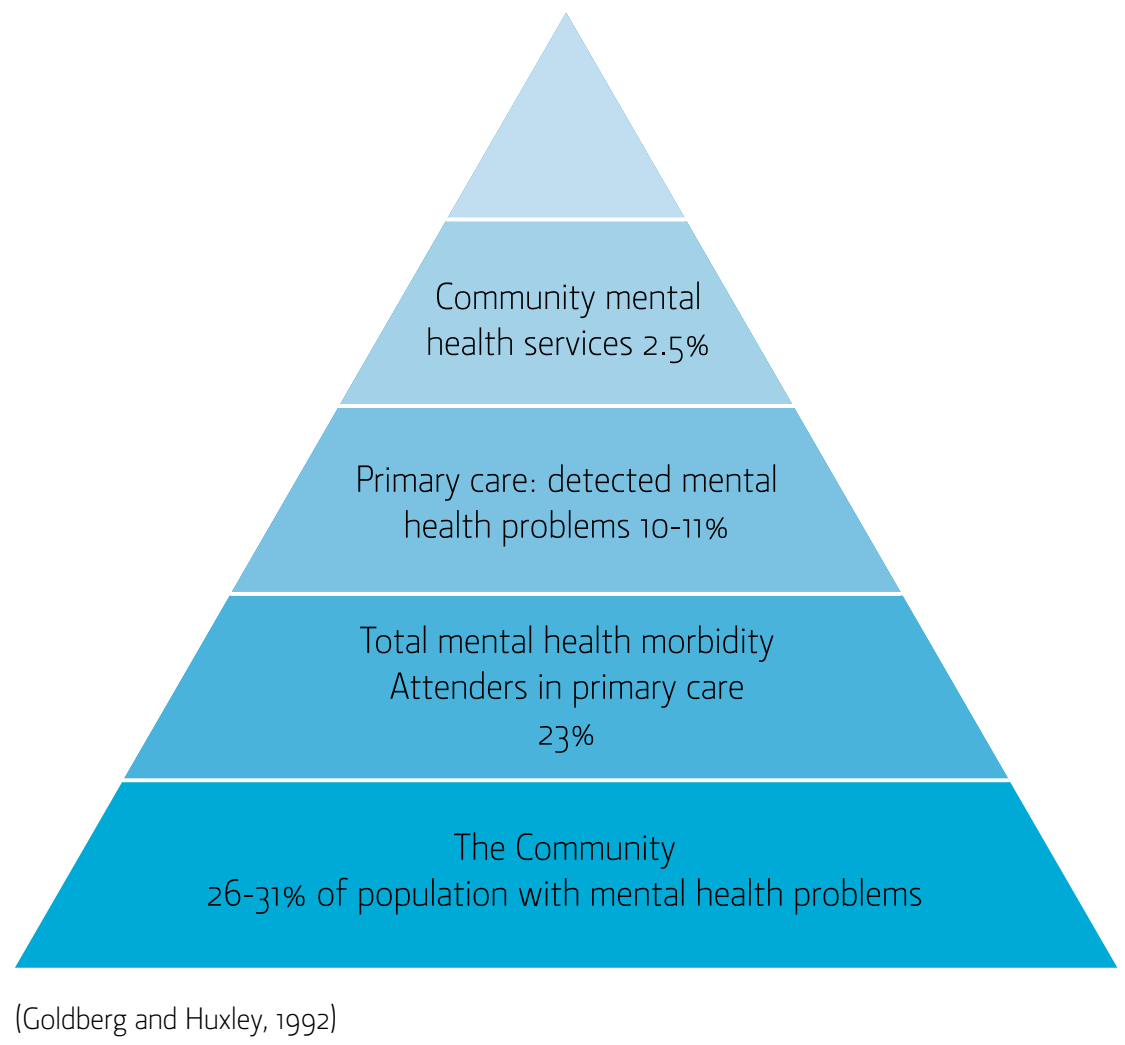


The Coldberg and Huxley model draws on data from a number of international sources. While there has been no national Irish study on the scale of UK or US studies, there is some Irish data to help us get an estimate of the number of individuals affected with mental health problems. The most useful of these studies is the National Psychological Wellbeing and Distress Survey (NPWDS) carried out by the ESRI for the Health Research Board between December 2005 and April 2006. The plan is to complete this survey every two years. A report with baseline results from the first survey was published in 2006 and we have used this data extensively in calculating the cost of mental health problems in Ireland. The NPWDS will be conducted every two years and we welcome very much this development. Researchers in Ireland will be in a much better position to monitor trends in the prevalence of mental health problems in Ireland. They will also be able to analyse a whole range of issues such as the relationship between psychological distress and socio-economic background.

The NPWDS was a telephone survey of a nationally representative random sample of 2,71 adults aged 18 years and over and living in private households. While some of the data was collected in December 2005 we will refer to the year of collection as 2006 when the majority of the data was collected. This is by far the largest national survey of mental health prevalence in Ireland. Various measures of mental health were collected in this survey. The short version of the General Health Questionnaire (CHQ12) was used as a measure of psychological distress. This questionnaire has been widely used as a screening measure to assess psychological distress in community samples and its validity has been found to be high. The HRB researchers used the bimodal method for scoring the $\mathrm{CHQ}_{12}$ with a score of four and above used as the cut-off score to indicate probable psychological distress. This is in line with recent surveys in England, Northern Ireland and Scotland (Tedstone Doherty et al. 2007: 21). The fact that the survey was a telephone survey has a number of limitations. People who are experiencing high levels of psychological distress may be reluctant to answer the phone or to talk to a surveyor. Other people at high risk of psychological distress may not have been included such as homeless people and people living in sheltered accommodation. It is likely therefore that the estimates in the survey are conservative.

The survey also included a question on a subjective measure of mental health problems. Respondents in the survey were asked if they had suffered from mental, nervous or emotional problems in the previous year. They were also asked to rate their mental health during the previous year on a five point scale from 'very poor' to 'very good'. Respondents were also asked how many times (if any) they had seen a CP about being anxious, depressed or about mental, nervous or emotional problems, and how many times (if any) they had used professional mental 
health services in the last 12 months. The survey also asked respondents about their use of prescribed medication for mental or emotional problems.

Tedstone Doherty et al. found that the $\mathrm{CHQ}_{12}$ score was four or higher in $12 \%$ of the respondents (2007: 33). The rate was higher for females (14\%) than males (10\%). Table 2.1 compares the results for Ireland, Northern Ireland, England and Scotland. Clearly, the results in Ireland are much closer to those in England than Scotland or Northern Ireland. The 2006 figures for Ireland are much more reliable than earlier surveys which used smaller samples. Nevertheless it is useful to look at previous national surveys. A Eurobarometer study on the mental health status of the European population using a 5 -item mental health index called the MHI-5 reported an Irish prevalence rate of mental health problems of $15.7 \%$ in 2002 (12.4\% for males, 18.9\% for females). Tedstone Doherty et al also asked people their subjective view of their mental health. $14 \%$ of the respondents (17\% of females and $12 \%$ of males) reported that they had experienced some mental, nervous or emotional problems, such as anxiety or depression, in the previous year. This is very similar to another smaller survey carried out recently for the National Economic and Social Forum (NESF, 2007). It found that $16 \%$ of employees surveyed had experienced mental health difficulties within the last two years.

Table 2.1: Percentage of respondents scoring for or higher on $\mathrm{CHQ}_{12}$ scale

\begin{tabular}{lrrr} 
& Overall & Males & Females \\
\hline Ireland (2006) & $12 \%$ & $10 \%$ & $14 \%$ \\
\hline Northern Ireland (2001) & $21 \%$ & $17 \%$ & $24 \%$ \\
\hline England (2001) & $13 \%$ & $11 \%$ & $15 \%$ \\
\hline Scotland & $15 \%$ & $15 \%$ & $19 \%$ \\
\hline
\end{tabular}

Sources: Tedstone Doherty et al, 2007 ; www.dh.gov.uk; www.nisra.gov.uk; www.scotland.gov.uk

A series of studies by the Department of Community Health and General Practice in Trinity College, Dublin, looked at the general health and service use of people living in different parts of Dublin (Deady et al., 2003; O'Keefe et al., 2002; Long et al., 2002). Table 2.2 presents some results from these studies which give us an estimate of the rate of self-reported stress among people living in the respective areas. 
Table 2.2: Selected findings from other Irish studies

\begin{tabular}{lrrr} 
& Docklands & Tallaght & Finglas \\
\hline Experienced stress in year prior to the survey & $53 \%$ & $59 \%$ & $63 \%$ \\
\hline Reported this stress as severe & $19 \%$ & $19 \%$ & $20 \%$ \\
\hline Experienced negative effects of stress & $78 \%$ & $83 \%$ & $83 \%$ \\
\hline Anxious as a result of stress & $19 \%$ & $20 \%$ & $24 \%$ \\
\hline Depressed as a result of stress & $11 \%$ & $14 \%$ & $18 \%$ \\
\hline Consulted GP because of stress & $26 \%$ & $35 \%$ & $41 \%$ \\
\hline Households with a person with a psychiatric illness & $8.6 \%$ & $3.5 \%$ & $3.1 \%$ \\
\hline
\end{tabular}

Source: Deady et al., 2003; O'Keefe et al., 2002; Long et al., 2002

Unfortunately, there is no information based on rigorous surveys, using standardised measures, of the prevalence of mental health problems in CP attendees. In the results of the studies in Table 2.2, self-reported attendance at a CP for stress ranged from $26 \%$ to $41 \%$. CPs themselves report a wide range in the prevalence of mental health problems among the people they see, depending on the profile of people in their locality (Copty, 2004). We do know that the majority of mental health care is delivered in primary care, with CPs referring only about $10 \%$ of their patients to specialist mental health services. A study conducted by the South Western Area Health Board in 2003 found that twenty-five per cent of primary care consultations constituted patients with mental health problems (Copty and Whitford, 2005).

The HRB study asked people whether they had attended their CP about being anxious or depressed, or about mental, nervous or emotional problems. A total of $9 \%$ of the sample reported speaking at least once to their CP about mental health problems in the previous year with an average of approximately 4.4 visits per person (Tedstone Doherty et al, 2007: 42). The total number of consultations for mental health problems represented about 13\% of the total number of consultations in that year which is considerably below the figures for consultations reported in the previous paragraph. The difference is probably due to the fact that the HRB survey was a representative sample of all the population which meant that only $31 \%$ of the respondents were in the General Medical Services scheme while the other studies focused on people in the GMS.

We do not have comprehensive data on the number of people attending mental health services in Ireland. There is a good deal of activity data, but it tends to be a record of the number of 
attendances at a particular service, or admission to a particular type of psychiatric hospital, rather than the number of people, and so it is difficult to estimate prevalence. The HRB survey found that $6 \%$ of respondents had been in contact with at least one of the following mental health services in the last 12 months: outpatient clinic, day centre, day hospital and inpatient psychiatric hospital/unit.

\section{Activity and Cost Sources}

For this study, we categorised costs according to the direct costs borne by the health and social care system as well as the indirect costs related to lost output and productivity associated with mental health problems. For the purposes of this study, mental health problems include depression and bi-polar disorder, schizophrenia and other psychotic disorders, as well as affective and anxiety disorders. We will not be taking into consideration costs incurred as a result of addiction, dementia or other disorders such as epilepsy or intellectual disability. The Health Expenditure statistics published by the Department of Health and Children only reports an overall figure for expenditure on psychiatric services in any year. It is generally believed that this overall figure includes some expenditure on services that are not psychiatric as well as ignoring expenditure on other services that might be properly understood as psychiatric. The various sources for activity data and costs are summarised in Table 2.3.

Our task was complicated by the fact that the latest year that activity and cost data were available tended to vary considerably between services. We wanted to use the results of the Health Research Survey so we decided to report costs for 2006 but we have noted where the estimate for 2006 is an extrapolation of an estimate for an earlier year. The National Psychiatric In-Patient Reporting System (NPIRS) operated by the Health Research Board provides data on the number of admissions to public and private psychiatric hospitals and in acute psychiatric units in general hospitals and the average length of stay. Information is also available on the number of attendances at day hospitals, day centres and out-patient clinics and the number of places in community residences. In 2006, the number of inpatient days amounted to 162,743 in public psychiatric hospitals, 135,898 in private hospitals and 249,138 in acute psychiatric units in public general hospitals. (All figures from Daly et al, 2007: 69)

Activity data for community mental health services is available for 2004. The number of attendances at outpatient clinics in 2004 was 212,644 while attendances at day hospitals amounted to 162,233 . In relation to day centres, there were a total of 413,771 attendances in 2004. Finally, there were a total of 3,063 people in community residences in 2004; 905 people 
were in low support residences, 626 in medium support residences and 1,534 were in high support residences. (All figures from the Mental Health Commission, 2006.)

Unfortunately, there is a grave deficiency of unit cost or expenditure data in relation to psychiatric care in Ireland. There is no published information at all. We are very grateful to the Mental Health Directorate of the HSE in the Mid-West area for giving us unpublished data on the cost of different mental health services in their catchment area. We used this data to estimate costs for acute psychiatric units in public general hospitals, day hospitals and community residences. There is also a dearth of information in relation to costs in private psychiatric hospitals; to overcome this deficiency, we utilized information obtained from the $\mathrm{VHI}$ about the amount of claims paid out for mental, psychoneurotic and personality disorders in 2006.

Table 2.3: Summary of sources of data used in calculating costs of mental health problems

\begin{tabular}{ll} 
Category & Source \\
\hline Acute units & The number of inpatient days was taken from Daly et al. (2007: 69). \\
& Unit costs were based on data supplied by the HSE West. \\
\hline Public psychiatric & The number of inpatient days was taken from Daly et al. (2007: 69). \\
hospitals & Unit costs were based on data supplied by the HSE West. \\
\hline Day centres & $\begin{array}{l}\text { The number of attendances was taken from Mental Health Commission } \\
\text { (2006: 14). The unit cost was based on data supplied by the HSE West. }\end{array}$ \\
\hline Community residences & $\begin{array}{l}\text { The number of residential places was taken from Mental Health } \\
\text { Commission (2006: 15-16). The average cost of a place was based on } \\
\text { data supplied by the HSE West. }\end{array}$ \\
\hline Day hospitals & $\begin{array}{l}\text { The number of attendances was taken from Mental Health } \\
\text { Commission (2006: 13). The unit cost was based on data supplied by } \\
\text { the HSE West. }\end{array}$ \\
\hline Outpatient clinics & $\begin{array}{l}\text { The number of attendances was taken from Mental Health Commission } \\
\text { (2006: 11) The unit costs were based on a study by Tilson et al. (2003) }\end{array}$ \\
\hline GP Consultations & $\begin{array}{l}\text { The number of consultations was based on various studies in Ireland } \\
\text { that indicated that one quarter of attendances to GPs was for mental } \\
\text { (public health system) }\end{array}$ \\
\hline $\begin{array}{l}\text { health problems. We had data on the total cost of the Ceneral Medical } \\
\text { Service from its Annual Report. }\end{array}$
\end{tabular}


Table 2.3: Summary of sources of data used in calculating costs of mental health problems continued

\begin{tabular}{ll} 
Category & Source \\
\hline $\begin{array}{l}\text { Prescribed Drugs } \\
\text { (public health system) }\end{array}$ & $\begin{array}{l}\text { The annual report of the CMS also gave us data on the total cost of } \\
\text { psycholeptics and psychoanaleptics prescribed under the CMS scheme. }\end{array}$ \\
\hline $\begin{array}{l}\text { Private Psychiatric } \\
\text { Hospitals }\end{array}$ & $\begin{array}{l}\text { The number of inpatient days was taken from Daly et al. (2007: 69). } \\
\text { We didn't have unit cost data for these hospitals so we used the unit } \\
\text { cost data for public psychiatric hospitals }\end{array}$ \\
\hline Private GP visits & $\begin{array}{l}\text { Our estimate was based on average expenditure on CP visits from the } \\
\text { Household Budget Survey. }\end{array}$ \\
\hline Prescribed Drugs & $\begin{array}{l}\text { Our estimate was based on average expenditure on CP visits from the } \\
\text { (privately bought) }\end{array}$ \\
\hline Prison & $\begin{array}{l}\text { Prevalence data was taken from Linehan et al. (2005). The cost of } \\
\text { prisons was based on annual reports }\end{array}$ \\
\hline Homelessness & $\begin{array}{l}\text { Prevalence data was based on data from the Simon Community. Unit } \\
\text { costs are based on adjusted PSSRU British data (Netten and Curtis, } \\
\text { 2002) }\end{array}$ \\
\hline Informal care & $\begin{array}{l}\text { The number of hours of care was based on CSO and Sainsbury data. } \\
\text { Each hour of care was valued at the minimum wage in Ireland in 2006. }\end{array}$ \\
\hline Lost output & $\begin{array}{l}\text { Prevalence data and hours lost due to mental health problems were } \\
\text { based on UK data. This was valued at average industrial wage in 2006. }\end{array}$ \\
\hline Lost output & $\begin{array}{l}\text { Suicide data was taken from the CSO. Lost output estimated and } \\
\text { valued by Kennelly, O'Shea and Ennis (2005) }\end{array}$ \\
\hline
\end{tabular}

Primary care plays an important role in the diagnosis and treatment of mental health problems as it is usually the first point of contact for people experiencing psychiatric problems. In order to estimate the cost of GP visits, data from the Statistical Analysis of Claims and Payments by the HSE and data from the Household Budget Survey conducted by the Central Statistics Office was analysed. These sources also provided information on the expenditure on medication prescribed for mental health problems. The sources for all of the cost data are contained in Table 2.3. It is well known that people with mental health problems have a higher rate of comorbidity with other illnesses but we were unable to estimate the cost of such illnesses. In that respect the amount spent on prescribed medication for psycholeptics and psychoanaleptics is likely to be an underestimate of the real expenditure on prescribed medication for people with mental health problems. 


\section{Health and Social Care Cost Estimates}

The cost per bed day in a public psychiatric hospital in 2006 was estimated to be $€ 434$ so the total cost was estimated to be $€ 77,414,000$. The cost of an inpatient day in an acute psychiatric unit in a general hospital was estimated to be $€ 268$ which yielded a total cost of acute psychiatric units of $€ 66,769,000$. A visit to a day centre was estimated to cost $€ 92$ which resulted in a total cost for day centres of $€ 38,067,000$. The annual cost of high support community residences was estimated to be $€ 26,957$ per year which yielded a total cost of $€ 41,352,000$. The cost of medium support residences was estimated to be $€ 18,566$ yielding a total cost of medium support residences of $€ 11,622,000$. The annual cost of a low support residence was $€ 2,651$ yielding a total cost of $€ 2,399,000$. The daily cost of a place in a day hospital was estimated to be $€ 182$ which would result in an overall estimate for day hospital provision of $€ 29,526,000$. In relation to outpatient clinics, the cost of a visit to an outpatient clinic was estimated to be $€ 94$ per patient yielding a total cost of $€ 19,989,000$. All of these calculations are based on the assumption that activity levels in community psychiatric services were the same in 2006 as they were in 2004. The other key assumption in all of these calculations is that the unit cost estimates in a particular area are around the average unit costs for all areas. We were unable to obtain unit cost data for private hospitals so we used the figures for public psychiatric hospitals. The total cost of private hospitals was estimated to be $€ 58,980,000$ in 2006.

The HSE publication, Statistical Analysis of Claims and Payments 2006, reported that the total amount paid to doctors under the General Medical Services scheme was $€ 404.72$ million in 2006 (including both fees and allowances). Taking one quarter of these payments to relate to mental health problems (based on the Trinity College studies cited above), we have a figure for public CP consultations for mental health problems of $€ 101,180,000$. The most recent Household Budget Survey found that the average household spent $€ 3.71$ per week on CP services in 2005. The total number of households in Ireland was 1,469,521 in 2006. Hence, the total amount spent by households on private CP services was estimated to be $€ 294,845,000$ in 2006 after allowing for inflation of $4 \%$ between 2005 and 2006. Attributing 13\% of this expenditure to mental health problems (based on the HRB survey) gives us a figure of $€ 38,330,000$ spent on visits to one's CP for mental health problems. The total spent on CP consultations (both CMS and private) is approximately $€ 139,510,000$.

In 2006, the total cost of psycholeptics and psychoanaleptics prescribed under the General Medical Services scheme, the Drugs Payment Scheme and the Long Term Illness Scheme was $€ 187,480,000$ including dispensing fees and VAT. The latest Household Budget Survey found 
that private households spent an average of $€ 4.54$ on medicines on prescription per week in 2005. Assuming that $14 \%$ of these medicines relate to mental health problems (based on the CMS proportions), we estimated that private households spent approximately $€ 50,507,000$ on medicines prescribed for mental health problems in 2006 after allowing for inflation of 4 per cent. This means that, in total, approximately $€ 237,987,000$ was spent on medication for mental health problems for people in private households in 2006.

The figures for private expenditure on CP visits and drug prescriptions are likely to overestimate the amount spent as evidence from other countries suggests that there is a strong relationship between the incidence of mental health problems and income. However we have not adjusted these figures downwards in the absence of accurate statistics on how mental health problems vary with income in Ireland. On the other hand, we have not included any estimates for private household expenditure on counselling and psychotherapy and other treatments for mental health problems due to a lack of data. The direct health and social costs are summarised in Table 2.4. Note that we have not included the amount of money that people with mental health problems receive from the State in the form of disability payments. From an economic point of view these payments are simply transfers that do not impose any cost on society.

Table 2.4: Direct Cost of Health and Social Care Due to Mental Health Problems, 2002 (€ millions)

\begin{tabular}{lr}
\hline Public Psychiatric Hospitals & 70.6 \\
\hline Acute Psychiatric Units & 66.8 \\
\hline Day Centres & 38.1 \\
\hline Community Residences & 55.4 \\
\hline Day Hospitals & 29.5 \\
\hline Outpatient Clinics & 19.9 \\
\hline GP Consultations & 101.2 \\
\hline Prescribed Drugs & 187.5 \\
\hline Total Public Expenditure & 569.0 \\
\hline Private Psychiatric Hospitals & 59.0 \\
\hline Private GP visits & 38.3 \\
\hline Private Expenditure on Psychiatric Drugs & 50.5 \\
\hline Total Private Expenditure & 147.8 \\
\hline Total Direct Costs & 716.8 \\
\hline
\end{tabular}




\section{Other Direct Care Cost Estimates}

Earlier in this chapter we noted that the consequences of poor mental health range far beyond the direct health and social care costs. The rest of this section provides estimates of care costs incurred in an economy other than direct health and social care costs. People with mental health problems are at particularly high risk of ending up in prison or being homeless so it is necessary to calculate costs in relation to both these categories. A study conducted by Linehan et al. (2005) found a prevalence rate of psychosis in male remand prisoners of $7.6 \%$. The average daily prison population in 2005 was 3,151 while the average cost of keeping an offender in prison in 2005 was $€ 90,900$. Applying the $7.6 \%$ prevalence rate to the 2006 prison population yielded a cost of approximately $€ 21,768,000$ or $€ 22,629,000$ in 2006 terms.

The Simon Community estimated that there were 5,581 homeless people in Ireland in 2002. The extent of mental health problems amongst this population is estimated to be in the range of $40 \%$. Data is also available from the Homeless Agency on utilisation rates for various forms of homeless accommodation in 2002. We did not have Irish data on the cost of hostel accommodation in Ireland, so we used data for the UK from the PSSRU (Netten and Curtis, 2002). Combining utilisation data and cost data suggests that the annual cost of homelessness related to mental health problems to be $€ 33,464,704$ for 2002 , or $€ 37,715,000$ in 2006 terms.

An important part of the burden of mental health problems is the informal care provided by family members and other care givers. The most recent Census found that 160,917 people aged 15 years and over classified themselves as carers in 2006 (CSO, 2007: 119). We don't have a breakdown of who the carers were caring for. The Sainsbury Centre for Mental Health estimated that $16.5 \%$ of carers in the UK look after people suffering from a mental health problem. Using this percentage yields an estimate of 26,551 carers in Ireland. The Census doesn't report the average number of hours of caring provided so we estimated this to be 21.44 hours per week (which is very close to an earlier CSO estimate of 23 hours of care per week). Valuing an hour of care at the minimum wage for 2006 of $€ 7.65$ per hour we get an estimate overall cost of the informal care provided by carers of people with mental health problems of $€ 226,453,000$. 
The total costs of prison, homeless and informal care costs are shown in Table 2.5.

Table 2.5: Other Direct Care Costs 2002 (€ millions)

\begin{tabular}{lr}
\hline Prison & 22.6 \\
\hline Homeless Hostels & 37.7 \\
\hline Informal care & 226.5 \\
\hline
\end{tabular}

$\begin{array}{ll}\text { Total } & 286.8\end{array}$

\section{Cost Estimates for Output Losses}

The 2006 Census included several questions on disability and the report on this section of the census was published in November 2007. The total number of people of all ages with at least one disability was 393,785 . Of these, 64,955 people identified one of their disabilities as being a psychological or emotional condition. People were able to choose more than one type of disability (there were 10 in all) and it isn't clear whether everybody with a mental health related disability would have identified themselves as having a disability due to a psychological or emotional condition. Some of the other types of disability included in the census such as 'difficulty in learning, remembering or concentrating' or 'difficulty in participating in other activities' might include people with a mental health problem. Equally the heading 'psychological or emotional condition' might include people with an intellectual disability. The 2002 Census also included a section on disability but it is not possible to compare the 2006 results with the 2002 results as there were only six types of disability included in the 2002 Census and these did not include 'psychological or emotional condition'. It is not clear at all what disability, if any, would have been chosen by people in the 2002 Census who identified themselves as having a psychological or emotional condition in the 2006 Census.

Of the 64,955 people with a disability due to psychological or emotional condition, 3,456 were under 15 leaving a total of 61,499 people aged 15 or over with this kind of disability. Of these 25,803 people $(13,105$ males and 12,698 females) stated that they were unable to work due to permanent sickness or disability. In addition, 4,627 people (2,734 males and 1,893 females) with this disability were unemployed. (The unemployment rate for people with this disability was $28 \%$ which was much higher than the national unemployment rate of $8.5 \%$ ) We valued the lost output due to unemployment and inability to work at the average industrial wage in 2006 
which was $€ 32,471$ for males and $€ 23,458$ for females. We used the average industrial wage in the absence of any detailed information about the human capital, experience, skills etc. of people with this disability. This yields a total figure for lost output due to unemployment or inability to work of $€ 856,584,000$.

The 2006 Census found that 11,854 people with a psychological or emotional condition were at work in 2006 but data on the average number of hours worked by these people has not yet been published. The Quarterly National Household Survey (QNHS) published by the CSO included a module on disability in the labour force for the first quarter of 2004 and found that the number of hours worked by persons suffering from a "mental, nervous or emotional" disability was 29.5 hours per week compared to the average in the country of 36.8 hours. If we value the difference of 7.3 hours at the average industrial hourly wage we get a total of lost output due to lower number of hours worked of $€ 64,944,000$.

As noted earlier, Tedstone Doherty et al. found that the CHQ12 score was four or higher in $12 \%$ of the respondents (2007: 33). Extrapolating the survey findings would suggest that 348,500 adults aged 18 years or older are experiencing symptoms of psychological distress. It is obviously critical to know the extent to which, if any, their productivity is affected by these symptoms. The information published so far by the HRB does not allow us to infer anything about this so we have taken the following approach. The HRB survey covered adults aged 18 or older so to ensure comparability between the HRB survey and the Census we subtracted the 980 people aged 15, 16 or 17 with a psychological or emotional disability in the 2006 Census leaving 60,519 people aged 18 or more with this kind of disability. We subtracted this number from 348,500 which left us with an estimate of 287,981 people with symptoms of psychological distress but who do not identify themselves as having a disability related to a psychological or emotional condition. The average employment rate for adults aged 18 or over is $57 \%$ so that would suggest that approximately 164,149 people with symptoms of psychological distress are working. Following the Sainsbury estimates for the UK, we assume that $2.5 \%$ of the potential output of this group of people was lost due to mental health problems. Valuing this output at the average industrial wage yields an estimate of lost output from people with mental health problems at work of approximately $€ 123,111,750$.

There are two additional costs that must be added to this estimate. First, it is necessary to account for production losses as a result of premature mortality. We do not have the kind of suicide data for 2006 that is required to calculate a detailed cost of lost output due to suicide. Kennelly et al. (2005) estimated that lost market and non-market output due to suicide in 2002 
amounted to $€ 238,502,286$. Experts in this area suggest that up to $90 \%$ of people who die by suicide have a mental health problem. If we assume that $90 \%$ of suicides are associated with a mental illness, we can infer that lost output due to suicide attributed to mental illness amounted to approximately $€ 214,652,000$ in 2002. The provisional data for 2006 suggests that 409 people died by suicide in Ireland in 2006 compared to 478 in 2002. Based on this difference and allowing for inflation of $12.7 \%$ between 2002 and 2006 we estimate that the total cost of lost output due to suicide in 2006 was approximately $€ 206,992,000$.

The total cost of lost output is therefore approximately $€ 1,251.6$ million. The value of nonmarket work that is not performed due to mental health problems must also be estimated. The cost of unpaid work in the Sainsbury report for England was $60 \%$ of the total value of lost market output. Applying this ratio to the Irish estimates yields a figure for lost output associated with non-market work of $€ 751$ million. This is obviously a rough calculation and we hope that large surveys of people with mental health problems are conducted soon so that we can learn more about the impact that their problems have on issues such as unpaid work.

All of the calculations on the value of lost output must be treated with a great deal of caution. The recent HRB survey is very welcome but much still has to be learned about the prevalence of mental health problems in Ireland. We have very little reliable information on the effect that mental health problems has on employment, wages earned or hours worked in Ireland. It is likely that on average people with mental health problems earn less than the average industrial wage. Finally, the cost of suicide estimate is based on assumptions about economic growth and labour market behaviour over a long period of up to 40 years, which may not turn out to be correct. Table 2.6 summarizes the lost output costs of mental illness.

Table 2.6: Lost Output Costs of Mental Health Problems, 2002 (€ millions)

\begin{tabular}{lr}
\hline Non-employment and under-employment & $1,044.6$ \\
\hline Premature mortality & 207 \\
\hline Unpaid work & 751.1 \\
\hline Total & $2,002.9$ \\
\hline
\end{tabular}

Adding these various costs together yields an estimate of $€ 3,006.5$ million for the direct and indirect costs of mental health problems in Ireland. Gross National Product in Ireland in 2006 was $€ 149,130$ million, so the various costs that we have calculated would be equivalent to 
just over $2 \%$ of GNP in 2006. Most estimates of the cost of mental health problems stop at this point, although doing so ignores the large costs associated with the pain and suffering experienced by individuals with mental health problems. Other studies in this area have concluded that quantifying the human cost of mental health problems is too difficult an issue and we have followed this approach as well.

\section{Conclusion}

The overall total economic and social cost of mental health problems is estimated to be over 3 billion in Ireland in 2006 (Table 2.7). The fact that the total cost is so large is no surprise given the wide impact that mental health problems have on individuals, economies and societies. It is difficult, however, to compare this figure with aggregate economic measures such as GNP because the cost of illness estimates includes elements such as the cost of unpaid work that are not reflected in CNP. Nevertheless it is worthwhile noting that our estimate of the total cost of mental illness in Ireland is over 2\% of CNP in 2006.

Table 2.7: Overall Distribution of the Cost of Mental Health Problems in Ireland in 2002

\begin{tabular}{lrr} 
Category & Cost $€$ & $\%$ \\
\hline Health and Social Care & 716.8 & 23.8 \\
\hline Other Direct care & 286.8 & 9.5 \\
\hline Lost Output & $2,002.9$ & 66.7 \\
\hline Total & $3,006.5$ & 100 \\
\hline
\end{tabular}

Our estimates of the overall cost of mental health problems in the Republic of Ireland are significantly lower than The Sainsbury Centre's estimates for Northern Ireland of $€ 4.3$ billion for 2002/2003. The primary reason for the discrepancy is the exclusion of human and social costs in our study. In addition, the prevalence of symptoms associated with psychological problems is over $40 \%$ lower in the Republic of Ireland compared to Northern Ireland. As more data on the prevalence of mental health problems in the Republic becomes available we will be in a better position to understand the effects of mental health problems on employment, wages and unpaid work which will allow us to make more reliable comparisons between Northern Ireland and the Republic of Ireland. Neither have we included children or people with dementia in our analysis, which would also bias our cost downwards. Similarly, spending on mental health as a 
percentage of the overall health care budget is almost twice as high in Northern Ireland as in the Republic of Ireland, which would again affect the comparative results.

We have been rigorous in attempting to place a monetary value on the various costs associated with mental illness in Ireland. To that end, we have included costs borne by the health and social care system, costs incurred by family carers, and those resulting from lost output and productivity. It is important to recognise the limitations associated with this analysis, in particular the lack of good quality data. There is little data on costs associated with mental health care in Ireland. We were forced to use an improvised bottom up approach because the Department of Health and Children only reports one overall figure for the cost of psychiatric services in Ireland. It is very unfortunate that a breakdown of costs between the different types of mental health services is not routinely available. We were fortunate to receive some reliable cost data for a number of mental health care facilities in the Mid-West region but we have no way of knowing whether the costs for these facilities are comparable to other areas in the country. Even with this local data, we still had to use UK data for some of our unit cost figures.

Estimates of the other direct care costs - prisons, homelessness and informal care - are also based on extrapolation from the UK. For example, we have no data on the number of people providing informal care to people with mental health problems, nor do we have any data on the average number of hours of care provided by informal carers to people with mental health problems. The publication of the first wave of the National Psychological Wellbeing and Distress Survey from the Health Research Board is a very welcome development and gives us a more reliable indication of the prevalence of mental health problems in the country than we have ever had. Future reports based on the survey will explore issues such as the variation in prevalence by geographic area and by socio-economic background. The size of the sample in the survey means that it is difficult to infer the extent of lost output among people identified as having symptoms of psychological distress. A larger prevalence survey would give us a much better idea of the impact that mental health problems has on employment, hours worked and wages earned. We also need more specialised surveys on the effects that mental health problems have on absenteeism and presenteeism in individual companies.

A major limitation of this study is that like most other studies undertaken in this area we ignored the human costs of mental health problems. These are likely to very high. In fact the Sainsbury Centre have tried to estimate the human costs of mental health problems in England and Northern Ireland and found that the human costs were larger than all other costs combined. This is clearly another area where more research is urgently required. 
We advise readers to be cautious in interpreting our results, which are subject to significant margins of error. We have not included sensitivity analysis in our estimation, because we believe that we have provided a robust estimate of costs based on very poor data for almost every variable. It would be spurious to provide other estimates, generated using equally contestable assumptions, based on equally poor data. The reader would be left with very little core estimates upon which to make a judgement of overall costs. Therefore, while the main purpose of this study is to try to establish the costs of mental illness borne by society, it has also served to shed light on the lack of information and data available in this area in Ireland. 
$\mathbf{4 4}$ THE ECONOMICS OF MENTAL HEALTH CARE IN IRELAND 


\section{Preferences for Resource Allocation in Mental Health Care in Ireland}

\section{Introduction}

The overall cost figures reported in the previous chapter made it clear that the economic burden resulting from mental health problems in Ireland is very large. It is difficult to say, however, whether current resource allocation for mental health care is adequate relative to that burden as citizens have never been asked to reveal their preferences in this regard. The absence of service users and citizens from the health care allocation process in Ireland is particularly noteworthy. The public has no direct voice and therefore no influence on the allocation of money among competing health care programmes. Opinion polls frequently report the general importance of health care in the lives of citizens, but these polls only scratch the surface of the public's preferences for health and health care spending. For example, when people say "health is important" it is impossible to know what they really mean given that it would be ludicrous to say otherwise. Consequently, the implications for resource allocation are vague. The case for involving the public in priority setting within health care, and mental health care in particular, is compelling, therefore, given their central role in funding the system and their knowledge of the benefits of the various health care programmes gained through their own experience and the experience of family members.

In this chapter we use a unique data set to provide information on the extent to which the public is willing to pay for a specific initiative in mental health care that is focused on changing the balance between institutional and community-based care in Ireland. Our data is derived from a cross-sectional survey of 435 people across the country. The survey uses a technique called contingent valuation which presents people with information about a hypothetical specific intervention in mental health care (in this case one that would result in 200 more people with mental health problems living in the community rather than in an institution), asks them to rank this intervention relative to two other health care programmes - cancer and elderly care - and asks about their willingness to pay extra in taxation for the intervention in mental health care. This technique (which is discussed in more detail below) has a number of advantages over other surveys which simply ask a number of general questions about how important people think mental health is in their lives. By presenting people with a specific mental health care intervention and asking them to rank it relative to other health care interventions we are much more likely to discover reliable estimates of how people might in fact respond if the Government proposed the kind of initiative that is contained in the survey. 


\section{Contingent Valuation}

Contingent valuation (CV) studies are designed to estimate how respondents value programmes, events, goods or services where information on consumer choices in relation to prices is not available because the good or programme in question is not sold in markets. The use of contingent valuation methodology is becoming increasingly popular as a means of supplementing expert opinion with the views of the public as expressed by their willingness-topay (WTP). Contingent valuation is a well established tool for the evaluation of policies relating to safety and the environment, and its application to health care evaluation is becoming more widespread, despite ongoing conceptual and methodological difficulties with the WTP approach (Jones-Lee, 1989; Arrow et al., 1993; Diener et al., 1998; Donaldson et al., 2004). Most of the applications of WTP in health care have, however, tended to focus on eliciting WTP values from service users for single programmes or for alternative options for treating the same conditions. Very few studies have examined the issue of whether WTP can be used as an aid to health care priority setting at a regional or national level (exceptions include Olsen and Donaldson, 1998 and O'Shea et al., 2001). This chapter uses WTP methodology to explore the issues of priority setting and resource allocation for mental health care in Ireland and the value that citizens place on different health care expenditures, with particular reference to mental health care.

CV-WTP studies can either evaluate a single health care programme or different health care programmes in a single survey i.e. perform a joint evaluation. The advantage of presenting respondents with more than one health care programme is that it reminds respondents of the trade-offs between programmes and that funds allocated to one programme will not be available for another, (Luchini et al., 2002; Protière et al., 2004). Joint evaluations surveys should therefore elicit more reliable WTP values. They also indicate how respondents value the alternative programmes at the margin. Furthermore, presenting respondents with just one health care programme may create an "embedding problem" i.e. respondents may place much the same value on a specific good (e.g. community mental health programme) as on a more widely defined set of goods (e.g. the health care sector). A recent collaborative research initiative carried out in six European countries - the Eurowill project - successfully elicited public preferences regarding three different healthcare programmes using a joint evaluation technique (Donaldson et al., 2004) and our work builds on the techniques used in the Eurowill project.

As well as asking respondents to state their maximum WTP for alternative health care programmes, CV surveys can also ask respondents to rank the different programmes, thus providing additional information about people's preferences. It is not unusual for respondents' 
WTP and rankings of programmes to differ considerably. One explanation for this anomaly could be that in answering WTP questions, respondents are making a trade-off between the programme being valued and their own income, while, in ranking programmes, respondents are forced to make trade-offs between the alternative programmes. Olsen argues that the answers to WTP questions reflect private preferences while the answers to the ranking question reveal the respondent's preferences as a citizen and member of society (Olsen, 1997: 609).

Serious methodological issues have been raised about the use of the CV-WTP. These issues indicate the difficulty of carrying out WTP studies in health care or in the public sector generally. They include:

- the reliability and consistency of the thought process assumed by WTP techniques

- the poor correlation between hypothetical and actual willingness-to-pay

- the discrepancy between the ranking of programmes and the WTP for programmes

- ordering effects - how programmes are ordered in the questionnaire may affect valuations

- starting bias - where you start the valuation process matters

- the variation of values in accordance with risk reductions presented to respondents

- the cognitive effect of the amount and type of information on each health care alternative that is given to respondents

- the effect of presenting respondents with payment cards as opposed to closed-ended WTP questions

It is clear that the application of the contingent valuation approach to priority setting in health care requires careful handling in order to mitigate the design problems inherent in the methodology. This is accepted by both supporters and critics of WTP. However, asking people directly to give values for different health care programmes has the potential to inform about the nature, depth and economic and social significance of the values provided, even if some precision is lost in the telling (Portney, 1994). This potential is the virtue of the application of WTP in health care. In the past, health care expenditure decisions in most countries have tended to be historical (i.e. based on what has evolved with some minor changes over time), with a heavy weighting on expert judgment in the decision-making process. Priority setting in health care should, however, incorporate the needs of the population, measures of efficiency and fairness, and the value or utility of different services to the population. Therefore, a strategic approach to priority setting needs to involve the public, as well as experts, if it is to have legitimacy (Hanemann, 1994). 
The difficulty lies in obtaining input from the public that is informative, deliberative, accurate and representative. WTP provides a more appealing vehicle for the elicitation of preferences than alternatives such as cost utility analysis, public opinion surveys, or small-scale qualitative methodologies. The WTP estimate incorporates all of the effects of the programme on the respondent, rather than just the health effects, as would happen in cost utility analysis using the quality adjusted life year approach. Moreover, WTP can help to identify the range of factors that are likely to influence the opinions of the public with respect to the valuation of health care programmes, including personal attributes, income, experience with the programme, socio-cultural background and ideology. The quality of the scenarios presented to respondents is critical to providing the information set necessary for them to make informed judgements on relative willingness to pay. There is a trade off in contingent valuation surveys between too much and too little information. Too little information and respondents will find it hard to pass judgement on a programme; too much information can lead to cognitive overload and consequent indecision.

The majority of studies that have employed WTP in the area of mental health care have been pricing and demand studies. These studies have tried to ascertain how much people would be willing to pay for the introduction of a proposed drug or programme/intervention for people suffering from particular types of mental health problems. Not surprisingly, there has been a lot of interest in the effect of new drugs on people with mental health problems. For example, O'Brien et al., (1995) assessed the economic value of a new anti-depressant, whereby respondents were presented with the effects of medication and asked to state the maximum amount they would be willing to play for a new drug that reduced each adverse effect. Wu et al., (2003) measured the economic value of drugs to treat Alzheimer's disease in which respondents were asked to value scenarios that also included adverse effects of the drug.

The paper that is most closely related to the approach used in this chapter is one by Matschinger and Angermeyer published in 2004. They examined the extent to which the Cerman public were willing to allocate resources to the care of people with mental disorders. People were asked to select three out of nine conditions for which available resources should on no account be reduced. Matschinger and Angermeyer found that a majority of respondents stated that funding on programmes such as cancer, AIDS and cardiovascular diseases should not be reduced. By contrast, only 10\% of the respondents selected schizophrenia while even fewer $-7 \%$ - stated that funding on depression should not be reduced. As far as we know there has never been any study that uses WTP methodology to explore resource allocation decision-making with respect to a mental health care programme involving the 
deinstitutionalizing of service users. Moreover, we have not found any other study where people's preferences for a mental health programme were explored in a situation where respondents are asked to compare three different health programmes.

\section{Methodology}

The design is a standard CV/WTP survey which describes for the respondent a hypothetical improvement in community mental health services designed to reduce admissions to inpatient care. The survey was conducted using face-to-face interviews with a sample of adults living in private households. The fieldwork period ran from May to October 2006. Given the relatively small sample size, a limited number of target areas (rather than a full national sample) was selected in order to maximise variation along three dimensions likely to be related to the CV/WTP measure: socio-economic status, age and urban/rural location. In line with best international practice, respondents were asked to compare three programmes: mental health, cancer and ageing. Our main focus in the paper is, however, on the results for mental health.

\section{The Questionnaire}

The questionnaire had eight main sections and took, on average, 30 minutes to complete. The sections in the questionnaire were:

1. Risk perceptions and experience

2. Ranking of the programs (Mental Health, Cancer, Ageing)

3. Willingness to pay for an expansion of the mental health program

4. Willingness to pay for an expansion of cancer treatment

5. Willingness to pay for an expansion of the ageing program

6. Difficulty with the questions

7. Interviewer record of level of interest

8. Demographic details

In terms of the survey itself, respondents were first given introductory information outlining the objective of the survey. The three programmes were named and the respondents were asked to think about them as if they were in competition with each other for funding. Respondents were then asked about their perception of them ever needing the programmes and their past experience with each of the health states. Next, respondents were presented with the programme descriptions and asked to consider the relative importance of each programme and 
to rank the programmes from most important to least important. This was followed by the willingness to pay questions. Demographic data, including details of income and education, were collected at the end of the interview. The full questionnaire is contained in Appendix 1.

\section{The Scenarios}

An important aspect of this study is the use of 'scenarios'. These are detailed descriptions of three different types of health programme and were shown to the respondent on cards as well as being read to them. The scenarios represented the different types of health care programmes that the respondents were asked to compare. The programme descriptions were developed following consultation with relevant experts in the field and were subjected to rigorous pilot-testing. The numbers used in the descriptions of the three programmes were based on estimates of what might be reasonable comparative increments given the limited knowledge of current activity and marginal costs in the area. The mental health programme in the survey was an expansion of community-based mental health services. The cancer care programme was an expansion of radiotherapy services while the third programme was an expansion of community-based services for the elderly. Table 3.1 contains the three scenarios used in the study as they were presented to the respondents.

\section{Eliciting Willingness to Pay}

The purpose of the willingness to pay exercise is to ascertain how much individuals would be willing to contribute each year to the mental health programme. The WTP values were elicited with the help of a payment card which listed a number of money values from 0 to $€ 200$ from which respondents were asked to indicate the value that corresponded to their maximum WTP (respondents whose WTP was over $€ 200$ had the option of writing their value in the space provided). The interviewer began by asking respondents if they would be willing to contribute anything in extra taxation for the given expansion in the mental health programme. All respondents, regardless of their answer to the taxation question, were then asked if they would be willing to pay if the payment was in terms of a voluntary contribution. The inclusion of the voluntary option provides a payment option for those people who distrust public mechanisms of health care resource allocation and prefer more direct voluntary contributions. If the respondent answered no to both of these questions, they were asked to explain the reasons why they were unwilling to pay. Otherwise, respondents were asked the maximum their household would be willing to contribute each year for the expansion in the mental health programme. They were reminded that their contribution would reduce what they had left to spend on other things. 
After the WTP question, respondents were asked for the reasons why they were willing to contribute to the programme. If individuals are consistent in their answers, then we would expect to see the order of WTP the same as for rankings. However, it is possible that despite being able to clearly rank the programmes, people are not able to discriminate between programmes in terms of willingness-to-pay. This may be due to people making judgements among programmes on the basis of the incremental effects of any new investment in the programmes rather than on the totality of individual allocations. For example, respondents could take the view that a particular programme gets enough resources already and therefore, irrespective of the benefits attached to the intervention they are being asked to value, will not sanction any further spending on the particular programme.

\section{Descriptive Statistics}

Table 3.2 reports the descriptive statistics for the variables collected in the survey. Sixty per cent of the respondents were female, eighteen per cent had primary education only and just over one third were single. About one quarter were aged 65 or older, a little less were aged between 50 and 64, and the remainder were evenly distributed among the other age categories. In terms of health, eighty four per cent rated themselves as having good or excellent health compared to other people their own age. About one fifth of the respondents were daily smokers. Over half reported that they had personal experience of cancer; almost forty per cent had personal experience with old age dependency, while approximately one fifth had personal experience with a mental health problem. These factors may have important implications for the way people rank programmes and their willingness to pay for each programme. 


\section{Table 3.1: Scenarios}

\section{Mental Health Programme}

- 200 more people with mental health problems (such as depression and schizophrenia) would be able to be treated and supported in the community (some at home, some in sheltered accommodation) as a result of an expansion of community-based mental health services.

- This would help reduce the number of people in public psychiatric hospitals from the present level of approximately 3,500.

- The additional community mental health services would be in the areas of community psychiatric nursing, sheltered accommodation and day hospitals.

- The additional services would be targeted at people with severe mental health problems living in the community, either at home or in sheltered accommodation.

- The expansion of community-based facilities would improve the quality of life of people with mental health problems living independently in the community and reduce the likelihood of their admission or readmission to inpatient care.

- The people benefiting from this programme will be men and women of all ages, with an average of 45 years.

\section{Cancer Programme}

- 200 more patients with advanced cancer could have relief from pain by radiotherapy.

- This would be in addition to the 2,000 or so people who are currently getting this treatment.

- Without this treatment they would get pain-reducing medicine. However, with medicine, many patients will not have satisfactory pain relief, while others will get significant side effects in the form of tiredness and poor quality of life.

- Radiotherapy for these patients may have good pain relieving effects and lead to improved functioning and quality of life among most patients.

- The treatment will have few side effects.

- On average patients will benefit from this treatment in their last year of life. The treatment will not prolong patients' lives.

- There are patients in every age group and the average age is 60 years old. Men and women are affected in equal numbers.

\section{Ageing Programme}

- 200 more physically and mentally dependent older people would be able to remain in their own homes as a result of an expansion of community care services.

- This programme would reduce the number of people in long-stay care from the present level of approximately 20,000.

- The additional community services would be in the areas of public health nursing, home help, and day care facilities.

- The additional services would be targeted at very high dependent elderly people living at home.

- The expansion of community care facilities would improve the quality of life of dependent elderly people living at home, provide support for their carers, and reduce admissions or readmission to longstay care for people currently on the margin between community care and residential care.

- The majority of people benefiting from this programme will be women aged 75 years and over. 
Table 3.2: Sample Statistics

Percentage of sample

(figures have been rounded)

\begin{tabular}{lr}
\hline Female & 60 \\
\hline Primary Education & 18 \\
\hline Single & 35 \\
\hline Cood Health & 84 \\
\hline Smoke & 17 \\
\hline Experience cancer & 55 \\
\hline Experience elderly care & 39 \\
\hline Experience mental health & 20 \\
\hline Age $<29$ & 17 \\
\hline Age 30-39 & 18 \\
\hline Age 40-49 & 18 \\
\hline Age 50-64 & 23 \\
\hline Age 65+ & 24 \\
\hline N=435 & \\
\hline
\end{tabular}

Interval regression

We carried out comprehensive statistical analysis on the data in order to better understand the factors that affect individuals' willingness to pay for the mental health programme. Interval regressions were used to control for observed differences among respondents and to test for the internal consistency of the reported WTP values. We used this approach because the reported WTP values are grouped. All respondents reported a WTP value that was on the payment card and so we interpreted the respondent's choice as indicating they were willing to pay at least the stated amount, but not willing to pay the next highest amount. We assumed that the true WTP value is in this range. The interval regression also controls for any censoring to the WTP values that may have occurred because the highest WTP value on the payment card was $€ 200$. 


\section{Rankings}

The rankings of the three programmes are shown in Table 3.3 from most important to least important. Respondents were permitted to rank programmes as being of equal importance approximately one fifth of the sample did so. For comparability across the groups, we restricted our sample to those respondents who reported a distinct ranking. In the initial rankings, the mental health programme was ranked most important by $19 \%$ of respondents, the cancer programme was ranked most important by $63 \%$ of respondents and the elderly programme received highest priority from 31\% of respondents. Mental health is ranked least important by $40 \%$ of people compared to only $11 \%$ and $26 \%$ respectively of respondents ranking the cancer and elderly programmes least important. The magnitude of the ranking differences is quite large - while two thirds of people rank the cancer programme as number one, and about one third rank the elderly care programme as number one, less than one fifth rank the mental health programme as number one.

Table 3.3: Ranking of Programmes

\begin{tabular}{lrrr} 
& $\begin{array}{r}\text { Mental Health } \\
\text { Programme }\end{array}$ & Cancer Programme & $\begin{array}{r}\text { Elderly Care } \\
\text { Programme }\end{array}$ \\
\hline Most Important & $\%$ & $\%$ & $\%$ \\
\hline Second Most Important & 18.6 & 62.8 & 31.0 \\
\hline Least Important & 41.7 & 25.8 & 42.7 \\
\hline Total & 39.6 & 11.4 & 26.3 \\
\hline & 100 & 100 & 100 \\
\hline Prefer Mental Health to Cancer & Number & & \\
\hline Prefer Mental Health to Elderly & 62 & $\%$ & \\
\hline Prefer Cancer to Mental Health & 116 & 18 & \\
\hline Prefer Elderly Care to Mental Health & 237 & 33 & \\
\hline
\end{tabular}

When programmes are compared between one another, one fifth of respondents prefer the mental health programme to the cancer one, while one third preferred the mental health programme to the elder care one. 
Almost 20 per cent of respondents said that either they themselves or somebody in their own family had personal first hand experience of a mental health problem. It would be reasonable to expect that a person's experience might have an impact on how they rank the different programmes and on their willingness to pay for the programme most associated with their own experience. It is somewhat surprising therefore that of those people with first hand experience of mental health problems, only $27 \%$ ranked the mental health programme as number one while almost $17 \%$ of people without first hand experience also ranked the mental health programme as number 1 .

Another reason why a person might rank a particular programme highly was if the person thought that they had a higher than average risk of ever needing the programme in question. Only $6 \%$ of people thought their risk of needing community-based mental health care services in the future was above average, $28 \%$ thought their risk was average, while almost two thirds of respondents thought that their risk was either a little or a lot less than average. Notwithstanding these differences, the perceived risk of needing a mental health care programme does not seem to alter the rankings very much. Over $14 \%$ of respondents who thought their risk below average ranked the mental health programme as number 1 while only $20 \%$ of those who regarded their risk as above average ranked the mental health programme as number 1 .

\section{Willingness to Pay}

The descriptive statistics regarding the willingness-to-pay (WTP) for the three programmes are shown in Table 3.4. The mean willingness to pay for the mental health care programme presented to recipients is $€ 92$ per year. Overall, however, people are willing to pay more for the cancer and elderly care programmes (both had mean values of $€ 106$ ) than for the mental health care programme. The mean and median values for the cancer and elder care programmes are statistically similar, while both are significantly above the mean and median values for the mental health programme. It seems that, while people value the expansion of community-based services for people with mental health problems, they value it less than similar communitybased investment in services for older people and the development of pain-relief cancer services. 
Table 3.4: Descriptive Statistics of Willingness-to-Pay (€)

\begin{tabular}{lrrr} 
& $\begin{array}{c}\text { Mental Health } \\
\text { Programme }\end{array}$ & Cancer Programme & Elderly Care Programme \\
\hline Mean $(€)$ & 91.57 & 105.85 & 105.95 \\
\hline Std. Dev. & 140.63 & 150.76 & 164.62 \\
\hline Median & 50 & 100 & 100 \\
\hline C.I. $95 \%$ & $76.18-106.97$ & $89.97-121.71$ & $88.23-123.67$ \\
\hline Missing (zero WTP) & 113 & 87 & 102 \\
\hline$N$ & 435 & 435 & 435 \\
\hline
\end{tabular}

Table 3.5 provides a more detailed analysis of the factors associated with the observed WTP valuations for the mental health programme. The lower valuation for the mental health programme shows remarkable consistency across all of the variables under consideration. For example, the mental health programme has a lower valuation whether respondents are healthy or unhealthy, male or female, single or married, smoker or non-smoker. The amount people are willing to pay for all three programmes is highest for the age band 40-49, presumably because people in this category are at the height of their earning power. While older age groups are over-represented in our sample, there is no evidence of any inverse relationship between age and WTP valuation for mental health care. The lowest WTP valuations occur in the youngest and oldest age categories for each of the three programmes, with no major difference in agerelated valuation among them. WTP values also show a consistent pattern of variation by income percentile from low to high across all programmes. Women are prepared to pay more than men for each programme. People who have personal or family experience of a mental health problem are willing to pay much more for the mental health programme than those without such experience. 
Table 3.5: Variation in WTP by Personal Characteristics

\begin{tabular}{lrrr}
\hline Variable & $\begin{array}{c}\text { Mental Health } \\
\text { Programme }\end{array}$ & $\begin{array}{c}\text { Cancer } \\
\text { Programme }\end{array}$ & $\begin{array}{r}\text { Elderly Care } \\
\text { Programme }\end{array}$ \\
\hline Female & 94.92 & 111.17 & 110.76 \\
\hline Male & 87.89 & 102.53 & 105.36 \\
\hline Single & 69.09 & 85.24 & 80.83 \\
\hline Married & 103.76 & 119.57 & 123.70 \\
\hline Cood Health & 59.54 & 66.44 & 73.31 \\
\hline Poor Health & 96.79 & 114.21 & 114.04 \\
\hline Smoker & 92.74 & 116.73 & 118.30 \\
\hline Non-smoker & 92.50 & 106.35 & 107.19 \\
\hline Experience Condition & 126.07 & 120.11 & 130.69 \\
\hline No experience of condition & 84.32 & 91.37 & 95.11 \\
\hline Income 25th percentile & 62.68 & 73.68 & 76.86 \\
\hline 50th percentile & 84.58 & 93.53 & 91.38 \\
\hline 75th percentile & 92.38 & 104.74 & 103.24 \\
\hline 9oth percentile & 96.14 & 109.77 & 106.67 \\
\hline Age under 29 & 69.85 & 92.07 & 88.2 \\
\hline Age 30-39 & 85.18 & 105.62 & 108.27 \\
\hline Age 40-49 & 139.85 & 182.62 & 172.17 \\
\hline Age 50-64 & 86.94 & 93.71 & 89.82 \\
\hline Age 65+ & 75.30 & 65.45 & 82.18 \\
\hline Mean & 91.57 & 105.95 \\
\hline
\end{tabular}

Table 3.6 presents the results from the interval regression of the logged WTP values for the mental health programme on respondents' characteristics. Basic theory would suggest that respondents with a higher income should have a statistically significant higher WTP. This is confirmed. Respondents with only a primary education have a significantly lower ( $5 \%$ level) WTP for the mental health programme. This is to be expected, given the correlation between education and income. This might also explain the positive and significant sign on good health. 
Table 3.6: Interval Regression of Log WTP

\begin{tabular}{lr} 
& Mental Health Programme \\
\hline Constant & $1.280^{\star \star}$ \\
\hline Female & -0.1209 \\
\hline Single & -0.0892 \\
\hline Primary education & $-0.9764^{* \star}$ \\
\hline Smoker & -0.1056 \\
\hline Good Health & $0.4427^{\star}$ \\
\hline Experience Condition & $0.2950^{*}$ \\
\hline Income & $0.3543^{* \star}$ \\
\hline Age 30-39 & 0.2584 \\
\hline Age 40-49 & 0.3932 \\
\hline Age 50-64 & $0.7256^{* *}$ \\
\hline Age 65 + & 0.4199 \\
\hline N & 214 \\
\hline
\end{tabular}

${ }^{* *} p \leq 0.05,{ }^{*} p \leq 0.10$. Reference: male, married, > primary education, non-smoker, bad health, no experience of condition, mean income, age<29.

People aged between 50 and 64 are willing to pay more for the mental health care programme. It is not clear from the data why age matters in the way that it does for mental health care. There are more married people in the age category 50-64, so maybe people with spouses and/or children who have experienced mental health problems at first hand are willing to pay more, but this is conjecture. Similarly, more people in this category are likely to be carers lof all types), which may give them higher levels of empathy with care recipients, particularly when the programme in question is concerned with increasing resources in the community. Previous experience with mental health problems is weakly related to higher WTP for the programme. Cender, being single and being a smoker do not have any statistical impact on reported WTP.

\section{Reasons for Contributing and Not Contributing}

Most likely, people have some underlying reason as to why they are willing to pay more or less for the mental health programme. The most obvious reason could be that people are thinking of either themselves or their family when making contribution decisions. We asked people to state the most important reason for their household willingness to pay for the mental health 
programme (Table 3.7). As expected, I/household member might benefit was the single most frequently reported reason for contributing to the mental health programme. While all of these reasons listed on Table 3.7 are distinct, it is possible to classify them into three broad categories; personal reasons ( 1 and 2), equity reasons (3,4 and 5) and effectiveness reasons (6 and 7 ). When the reasons are combined in this way one could argue that over forty two percent of respondents cited an equity related reason as the most important factor underlying their willingness to contribute to the mental health programme, while 19 per cent contributed for effectiveness reasons.

Table 3.7: Most Important Reason Willing to Contribute to Mental Health Programme

1. I/household member might benefit 27.6

2. Family/friend has used the service 8.0

3. Other people will benefit $\quad 18.6$

4. Promote more equal access to care $\quad 10.5$

5. Reassuring to know care is accessible 13.3

6. Programme will improve health $\quad 14.6$

7. Support technical progress in medicine $\quad 4.3$

8. Other 3.1

People were also asked why they were not willing to contribute to the mental health programme (Table 3.8). The most frequent reasons given for not contributing were: can't afford it or health services should be more efficient. While the affordability reason might have been expected, an equal number of people cite efficiency reasons why the mental health service should not receive any more resources. There was no difference in the perception of efficiency across programmes, suggesting the existence of a generic public sector efficiency issue for respondents. The least frequent reason given for not contributing to mental health care was that the user should pay. People seem to value public provision and do not want user charges to be part of that provision. Similarly, only 6 per cent of respondents gave the reason for not contributing that they preferred other ways of paying for care, such as insurance. 
Table 3.8: Most Important Reason Not Willing to Contribute to the Mental Health Programme

\begin{tabular}{lr} 
Reason & Percentage of sample \\
\hline No value to household & 4.9 \\
\hline Other programmes more valuable & 3.9 \\
\hline Other public sector budgets should be cut & 3.9 \\
\hline The users should pay & 1.9 \\
\hline Health services should be more efficient & 34.0 \\
\hline Can't afford it & 35.9 \\
\hline Prefer other ways of paying (e.g. insurance) & 5.8 \\
\hline Other & 9.7 \\
\hline $\mathbf{N}$ & 103 \\
\hline
\end{tabular}

The final question in the survey asked people which three areas of health care provision and prevention that they would prioritize if more resources were available. Respondents were shown a list of fourteen areas. Their responses are reported in Table 3.9. A number of results stand out in this table. First of all, here is more evidence of the public's view that additional resources should be devoted to cancer in the first instance. It is also striking however the very high percentage that state they would like to see extra resources devoted to suicide. This is particularly noteworthy given the relatively small amount of resources allocated to suicide prevention in Ireland. Far more people would devote extra resources to suicide than to mental health which may indicate that many people do not think of suicide as a mental health issue. It could also reflect the relatively high level of media coverage about suicide in recent years. It is also important to note that this question included prevention as well as care and perhaps people think of suicide as something than can be prevented, whereas they may think of poor mental health as something that is less preventable. 
Table 3.9: Priorities in Health Care and Prevention

Percentage of sample

\begin{tabular}{lc}
\hline Cancer & 68.4 \\
\hline Suicide & 38.5 \\
\hline Heart disease & 37.8 \\
\hline Community care for the elderly & 31.8 \\
\hline Motor vehicle accidents & 21.2 \\
\hline Mental health & 20.7 \\
\hline Residential care for the elderly & 16.6 \\
\hline Drug treatment & 13.1 \\
\hline Alcoholism & 10.3 \\
\hline Children's domestic accidents & 8.5 \\
\hline Diabetes & 8.5 \\
\hline Smoking & 4.6 \\
\hline Back pain & 3.9 \\
\hline Other & 2.1 \\
\hline Obstetric care & 1.4 \\
\hline$N$ & 434 \\
\hline
\end{tabular}

\section{Discussion}

The survey provides us with a unique and fascinating insight into how a large sample of people value a mental health care programme both in itself and relative to two other health care programmes. The cancer programme is clearly the most important programme in the rankings, followed by the elderly care programme and the mental health programme. The fact that the cancer programme is ranked highest is not surprising, given its effect on mortality, the important influence of the National Cancer Strategy on the allocation of resources within health care, and the relatively large number of people who had personal first hand experience with cancer. The higher ranking of the elderly care programme over the mental health programme may surprise some people, but much public attention has been focused on older people in recent years mainly as a result of high-profile care and financing scandals within the system, within the private sector in particular. Even when people have first hand experience of mental health problems their ranking is not affected much. People generally consider themselves at low 
risk of needing mental health care services and even when they do, their rankings are largely unaffected. Civen the rankings, it is not surprising that the median WTP value for the mental health programme is significantly less than both of the other programmes.

However, it is important to remember that the absolute value of the willingness to pay for mental health care is generally positive and relatively high. People do value mental health care or, more specifically, they value the community-based programme outlined in this survey. If we extrapolate from the sample to the whole population then the total willingness to pay for the specific mental health programme would be in the order of $€ 200$ million per year which would far exceed the annual cost of such a programme. Note that we deliberately did not mention the cost of the programmes to the respondents because such information might bias their responses.

At the same time it is worth thinking about the relatively low WTP for mental health care and the generally lower ranking for the mental health programme compared to the other two programmes. It may be that people think more about the value of cancer and elderly care programmes to themselves and their families when valuing cancer and elderly care services than they do when valuing mental health care. Almost 50\% of respondents cite personal reasons for supporting cancer and elderly care expenditure, while the corresponding proportion citing these reasons for positive mental health care monetary valuations is only $33 \%$. In contrast, respondents seem to be motivated more by equity reasons when it comes to mental health care valuations. These reasons are not as strongly represented in cancer or elderly care valuations. Therefore, it seems that the 'self' is less important for the valuation of mental health than the 'other', suggesting that people may think about poor mental health as someone else's problem rather than their own (or their families).

It is worth noting that while 6 per cent of the respondents thought that they had a higher than average chance of ever needing home-based community mental health care services, over 20 percent thought that they had a higher than average chance of getting cancer and over 15 percent thought that they had a higher than average chance of ever needing home-based community elderly care services. It is possible that people found it easier to imagine themselves or a family member as directly being in the scenario described for cancer or elderly care than that outlined for mental health. It is also likely that some respondents might have been afraid to admit to needing mental health care given the stigma associated with mental health problems. When you consider the international prevalence rates of mental health problems, it is remarkable that less than twenty per cent of the respondents said that they had personal 
or family experience of mental health problems. Stigma is likely to be an issue here as well. Memory could be another. It may be easier to remember that a close relative died of cancer or needed residential elderly care than it is to remember that a close relative was treated for depression at some time. Another possibility is that when people are asked to think about mental health problems they may think about people with severe examples of such problems rather than the more common types of depression and anxiety disorders.

A relatively small number of people (15\%) indicated that "the designated programmes will improve health" was the reason for their contribution to the mental health programme. One possibility for the relatively low valuation for mental health is that respondents don't think that there is a clear direct relationship between health care inputs and outcomes and mental health. Even if you give people reasonable programme descriptions, including information on outcomes, this may not be enough to overcome a priori uncertainty about the marginal contribution of the programme to better mental health. It could also mean that the public are genuinely more circumspect in their views of the effectiveness of health care programmes than are health professionals. It is not that people do not value health care programmes - they clearly do - but more for reasons they might benefit from them, rather than that the various programmes will improve health. The distinction between might and will may be important for respondents in this survey. 


\section{Conclusion}

Rising public expenditures on health care have led policy-makers around the world to focus their attention on the subject of rationing or priority setting to ensure the system is getting value for money. This paper provides information for the first time on the amount of money that people are willing to pay for a marginal change in community-based mental health care in Ireland. It also provides valuable information on how this marginal change is ranked relative to other marginal improvements in cancer care and elderly care. The survey shows that people do value spending on mental health care highly. However, the valuation attached to a specific intervention in mental health is less than that assigned to cancer and elderly care programmes. Stigma and its close ally discrimination may partly explain the low priority accorded to mental health care in the resource allocation process, relative to other areas of spending.

The results suggest that much work needs to be done to improve the public perception and understanding of mental health in relation to both personal risk and social consequences. Mental health does not have the same recognition value, or receive the same attention, within the policy process as either cancer or care of the elderly. If people do not understand mental health problems, or are wary of it for stigma or other reasons, or do not feel at risk of ever needing mental health care services, then it is unlikely that they will place a high value on services designed to improve the lives of people with poor mental health. At the same time, it is very encouraging that the aggregate amount that people are willing to pay for the mental health programme would far exceed the annual cost of such a programme.

The public need much more information on the extent of mental health problems within the population and on the value of prevention and treatment programmes based in the community. People have to be convinced of the importance of spending on mental health care at all levels of society. If that happens, it is more likely that mental health will become more highly valued within the policy process, leading to higher levels of expenditure. An increased emphasis on the investment returns to expenditure on mental health care will also help the prioritisation process. Individuals benefit from increased spending on mental health care, but so do communities, society and the economy. For all of these reasons, mental health must become a national health priority, with specific targets for expenditure, evaluation and outcomes. Selling that positive discrimination message to the public and to the government is the responsibility of all stakeholder groups in the mental health field. It is not that the public do not value mental health, our results confirm that they do, rather; in a society where resources are scarce they do not value mental health highly enough. 
$66 \mid$ THE ECONOMICS OF MENTAL HEALTH CARE IN IRELAND 


\title{
Balance of Care in the Community and at Work
}

\author{
Introduction
}

The previous chapter suggests that citizens are willing to support new community-based programmes for people with mental health problems. The problem is that we know very little about the efficiency or effectiveness of various alternative programmes for supporting people with mental health problems living at home in this country. This chapter brings together some published evaluation literature from other countries that may aid decision-making with respect to the allocation of scarce mental health care resources in Ireland in the future. Two main issues are considered: balancing institutional and community-based care for people with mental health problems; and work as the key to greater social inclusion for people with poor mental health. Deinstitutionalisation has resulted in the movement of psychiatric services away from large hospitals and asylums into community settings so that people with mental health problems can be treated as close to their own homes as possible. There remains, however, a dearth of studies on the efficiency and effectiveness of community-based programmes for mental health care in Ireland. Similarly, there are very few studies on optimal employment strategies and programmes for people with mental health problems in Ireland, which means that we also have to rely on international evidence for policy guidance in this area.

\section{Balance of Care Issues}

Recent national and international policy in mental health care has been characterised by a trend towards de-institutionalisation and the provision of community-based care for people with mental health problems. A Vision for Change makes a commitment to deliver evidence-based and best practice interventions as close as possible to where the user lives and recommends that if inpatient care is necessary it is to be provided in the least restrictive setting (Department of Health and Children, 2006: 13, 15). In a similar vein, the 2001 World Health Organization report "Mental Health: New Understanding, New Hope" states that an ultimate goal is community-based treatment and care... which is readily accessible to patients and their families (WHO, 2001).

A variety of factors have contributed to the move away from the provision of mental health care in large hospitals and asylums including: a better understanding of mental health problems, the development of improved drugs and psychotherapies, and a recognition that care in the community may produce better outcomes, as well as respecting patient's human rights and civil 
liberties (Knapp et al., 2004; McDaid and Thornicroft, 2005). A key question that policy-makers and service planners face, however, is what should be the balance in provision among the different services available. What works, what is cost-effective, and what is appropriate within different budgetary constraints?

There is no blueprint for the development of optimal balance of care arrangements for people with mental health problems. A range of factors are likely to influence the mix of health and social care services between community and residential care. These include population needs, availability of resources, organizational structures, institutional arrangements and local culture. The World Health Organisation does, however, offer some guiding principles for the organisation of mental health services which incorporate efficiency, equity and human rights elements. These include protection of human rights, accessibility, comprehensiveness, coordination and continuity of care, effectiveness, equity and efficiency (WHO, 2003).

Our focus is on the efficiency and effectiveness elements of service provision along the continuum between home care and residential care. In conducting economic evaluations of community-based care for people with mental health problems, researchers are faced with a number of measurement and methodological challenges. A critical component of an economic evaluation is the data on outcomes and the effectiveness of the programmes under consideration. The most precise and unbiased evidence on outcomes is generally determined by a randomised controlled trial (RCT). However, it is difficult for investigators to conduct RCTs in the area of community-based mental health care. Hence, the results of economic, clinical and social evaluations must be treated with caution.

In an attempt to overcome this problem, the PRiSM Psychosis study investigated the outcomes of community mental health services for epidemiologically representative cases of psychosis in London (Thornicroft et al., 1998). The results suggest that the health and social gains reported in experimental studies of community health services are replicable in ordinary clinical settings, and are more effective than hospital oriented services which they replace. The evidence in this case supports a community oriented rather than a hospital oriented approach, with little difference among various community mental health team models. Notwithstanding these results, care should be taken in the interpretation of the available economic evaluation literature. In general, while the evidence supports the view that care in the community is superior to hospital care, achieving better outcomes at lower or equal cost, it is not at all clear what types of community care are most effective. Some of the main studies are reviewed in the following sections. 


\section{Cost-Effectiveness of Community Care Models}

The proposed community-based mental health service in Ireland will be coordinated and delivered through community mental health teams (CMHTs), which are multidisciplinary teams working in defined geographical areas whose function is to serve the needs of particular care groups across the lifespan from childhood to later life. They are a useful starting point in our attempt to bring together evidence of cost-effectiveness that might be useful for policymakers in making decisions on resource allocation in this country. A large number of reviews of community mental health teams (CMHTs) suggest that there are benefits to the introduction of generic community-based multidisciplinary teams (Tyrer et al., 1995, 1998, 2003; Thornicroft et al., 1998; Burns, 2001; Simmonds et al., 2001). The main findings of these reviews were that mental health care services delivered by CMHTs resulted in greater user and carer satisfaction and fewer people leaving treatment early. The data also suggested that CMHTs may reduce suicides and the number of suspicious deaths, but the relatively small numbers of deaths included in the studies under examination did not allow a definitive conclusion to be made in relation to this outcome. Similarly, incomplete data made it impossible for the reviewers to come to clear conclusions regarding the effect of $\mathrm{CMHT}$ s on inpatient admission and duration of stay, clinical and social functioning, and family burden. However, continuity of care and service flexibility was shown to be more developed where a community mental health team model was in place (Sytema et al., 1997). All of the studies under review reported that the average total cost of care was less for patients treated by CMHTs than standard care. In contrast, however, other authors have cited evidence from the National Collaborating Centre for Mental Health that suggests that CMHTs do not result in real cost savings (Knapp et al., 2004).

A more specialized form of the CMHT approach is assertive community treatment (ACT) which provides a form of specialized mobile outreach treatment for people with more severe and enduring mental illness. Characteristics of ACT include small caseloads and the provision of services 24 hours a day, 7 days a week. There is now strong evidence that ACT produces the following advantages in areas with high levels of resources (Thornicroft and Tansella, 2003):

- Reduced admissions to hospitals and use of acute beds

- Improved accommodation status and occupation

- Increased service user satisfaction 
Assertive community treatment also reduces the cost of inpatient services, though it does not change the overall costs of care (Phillips et al., 2001). There is, however, no evidence that assertive community treatment produces improvements in mental state or social behaviour (Thornicroft and Tansella, 2004).

\section{Cost-Effectiveness of Case Management}

Another form of individualised care is case management which covers a range of tasks including needs assessment, planning and monitoring an individual's care, advocacy, and supportive counselling (Ziguras et al., 2002). Some commentators have labelled it a method of delivering care rather than a clinical intervention in its own right (Thornicroft and Tansella, 2003). Evidence gathered by Marshall et al., (1998) based on a review of 10 randomised controlled trials examining the effectiveness and costs of case management revealed that, while case management increased the number of patients remaining in contact with psychiatric services, it doubled the number of psychiatric hospital admissions. The cost data proved difficult to analyse but suggested that case management may increase health care costs. The overall conclusion of the review was that case management does not produce clinically significant improvements in mental state, social functioning, and quality of life. The reviewers questioned the extent to which case management should be considered an efficient and effective model of mental health care.

In contrast, Gorey et al. (1998) conducted a meta-analysis of 24 published studies of case management and concluded that $75 \%$ of those participating in case management had better outcomes in terms of improved mental state, psychosocial functioning and quality of life than those who did not participate. In addition, case management reduced costs due to a reduction in hospitalisation rates. Chan et al., (2000) compared case management to traditional community psychiatric nursing care and found that, while case management resulted in higher costs, it also produced greater improvements in psychological condition, functioning and patient satisfaction. Therefore, it is up to policy makers to decide if the extra effectiveness achieved by this mode of treatment is worth its extra cost (Roberts et al., 2005).

Marshall and Lockwood (1998) compared case management with assertive community treatment (ACT). ACT was also assessed as an alternative to standard community care and traditional hospital-based care. The findings showed that ACT resulted in lower admissions to hospital than traditional inpatient or standard community care but there was insufficient data to allow a comparison with case management on this outcome. ACT also resulted in a 
shorter duration of stay when compared to its alternatives. ACT proved superior to standard community care in relation to accommodation status, employment and patient satisfaction. There were no significant differences between ACT and standard community or inpatient care in terms of clinical or social functioning, while insufficient data prevented a comparison with case management in this domain. However, service labels are sometimes incorrectly applied in comparisons between similar type programmes. If researchers are indeed erroneous in their classification of treatments, this would obviously cast doubt over any conclusion about the superiority of ACT over case management (Burns et al., 2001).

\section{Cost-Effectiveness of Home Treatment}

In order to overcome this limitation and the difficulties inherent in classifying the different types of community-based care, Burns et al. (2001) conducted a systematic review of community-based care for mental health under the more comprehensive title "home treatment". They defined home treatment as a service that enables the patient to be treated out of hospital as far as possible and to stay in their usual place of residence (Burns et al., 2001:4). The main objectives of the review were (a) to assess if home treatment was more effective than inpatient treatment in reducing hospital days and costs; and (b) to ascertain if home treatment services were more effective than other community-based services in reducing hospital days and costs. While the review was based on Cochrane methodology, non-randomised studies were also included if they compared two services. The inclusion of non randomised trials was due to the fact that randomised controlled trials may have a low degree of external validity and their results may not generalise to real world settings of service delivery (Drummond et al., 1997; Burns et al., 2001). The main outcome measure used was average days in hospital per patient per month over the follow up period.

The review included 91 studies, 56 of which involved randomised controlled trials. The main conclusion was that home treatment demonstrated a clear advantage over inpatient care but its benefits over other forms of community-based care was uncertain. 22 of the studies examined included economic evaluations but they failed to provide conclusive evidence of the costeffectiveness of home-based care due to methodological problems involving sample size, the heterogeneity of services, outcome measures and the quality of the analysis (Burns et al., 2001). 


\section{Cost-Effectiveness of Re-Settlement Studies}

A major international trend in recent years has been the resettlement of long-stay psychiatric patients from residential to community-based settings. One randomised controlled trial looking at the costs of moving people from hospital-based to community-based services offering problem-oriented, home-based care found that the community programme was significantly less costly in the short to medium term (Knapp et al., 1995). This London-based study evaluated the TAPS (Team for the Assessment of Psychiatric Services) Programme and also incorporated information on the quality of care and health outcomes for former long-stay patients discharged from two psychiatric hospitals into the community. At the 5 year follow up, 90\% of participants still alive were living in the community, with almost two thirds of these in their original community placement. Over one third of the patients were readmitted to hospital at least once during the 5 year period while at the end of the follow up, only $10 \%$ of the sample were inpatients. Patient death or suicide rates did not increase as a consequence of the move to the community; while less than $1 \%$ of the study members became homeless and only $2 \%$ committed serious assaults over the 5 year follow up. Several other studies have also found that outcomes are more favourable for most patients who are discharged to community care (Shepherd and Murray, 2001; Tansella, 1986; Thornicroft and Bebbington, 1989).

\section{Cost-Effectiveness of Crisis Intervention}

One of the biggest challenges to the successful implementation of de-institutionalisation is to provide adequate and effective treatment to people with severe mental health problems who experience an acute episode and need intensive care. The most common form of community-based mental health care for such cases is the crisis intervention model. Joy et al. (2003) conducted a systematic review of this form of care using Cochrane methodology. The objective of the review was to examine the outcomes of crisis intervention in comparison to the alternative of standard care. The authors compared the two services under eight main headings:

1. Death or harm: There was no evidence of the impact of crisis intervention on this outcome.

2. Hospital use: This outcome proved difficult to investigate as inpatient admission is a fundamental component of standard care. Therefore, the authors compared standard care services and crisis intervention in terms of repeat admissions, as this excludes index admissions for the former group. Pooled data from three studies implied that crisis intervention resulted in fewer repeat admissions. However this result was inconclusive as 
very positive data from one study was offset by data from the other two studies which found no differences in repeat admissions between the two forms of care.

3. Failure to adhere to one's treatment programme: There was conclusive evidence that people treated by a crisis intervention team were more likely to stay in care for at least a year.

4. Clobal state and mental state: Only one study had usable data for global measures of outcome and while there was some indication that crisis intervention was superior on this outcome, no significant differences were found between the two treatments. In relation to mental state, each trial used different measurement instruments so it was not possible to pool the data.

5. Burden: The results irrefutably showed that crisis intervention resulted in less of a burden on family members. However, the effects of the two treatments on community burden in terms of employment, numbers of people being arrested or using emergency teams were ambiguous.

6. Satisfaction: User and family satisfaction was higher in the crisis intervention group as opposed to the standard care group.

7. Economic cost: There was limited data available in this respect but it indicated that home care in the form of crisis intervention was cheaper than standard care.

8. Staff satisfaction: There was a lack of data addressing issues such as staff recruitment, despondency and burnout which play an important role in the successful operation of crisis intervention packages.

The authors concluded that home-based care may provide treatment that yields higher user and family satisfaction and lower family burden than conventional inpatient care. Home-based care also appears to be cheaper.

Economic evaluation was also utilised in relation to a community-based programme developed in London as an alternative to inpatient care - the Maudsley's Daily Living Programme (DLP). A randomised controlled trial recruited 189 people who were facing crisis admission to the Maudsley Hospital and assigned them to either the DLP (the experimental group) or to standard hospital care (the control group). The outcomes examined included number of admissions and duration of inpatient stay, clinical and social functioning, and patient and relative satisfaction. The outcomes were compared at the baseline and at 4, 11 and 20 months respectively. The results revealed that the DLP programme produced more favourable outcomes and greater patient and family satisfaction than its comparator. The costs of the DLP were also compared with traditional hospital-based care (Marks et al., 1994; Knapp et al., 1994). Three main cost 
categories were considered: services used in the treatment and support of patients, lost employment opportunities and the burden of informal care. This analysis concluded that costs incurred by the DLP were lower than those of the hospital-based alternative leading the authors to conclude that the community-based programme was more cost-effective. However, after four years all of the clinical gains, as well as the cost advantage, that the DLP had were lost (Audini et al., 1994; Knapp et al., 1997).

Another alternative to inpatient care for people with severe mental health problems suffering an acute episode is admission to a crisis house (Thornicroft and Tansella, 2003) i.e. a house in a community setting staffed by mental health professionals. Sledge et al. (1996) found that crisis houses were more cost effective than inpatient care. This finding was replicated by Fenton et al. (2002) who investigated the costs and cost-effectiveness of a residential crisis programme as an alternative to admission to an inpatient psychiatric unit for people with serious mental health problems. While there was no significant difference between the treatments with respect to their effectiveness in terms of symptom reduction or increase in days living in the community, average acute treatment episode costs proved to be $44 \%$ lower for the crisis residential programme giving it a clear cost-effectiveness advantage.

\section{Cost-Effectiveness of Day Hospital Provision}

Marshall et al. (2001) conducted a systematic review of day hospital care as an alternative to outpatient care and in-patient care. The review suggests that day hospital care resulted in improved psychiatric symptoms compared with the outpatient alternative. However, the data did not support the superiority of day treatment programmes over outpatient in relation to other clinical and social outcomes or costs of care. Day hospitals can significantly reduce admissions to inpatient care while the psychiatric symptoms of day hospital patients also appeared to improve more quickly than if they are cared for as an inpatient. Therefore, acute day hospitals that provide intensive psychiatric care without the major overheads may be a cost effective alternative to inpatient care. However, the authors also note that other forms of community care, such as Assertive Community Treatment, may result in even greater reductions in inpatient admissions than acute day hospitals. In addition, the cost savings achieved by day hospital care are modest, implying that this form of care may be a suitable alternative only in situations where demand for inpatient care is high and facilities already exist which are suitable for conversion (Marshall et al., 2003). 


\section{Evaluation of Family Support within Community-Based Care}

Families are critical in the development of community care provision for people with mental health problems. The significant contribution that informal care makes to mental health care services has led to a much greater recognition of the important role it has to play in the effort to treat people with poor mental health in the familiar environment of their own community. However, it is becoming more and more recognised that this form of care may have negative effects on family members in terms of increased financial and psychological burden unless resources are devoted to supporting families in their delivery of care. An effectively managed community care service that is comprehensive and personal can improve the quality of life of care recipients and their families. A good example of the latter is the Clondalkin model of community-based care in Ireland which combines comprehensive provision with integrated delivery of support services for service users and their families. Both formal and informal support services are available to families. This service was shown to be effective in reducing length of time in hospital for service users but not at the cost of increasing the burden on families. In fact the reverse happened; the burden on families decreased (Keogh, 1997).

\section{Factors Affecting Care Givers' Burden}

The increased recognition of the burden placed on family members caring for relatives has led researchers to investigate the factors that are most likely to contribute to a negative experience of care giving. While studies have shown that contributory factors may include the psychiatric diagnosis and quantity of symptoms, duration of illness, length of treatment and treatment setting, and relationship with patient, there has been little consensus about the relative effect of these various features on family burden (Lowyck et al., 2004; Möller-Leimkühler, 2005). This is mainly due to the measurement difficulties presented by the concept of family burden and indeed by informal care in general.

In order to avoid some of these methodological weaknesses, Möller-Leimkühler (2005) examined caregiver burden using a multidimensional model and combined standardised and qualitative data assessment and analysis. The results revealed that caregiver's stress outcome is statistically not influenced by objective stressors such as the clinical ratings of the severity of illness, type of symptoms and psychosocial functioning at first admission. Instead, the most significant predictors on stress outcome included relatives' expressed emotions, the extent of their emotion-focused coping, and their generally used negative stress response. The burden of care and perception of stress was influenced more by the carer's subjective appraisal of 
that burden and the coping ability of each individual carer than by the objective stressors themselves. This assertion is supported by Harvey et al. (2001) who discovered that caregivers' negative appraisal of care was a strong predictor of their psychological distress. These studies suggest that interventions to increase the coping capacity of carers should be developed to enable family carers to deal with the consequences of caring for a family member with a mental health problem more effectively.

A longitudinal study of carers conducted by Hirst (2005) using data from the British Household Panel Survey found that the risk of psychological distress amongst carers increased with the intensity of care, implying that carers who provide long hours of care are more vulnerable to adverse psychological consequences of care, women more so than men. Such negative effects were more pronounced around the start and end of the care giving period and continued even when the care giving episode had concluded. The results emphasise the importance of recognising the heterogeneity of the caring population with respect to circumstances and hours of care when considering the effects of care and evaluating supportive interventions. This point is also supported by Östman and Hansson (2004) who found that caregiver burden was more extensive if the carer and patient lived together, had a longer relationship of care, if care giving was provided on a daily basis, and if care giving was evaluated negatively by the care provider.

Wolff et al. (2006) investigated several models used to conceptualize and measure the cost of informal care and examined which of these models of financial burden best correlated with measures of psychological burden. The models ranged from the most conservative which only measured family burden in terms of time spent providing care tasks to a more extensive model that included time, in-kind and monetary contributions of family caregivers as well as costs incurred due to the negative health and stress of care giving. Reciprocity was also explored in this study. Two main conclusions emerged from the study. The first is that the burden imposed on informal care givers is likely to negatively impact on their health and increase their experience of stress which in turn increases the cost of informal care giving. The second is that the ability of recipients of care to give back diminishes the financial and psychological burden imposed on carers. Reciprocal giving appears to counteract the objective and subjective burden experienced by family care givers as well as reducing their financial burden Therefore, people with mental health problems must be encouraged and empowered to reciprocate in ways that are important to the care giver, for example by actively contributing to the household and/or managing his/her own care. 
The growing awareness of the detrimental effects that care giving can have on informal carers has led to an increase in the provision of supportive interventions targeted to the specific needs of this vulnerable group. In particular, mutual support groups may be an effective way to reduce family burden (Citron et al., 1999). These groups can assist families by offering role models to help carers cope with the problems they typically encounter and providing an environment in which relatives can express their feelings and share their problems without feeling a sense of shame or stigma. Norton et al. (1993) conducted a cost benefit analysis of membership of one such self-help group in the USA - the Alliance for the Mentally III (AMI). The study elicited information from 59 family caregivers who were members of AMI and 40 family caregivers who were non-members using a structured interview. The evidence revealed that while there are costs associated with membership, the benefits of membership outweigh the costs and that these benefits are positively associated with levels of participation. These findings imply that measures might be put in place to assist the establishment and maintenance of peer support groups for relatives and carers of people with a mental health problem and active participation in such groups should be encouraged.

\section{Work and Mental Health}

Work and employment represent important objectives for people with poor mental health and are important elements of a holistic community care programme. Active participation in the workforce, both formal and informal, brings with it many clinical, economic and social benefits and plays an important role in enabling people with mental health problems to become integrated into the community in which they live. Employment can lead to improvements in clinical outcomes by fostering self esteem thus alleviating psychiatric symptoms and reducing dependency. The economic and social benefits of work include social inclusion and economic independence. It is not surprising that studies have consistently shown that the majority of people with a mental health problem want to be gainfully employed.

While getting people with mental health difficulties into the workforce is important so also is maintaining the mental health of all workers, irrespective of previous history of mental difficulties. Unfortunately, there is increasing evidence of poor mental health within the workplace. Therefore, while work is important for mental health, it is no guarantee against poor mental health and in some instances can be a contributory factor to mental health problems. Within the European Union, overall work-related stress is now believed to affect one third of the workforce (Ivanov, 2005). Studies from the United States suggest that 18\% of the workforce may have some form of clinical psychiatric disorder at any one point in time 
(Kessler et al., 1994). Not surprisingly, therefore, there are high levels of absenteeism, lost productivity and early retirement due to mental health problems. Data collected by the Mental Health Economics European Network (MHEEN) confirm a trend of increasing absenteeism, presenteeism and early retirement due to poor mental health across Europe for both men and women. Indeed, on current trends, mental health problems will soon overtake musculo-skeletal problems as the leading cause of absenteeism in a number of European countries such as Germany and Spain (Wynne and MacAnaney, 2004).

While our concentration in this review is on the cost-effectiveness of programmes designed to increase the labour force participation of people with mental health problems, it is necessary to say something about the promotion and protection of good mental health within the existing general workforce. After all, there is little point in seeking to increase the labour force participation rates of people with poor mental health if no attention is paid to their mental health once they become employed, or to the mental health of the existing labour force. Up to now, workplace mental health has been discussed within the framework of occupational health and safety programmes, the majority of which have focused on physical health. Traditionally, mental health programmes were not seen as part of health promotion in the workforce. This is beginning to change. The 2005 Helsinki intergovernmental conference on mental health demonstrated a new political commitment to prioritise mental health in the workplace. A detailed action plan was endorsed by Ministers to cover the creation of healthy workplaces through the introduction of measures to encourage exercise, changes to work patterns, sensible hours, healthy management styles and occupational health and safety. The problem is that relatively little is known about the cost effectiveness of workplace interventions (Schaufeli, 2004). One recent systematic review of workplace interventions could only find six studies in this field, none of which presented information on cost-effectiveness (Michie and Williams, 2003). Clearly, much work remains to be done to provide the evidence that will help translate political rhetoric into policy and practice for mental health promotion in the workplace.

\section{Vocational Rehabilitation Schemes}

The evidence is stronger with respect to the impact of vocational rehabilitation on people with mental health problems. While there are many different types of vocational rehabilitation schemes, it is possible to dichotomise existing programmes under two main headings:

- Pre-Vocational Training (PVT)

- Supported Employment (SEm) 
Pre-vocational Training (PVT) is the traditional approach to helping people with severe mental health problems return to work. This model uses a train and place approach. The main characteristic of this model is that participants undertake a period of training in sheltered workshops before being placed in a work environment.

Supported Employment (SEm) schemes place clients in competitive employment without extended preparation. This approach offers an alternative to the train and place approach by placing participants in real jobs without prior preparation and then providing ongoing support once they are established in the workplace. SEm emerged due to dissatisfaction with the PVT model as critics argued that the latter fostered dependency and discouraged users from seeking competitive employment.

Crowter et al. (2001) conducted an extensive review of vocational rehabilitation programmes for people with severe mental illness including schizophrenia and schizophrenia-like disorders, bipolar disorder, and depression with psychotic features. The objective of the review was to assess the effectiveness of PVT and SEm in assisting people with these conditions to obtain competitive employment. All of the studies, with one exception, were conducted in the United States. This may have implications for generalizing the results to countries with different economic conditions, welfare structures and cultural attitudes to work. The review entailed the following comparisons:

- Pre-vocational Training (PVT) versus standard hospital care

- Pre-vocational Training (PVT) and standard community care versus standard community care

- Supported Employment (SEm) and standard community care versus standard community care

- Pre-vocational Training (PVT) versus Supported Employment (SEm)

The main results of the review were:

- There was little evidence that PVT or SEm programmes improved psychiatric symptoms, quality of life or social functioning. However, this finding must be interpreted in light of the methodological limitations affecting the ability to detect improved outcomes. Specifically, only a minority of participants in vocational rehabilitation programmes were successful in securing competitive employment. As a consequence of this, a larger sample is necessary to detect significant improvements in clinical and social outcomes. In addition, the small sample size may disguise improvements in clinical symptoms among people with severe mental illness who are engaged in active employment. 
- When PVT was compared to standard community or hospital care the review found no evidence to suggest that PVT was more effective on the employment outcome than standard community or hospital care. In relation to clinical outcomes, while participants in PVT programmes initially appeared less likely to be admitted to hospital than their counterparts receiving standard community care, further analysis using a random effects model found no significant difference in this regard.

- Only one trial compared SEm to standard community care. Although evidence from this trial appeared to suggest that SEm was superior to standard community care, the findings are difficult to interpret as the participants of the SEm programme also received Assertive Community Treatment in addition to SEm.

- When the reviewers compared PVT and SEm, the main finding of the review was that SEm was superior to the PVT alternative on the primary outcome, namely securing competitive employment. Five RCTs demonstrated that participants in SEm programmes were significantly more likely to be in competitive employment at six time points across 18 months. SEm also compared more favourably to PVT in relation to secondary outcome measures such as average hours worked and average monthly earnings. This finding led the authors to conclude that Supported Employment is more effective than Pre-Vocational Training in helping people with serious mental illness obtain competitive employment.

While vocational outcomes such as employment tenure and wages earned are the primary measures of effectiveness in studies evaluating vocational rehabilitation programmes, Bond et al. (2001) examined non-vocational outcomes among four distinct categories of service users: people engaged in a significant amount of competitive work, people participating in sheltered work placements, people undertaking a minimum amount of competitive work, and people not working at all. The results revealed that the psychiatric symptoms and self-esteem of people participating in competitive employment improved over the timeframe of the study and they had more satisfaction with vocational services, finances and leisure activities than the rest of the sample taken together. The authors concluded that it is continued exposure to employment, rather than brief contacts with workforce participation, that has beneficial effects.

Twamley et al. (2003) carried out a literature review and meta-analysis of randomised controlled trials conducted in the area of vocational rehabilitation for people with schizophrenia and other psychotic disorders. The review covered 1 published RCTs of vocational rehabilitation programmes, 9 of which were trials studying supported employment models including Individual Placement and Support (IPS). Eight of the trials included in the review were also examined in the Cochrane Review by Crowther et al. (2001). The main findings of the review supported 
those of the Cochrane Review, namely that vocational rehabilitation in the form of supported employment programmes are more effective in respect of employment outcomes than the more traditional train and place programmes. However, despite supported employment proving more effective, almost half ( $49 \%$ ) of its participants failed to secure competitive work at any time during the period of the study. Therefore, further improvements may need to be made in order to increase the number of clients successfully gaining employment.

Twamley et al (2003) recommended that intangible outcomes such as job satisfaction and non-vocational outcomes such as quality of life and community functioning as well as psychiatric symptoms and re-hospitalisation rates need to be taken into account in evaluations of vocational rehabilitation programmes. Similarly, upon completion of a review of the costeffectiveness of supported employment programmes, Schneider (2003) notes that the scope of benefits included in such studies is confined to mainly employment outcomes such as earnings and job tenure. She recommended that more effort be made to include intangible benefits such as quality of life, job satisfaction and social inclusion. The latter is of particular importance as this is an appealing feature of the supported employment model.

Finally, with respect to employment, advocates of vocational rehabilitation programmes argue that gainful employment promotes economic independence and reduces dependency on state aid among people with mental health problems. This has the potential to make vocational rehabilitation programmes very attractive from a cost benefit perspective. In addition, the resources saved from the reduction in state subsidies could in turn be channelled into developing and expanding vocational rehabilitation programmes. However, while increased earnings from work may reduce dependence on state benefits, this may not necessarily be to the advantage of the individual employee who may find that an increase in private income does not offset the reduction in public benefits resulting in a reduction in their overall income. This may especially be relevant for people with poor mental health who may find themselves in part-time or low paid jobs. Therefore, it is important that economic evaluations of supported employment programmes take into consideration not only the securing of competitive employment and wages earned, but also the effect of this on social welfare benefits received and total income (Clark et al., 1998). Vocational rehabilitation programmes do not always lead to economic self-sufficiency on the part of participants, who may continue to rely on transfers from the state for at least part of their income. 


\section{Lessons for Ireland}

Recent national and international mental health policy has been characterised by a shift in the provision of mental health care services away from large institutions and asylums into community-based settings. The evidence presented in this chapter supports an integrated community-based approach to mental health care delivery, supported by efficient hospital provision where appropriate and necessary. Care is not necessarily cheaper or better because it is based in the community; it has to be properly resourced and managed and may, therefore, be sometimes more expensive than the institutional alternative. It is likely, however, to yield better outcomes for users and their families. Community-based programmes are also more acceptable to service users leading to increased satisfaction.

The most recent systematic attempt to address key balance of care issues between community and hospital settings in Europe was undertaken by Thornicroft and Tansella (2003, 2004). Their review suggests that there are no persuasive arguments or data to support a hospital only approach, nor is there any scientific evidence that community services alone can address all mental health needs. They advocate a balanced care model of mental health service provision. This implies that services are provided in normal community settings close to the population served, while hospital stays are as brief as possible, promptly arranged, and used only when necessary. This balanced interpretation of community-based services goes beyond the rhetoric about whether hospital care or community care is better, and instead encourages consideration of what blend of approaches is best suited to a particular area at a particular time. Clearly, the organisation of resources around and within the cooperative teamwork framework provided by the Community Mental Health Team is critical for this evolving balanced care model to be successful in Ireland.

One implication of this balanced care model is the need for bridging finance during the transition period when mental health care services are moving from institutions into the community. As the initial move to community-based care will prove costly it is essential that mental health budgets are ring-fenced so that resources released from the sale of hospitals and asylums are not lost to other health priorities. There is a danger of this happening if community care is perceived to be cheaper than the more traditional forms of care it is replacing, thereby justifying a reduction in the overall mental health budget (McDaid and Thornicroft, 2005; WHO, 2001). 
One form of community-based mental health care which is under appreciated is that of informal care provided by family members. People with mental health problems are becoming increasingly reliant on this type of care and while it can have beneficial effects for care recipients as they receive care in familiar surroundings by persons close to them, it is necessary that attention is paid to the impact of this form of care on the caregivers. The burden of caring for a person with mental health problems can manifest itself in the form of financial strain, increased physical and mental ill-health, and a reduction in social relations and quality of life.

The research into what factors contribute to a negative experience of care giving and studies suggest that the important influences include intensity of care, living arrangements lif the carer shares a household with the service user), relationship of care and negative evaluation of care by care-giver. Therefore, it is important to recognise the heterogeneity of this population with respect to circumstances and hours of care when considering and evaluating supportive interventions for informal care givers. Interventions geared towards alleviating carer burden must target the way caregivers perceive and cope with the stress caused by caring for a loved one with a mental health problem. The interventions should try to influence the way that carers appraise their circumstances and to increase the coping capacity of individual carers so that they can better deal with stressful situations. Social support, while not necessarily altering the stressful situation, can alter carer perception resulting in a reduced sense of burden and a feeling of empowerment. Evidence also suggests that measures should be put in place to assist the establishment and maintenance of peer support groups for relatives and carers of people with a mental health problem in Ireland and active participation in such groups should be encouraged.

The social integration of people with poor mental health is an important objective of community-based mental health care. One important way of achieving social integration is to encourage and support service users to become active participants in the labour force. The traditional model of vocational rehabilitation trains participants in sheltered workshops prior to their entry into the competitive job market. This approach has been supplanted in recent times by the supported employment model in which clients are placed in competitive employment and support structures are put in place to assist their progress. Research has revealed that this variant of vocational rehabilitation has proved to be more successful in achieving sustained positive employment outcomes than its predecessor, leading to higher levels of social inclusion. However, some studies have shown that although it is superior, supported employment does not result in full employment signalling that more resources may need to be devoted to this model in order to increase its effectiveness. 
It is important that in implementing vocational employment programmes, policymakers do not do so on the basis that such interventions will result in reduced expenditure in other areas such as social welfare or support payments. In fact, government expenditure may increase if participants in such programmes are able to avail in education or training grants or back to work allowances. Hence, in evaluating such programmes, it is necessary to recognise that the costs and benefits of such programmes are shaped by influences outside the mental health care sector, especially labour market structures, tax and benefit structures and the interplay of these factors.

Therefore, the implementation of vocational employment programmes may or may not reduce overall government expenditure. Employment can, however, result in the successful community integration and social inclusion of people with poor mental health. It is essential that social inclusion benefits are measured and valued in order to provide irrefutable evidence in support of the continued expansion of employment programmes for people with mental health problems. 


\section{Conclusions}

Recent years have finally seen mental health become more important in global health policy agendas, particularly within Europe. For example, all 52 member states of the WHO European Region, as well as the European Union and the Council of Europe, endorsed a Declaration and Action Plan on mental health in 2005 (WHO, 2005). The European Commission issued a Green Paper on developing strategies to improve mental health in the European Union around the same time (European Commission, 2005). In Ireland, the publication of A Vision for Change reflects the importance now attached to mental health issues in this country. After years of relative neglect, mental health has finally begun to receive the attention it deserves. Now is an opportune time for policy makers and service providers to consider the economic case for increased investment in mental health services.

There has been little or no attention paid to economic aspects of mental health in Ireland up to now, so this report is novel in its coverage and focus. There has been no tradition of economic analysis of mental health data and no dedicated health economists working in the field. There is no consistent database that brings together economic and social information on mental health. There is good information on inpatient activity, but little on anything else. Data on national prevalence rates is limited. Unit cost data is not systematically collected, making it difficult to examine the relative costs of various programmes. Similarly, we know practically nothing on the consequences for Irish society and the economy on the impact that mental health problems can have on many aspects of life including physical health, family relationships, social networks, employment status, earnings and broader economic status. We know that mental health problems can lead to stigma and discrimination, but know little about the direct impact both can have on the lives of people with mental health problems and their families.

Overall, therefore, conclusions from this report, although necessarily tentative given information lacunae, contain the seeds for a more enduring role for economic analysis within mental health care, particularly when it comes to exploring the economic and social returns from greater public investment in the field.

Our very brief summary of the research in the preceding chapters is as follows: policy makers cannot afford not to invest in mental health; service providers and researchers in Ireland need much better data for any extra investment to yield the maximum returns in both health and the broader quality of life; advocacy groups and researchers need to increase their efforts to persuade the public that increased investment in mental health services represents a wise and just use of resources. 
The reasons that policy makers should invest more in mental health are: (1) the economic cost of poor mental health in Ireland is very significant; (2) the Irish public has expressed a willingness to pay extra taxation for a mental health programme that would enable more people to live in the community; and (3) there is a burgeoning economic base of evidence about particular interventions which have a positive effect on the quality of life of people with mental health problems. And yet that advice comes with a caution. We simply do not have comprehensive data for Ireland to allow us to be confident about the accuracy of our estimate of the cost of mental health problems in the country. Our review of the balance of care and of employment support programmes was almost entirely based on studies carried outside of Ireland. The data from our contingent valuation study suggests that while many people are prepared to pay something in extra taxation for a new mental health programme, it was still ranked third by a majority of people when we asked them to compare the mental health programme to a cancer care programme and an elderly care programme. We cannot be sure why the mental health programme was ranked relatively low, but it is clear that more must be done to persuade the public that additional investment is needed in the mental health services.

The economic costs of mental health problems are very high in Ireland. We have provided baseline estimates which suggest an overall cost of just over $€ 3$ billion in 2006 , equivalent to just over 2 per cent of CNP. This result is lower than overall cost-of-illness estimates for the UK and Northern Ireland, mainly because we have excluded human and social costs from our analysis. The health care system accounts for less than one quarter of overall costs in our study. The majority of economic costs occur outside the health sector, largely in the labour market as a result of lost employment, absenteeism, lost productivity, premature retirement, and premature mortality. Other costs may fall on informal care, hostel accommodation and criminal justice agencies. Typically, studies have estimated these combined non-health care costs at between 60-80 per cent of the total economic impact of mental health problems (Knapp et al, 2004), similar to what we have found in our work.

The overall cost of mental health problems in Ireland is, therefore, significant in both absolute and relative terms; only cardiovascular disease is likely to contribute more to the overall burden of illness in Ireland. Civen the multi-faceted impact of mental health problems and the many and damaging consequences of poor mental health, it is surprising how little attention has been focused on the returns to greater investment in mental health care. The evidence shows that it is possible to impact on many of the elements that contribute to the burden of illness if the political will exists to direct more resources towards mental health. However, the development of national policies and the level of funding for mental health services or initiatives have been 
disappointing across the length and breadth of Europe (Knapp et al., 2006). Ireland is no exception to this trend. Although per capita expenditure on mental health care has increased in recent decades, spending as a proportion of GNP remains on the low side in comparison with similarly developed countries in Europe. The proportion of total health system expenditure devoted to mental health care in Ireland, at just over 6 per cent, is also small relative to other countries. Clearly, we have not yet made the investment connection between increased public spending on mental health care and individual and social gains.

Making mental health a national health priority would be an important first step to realise the potential gains associated with increased spending on mental health. To begin, we should set a target of 10 per cent for mental health care expenditure as a proportion of overall health expenditure, to be realised over a five year period. This would be an important recognition of the effect of mental health problems within our society. In case people think of this target as ambitious, attaining it would still leave this country 3 percentage points behind the current UK figure of 13 percent. While international expenditure comparisons are difficult and sometimes misleading due to different accounting procedures, there is considerable scope to increase overall expenditure on mental health care in Ireland to bring it in to line with similarly developed countries.

Our work shows that citizens do value spending on mental health care. The contingent valuation study showed people are willing to make significant tax contributions to new community-based services for people with mental health problems, counteracting the view sometimes expressed that people do not care at all about mental health care. However, the same study shows that people tend to value spending on cancer and ageing programmes more than they do mental health care. This finding holds whether people have had experience of mental health problems or not. These results are not all that surprising since mental health care is not a topic that commands great attention from the public either in Ireland or elsewhere.

One of the problems is that many people have little knowledge about mental health problems, which leads to negative attitudes forming which affect judgements on resource allocation and prioritisation, especially when people are asked to compare mental health problems against more recognisable and socially acceptable illnesses and conditions such as cancer. Thornicroft (2006) notes that there is no country, society or culture in which people with mental health problems are valued the same as people without mental health problems. This leads to people underestimating their own or their families' use of mental health care services and undervaluing 
interventions designed to improve care and conditions for people with mental health problems. Our results show this is likely to be the case in Ireland.

Increasing expenditure on mental health care is a necessary but not sufficient condition for realising the potential of people with mental health problems. Expenditure needs to be increased but money needs to be spent wisely. Historically, mental health care budgets in this country have been determined incrementally on the basis of historical precedent and political judgement rather than on the basis of an objective measure of population health needs. That is still the case, although efforts are currently being made to link expenditure to socio-economic indicators. This process needs to be accelerated and formulae found to link expenditure to indicators of population need. Information is the key to a more efficient and equitable allocation of resources. A community-based analysis of need, linked to local and national prevalence studies should be the first step in setting up new resource allocation structures. A national morbidity survey every five years is necessary to determine the prevalence of mental health problems in the population. We must also generate comprehensive, annual information on existing services by catchment area, including information on unit costs. This would tell us where the gaps are, thereby ensuring greater degrees of equity in the allocation of resources. We already have much of the population-based data on demography and deprivation could be used to supplement the information on prevalence. Performance indicators should be used to ensure compatibility between need and service delivery, once such information becomes available.

Unfortunately, we have been slow in utilising the information on need that is available and slower still in initiating new sources that might provide better data, particularly at population and community levels. Any new allocation process must also be accompanied by a system of rewards and penalties to ensure that agencies spend any additional resources on the intended recipients and target areas. There is some anecdotal evidence that existing monies allocated to mental health are not always spent on mental health. Without incentive mechanisms and penalty clauses, there is no guarantee that any increased funding will be spent wisely and on intended recipients.

There has been a major shift in mental health care expenditure in Ireland towards communitybased care. The evidence that community-based services are more likely to be effective in promoting quality of life among people with mental health problems, and not necessarily at greater cost, has mainly come from studies done in other countries. This is not necessarily a bad thing, since being able to learn from the published evaluation literature from other countries 
is one of the advantages of being latecomers to rational resource allocation decision-making. Unfortunately, there remains a relative paucity of completed health economic evaluations from both developed and developing countries, so the learning base is relatively shallow (WHO, 2006).

It is now accepted generally that resource allocation in mental health care is not simply a dichotomous choice between institution and community. Instead, a balanced care approach is required, where frontline services are based in the community but hospitals and other related care settings play important roles as specialist providers. Addressing questions of efficiency in relation to balance of care in Ireland will require specific domestic research funding to support the development of an evaluative framework for the analysis of mental health care spending in the country. This could be done through the Health Research Board and the Mental Health Commission. One of the difficulties is that, even with increased research funding, a shortage of researchers on mental health care may undermine progress in the field. There simple isn't enough interest in mental health research at the moment within the universities in Ireland, particularly in relation to the economics of mental health.

Nowhere is disadvantage and discrimination for people with mental health problems more obvious than in relation to paid and unpaid work. The impact of mental health problems on people's ability to work has been well documented. Those with long-standing mental health problems are far less likely to be employed than the general working age population. There is a significant gap between the willingness of people with mental health problems to work and their ability to find work or sustain a working life. Evidence collected by the MHEEN group confirms a trend of increasing absenteeism and early retirement due to mental health problems (particularly from depression) across Europe for both men and women. Work has a therapeutic impact as well as an outcome effect; people value work for its creative potential as well as for its earnings potential. In that respect, people with mental health problems are no different to people without mental health problems in seeing work as necessary for the attainment of income, social status and integration. Thus, work does not always have to be market-based to be valued, but it has to be meaningful.

There is a good deal of evidence, some of which was outlined in Chapter 4, about what works in relation to employment policies for people with mental health problems. Cenerally, studies have shown that the place and train model is more effective than pre-work training in helping people find competitive employment. Moreover, placing individuals in open employment and providing them with ongoing support is more cost-effective than vocational rehabilitation approaches. But even where proven interventions are available, there are many barriers that 
prevent people with mental health problems from taking up work. These barriers include: stigma and discrimination, poorly structured social welfare systems, low expectations, fear of failure, lack of life skills and employers' lack of knowledge in dealing with mental health problems. These barriers are real, suggesting that concerted, person-centred, actions are required to address work-related issues for people with mental health problems. The Helsinki Declaration is an important symbol of the importance of workplace mental health issues but practical interventions need to follow. In Ireland, such interventions should concentrate on getting more people with mental health problems into the labour force and ensuring they stay there through dedicated, firm-specific mental health well-being programmes that cover all workers and employers.

There is a strong relationship between poor mental health and social deprivation, with the causal relationship working in both directions. People who live in areas of high deprivation are at an increased risk of developing mental health problems. Mental health problems may also deny people ordinary opportunities, including work, education and social networks. Poverty and social deprivation exacerbate the prejudice and discrimination experienced by people with mental health problems leading to life-time cumulative cycles of disadvantage. While it is true that people with mental health problems are drawn from every section of society, and stigma and exclusion affect people in all social groups, being poor is both a cause and consequence of mental health difficulties. Policy interventions that address the causes and consequences of poverty are likely to impact positively on mental health problems within economically disadvantaged communities and are a pre-requisite for any new investment programme in mental health in the country.

It is difficult to change negative public attitudes to mental health problems in the short term, particularly if these attitudes are linked to the public stigmatisation of people with such problems. Public stigma comprises three components: stereotype, prejudice and discrimination which, on their own and in combination, have the potential to blight the lives of people with mental health problems and their families. Stigma increases personal suffering, social exclusion and can impede access to housing and employment. Employers may not want to hire people with a history of mental health problems, while the fear of stigma may encourage mental health professionals to dissuade individuals from seeking work for fear that this will be ultimately be unsuccessful. Stigma may also help to partly explain the reluctance within society at government and policy levels to invest significantly in mental health. Public campaigns to address stigmatisation and its consequences should be a priority at national and local level. We have had national campaigns to address poverty, legislation to deal with disability and 
campaigns to highlight age discrimination. We now need a similar campaign to address the stigmatisation of people with mental health problems and promote their social inclusion within society. Negative public attitudes to mental health problems can be addressed through education, training and public information campaigns.

This report makes a strong argument for greater investment in mental health in Ireland. In particular, the report uses economic analysis and evidence to make the case for greater spending on mental health care. For the first time, we have an estimate of the overall cost of mental health problems for the Irish economy, which at 2 per cent of GNP should leave no one in any doubt about the national significance of the overall economic burden. Reducing the burden will require additional resources to raise mental health care spending as a proportion of overall health care expenditure from the current level of 6 per cent to 10 per cent over a five year period. This report has shown that there is public support for additional communitybased spending on mental health care in Ireland. Investment in innovative interventions is now required, with new programmes assessed for their cost effectiveness. We will need to develop the research capacity to undertake economic evaluation of mental health care programmes in Ireland, but that we must do to ensure that both costs and outcomes are part of the assessment of new programmes. New programmes to help people with mental health problems return to work and remain in work are also merited. Such interventions can be justified on both efficiency and equity grounds. All of the economic evidence suggests that the individual and social returns from judicious investment in mental health in Ireland are likely to be high and sustained. 


\section{Bibliography}

Ament, A. and Evers, S. (1993). "Cost Of Illness Studies In Health Care: A Comparison Of Two Cases." Health Policy, 26: 29-42.

Amnesty International, (2003), Mental IIIness: The Neglected Quarter Summary Report, Amnesty International, Dublin.

Arrow, K., R. Solow, P. Portney, E. leamer, R. Radner \& H. Schuman, (1993). Report of the NOAA Panel of Contingent Valuation. Federal Register, 58, pp. 4601-4614. Washingdon DC.

Audini, B., Marks, I. \& Laurence, R.E. (1994). "Home-Based Versus Out-Patient/In-Patient Care For People With Serious Mental IIIness: Phase li Of A Controlled Trial." British Journal of Psychiatry, 165:204-210.

Bond, G.R., Resnick, S.C., Drake, R.E., Xie, H.Y., McHugo, G.J. \& Bebout, R.R. (2001). "Does Competitive Employment Improve Nonvocational Outcomes For People With Severe Mental Illness?" Journal of Consulting and Clinical Psychology, 69(3):489-501.

Browne, C., Daly, A. \& Walsh, D. (2000) Activities of Irish Psychiatric Services 1998 Dublin: Health Research Board.

Browne, C., Daly, A. \& Walsh, D. (1999) Activities of Irish Psychiatric Services 1997 Dublin: Health Research Board.

Burns, T., Knapp, M., Catty, J., Healey, A., Henderson, J., Watt, H. \& Wright, C. (2001) “Home Treatment For Mental Health Problems: A Systematic Review." Health Technology Assessment, 5 (15).

Byford, S., Fiander, M., Torgerson, D., Barber, J., Thompson, S., Burns, T., Van Horn, E., Gilvarry, C. \& Creed, F. (2000). "Cost-Effectiveness Of Intensive V. Standard Case Management For Severe Psychotic Illness: Uk70o Case Management Trial." British Journal of Psychiatry, 163:55-61.

Byford, S., Torgerson, D.J. and Raftery, J. (2000) "Cost Of Illness Studies." British Medical Journal, 320:1335. 
Central Statistics Office (2004) Census 2002 Report - Volume 10 - Disability and Carers. Dublin: Central Statistics Office.

Central Statistics Office, November, (2002) Quarterly National Household Survey Statistical Release, Disability in the Labour Force Second Quarter, 2002, Central Statistics Office, Dublin. Retrieved on the ${ }^{\text {st }}$ February 2006 from http://www.cso.ie/releasespublications/pr_healthsocarchivezooz.htm

Central Statistics Office. (2001) Household Budget Survey 1999-2000. Dublin: Central Statistics Office.

Chan, S., Mackenzie, A. \& Jacobs, P. (2000). "Cost-Effectiveness Analysis of Case Management versus a Routine Community Care Organisation for Patients with Chronic Schizophrenia." Archives of Psychiatric Nursing, 14(2):98-104.

Chilvers, R. MacDonald, G. \& Hayes, A. (2003). "Supported Housing For People With Severe Mental Disorders". Cochrane Database of Systematic Reviews, Issue 1.

Citron, M. Soloman, P. \& Draine, J. (1999). "Self-Help Groups for Families of Persons with Mental Illness: Perceived Benefits of Helpfulness." Community Mental Health Journal, 35:15-30.

Clark, P.B. \& Wilson, J.Q. (1961) "Incentive Systems: A Theory Of Organisations." Administrative Science Quarterly, 7:129-166.

Clark, R.E., Dain, B.J., Xie, H., Becker, D.R. \& Drake, R.E. (1998a). “The Economic Benefits of Supported Employment for Persons with Mental Illness." The Journal of Mental Health Policy and Economics, 1:6371.

Clark, R.E., Xie, H., Becker, D.R. \& Drake, R.E. (1998b). "Benefits and Costs of Supported Employment from Three Perspectives." Journal of Behavioural Health Services and Research, 25(1):22-35.

Commission on the Status of People with Disabilities, c.1997, A Strategy for Equality: Summary of the Report of the Commission on the Status of People with Disabilities

Compty, M. and Whitford, D.L., (2005) "Mental Health In Ceneral Practice: Assessment Of Current State And Future Needs." Irish Journal of Psychological Medicine, 22(3): 83-86. 
Crowther, R., Marshall, M., Bond, G. \& Huxley, P. (2001) "Vocational Rehabilitation For People With Severe Mental IIIness." The Cochrane Database of Systematic Reviews, Issue 2.

Currie, G., Dymond Kerfoot, K., Donaldson, C. and Macarthur, C. (2000). "Are Cost Of Injury Studies Useful?" Injury Prevention, 6:175-176.

Daly, A. \& Walsh, D. (2004) Mental Illness in Ireland 1750-2002, Reflections on the Rise and Fall of Institutional Care) Dublin: Health Research Board.

Daly, A and Walsh D., 2003, Activities of Irish Psychiatric Services 2002, Mental Health Research Division, Health Research Board, December 2003

Daly, A. \& Walsh, D. (2003) Activities of Irish Psychiatric Services 2001. (pdf) Dublin: Health Research Board.

Daly, A. \& Walsh, D. (2002) Irish Psychiatric Hospitals and Units Census 2001. (pdf) Dublin: Health Research Board.

Daly, A. \& Walsh, D. (2001) Activities of Irish Psychiatric Services 2000. (pdf) Dublin: Health Research Board.

Daly, A. \& Walsh, D. (2000) Activities of Irish Psychiatric Services 1999. (pdf) Dublin: Health Research Board.

Daly, A., Walsh, D, Comish, J, O'Doherty, YK., Moran, R \& O'Reilly, A. (2005). Activities of Irish Psychiatric Units and Hospitals 2004. Dublin: Health Research Board.

Daly, A., Walsh, D., Moran, R. \& Kartalova O'Doherty, Y. (2004) Activities of Irish Psychiatric Services 2003 [Revision B]. (pdf) Dublin: Health Research Board.

Davies, L. and Drummond, M. (1994). "Economics and Schizophrenia: The Real Cost." British Journal of Psychiatry, 165 (suppl.25), 18-21.

Deady, J., Long, J. and O'Dowd, T. (2003) People Living In Finglas And Their Health. Northern Area Health Board and Department of Community Health and Ceneral Practice, TCD. 
Deloitte and Touche, (in conjunction with the York Health Economics Consortium) 2001, Value For Money Audit Of The Irish Health System, Vol. II: Main Report

Department of Health and Children (2006). A Vision for Change. Report of the Expert Group on Mental Health Policy. Dublin: The Stationary Office.

Department of Health and Children (2003) Health Statistics 2002. Dublin: The Stationary Office.

Department of Health and Children. (2001) Quality and Fairness: A Health System for You. Dublin: The Stationary Office.

Department of Health and Children (1993) Health Statistics 1993. Dublin: The Stationary Office.

Dept. of Health and Children, Planning for the Future, Report Of A Study Group On The Development Of Psychiatric Services, 1984, Dept. of Health and Children, Dublin. Dublin

Diener, A., B. O'Brien \& A. Gaffni, (1998). Health Care Contingent Valuation Studies: A Review And Classification Of The Literature. Health Economics, 7 (4), pp. 313-326.

Dixon, L., Hoch, J.S., Clark, R., Bebout, R., Drake, R., McHugo, G. \& Becker, D. (2002). "Cost-Effectiveness of Two Vocational Rehabilitation Programmes for Persons with Severe Mental Illness." Psychiatric Services, 53(9):1118-1124.

Drummond, M.F., O'Brien, B., Stoddart, G.L. \& Torrance, G.W. (1997). Methods for the Economic Evaluation of Health Care Programmes (2 ${ }^{\text {nd }}$ ed.). Oxford: Oxford University Press.

Drummond, M. (1992). "Cost-of-Illness Studies. A Major Headache?" PharmacoEconomics, 2(1): 1-4.

European Commission (2005) Green Paper "Improving The Mental Health Of The Population: Towards A Strategy On Mental Health For The European Union."

Expert Group on Mental Heath Policy (2006). "A Vision for Change”. Dublin: The Stationary Office.

Fenton, W.S., Hoch, J.S., Herrell, J.M., Mosher, L. \& Dixon, L. (2002). "Cost and Cost-Effectiveness of Hospital vs Residential Crisis Care For Patients Who Have Serious Mental Illness." Archives of General Psychiatry, 59:357-364. 
Calster, G.C., Champney, T.F., \& Williams, Y. (1994). "Costs Of Caring For Persons With Long-Term Mental Illness In Alternative Residential Settings".

Ceneral Medical Services (Payments) Board. (2003). Report for the Year Ended 37st December 2002. Dublin: Ceneral Medical Services (Payments) Board

Corey, K.M., Leslie, D.R., Morris, T., Carruthers, W.V., John, L. \& Chacko, J. (1998). "Effectiveness Of Case Management With Severely And Persistently Mentally III People." Community Mental Health Journal, $34(3): 241-250$.

Greenberg, P.E., Sisitsky, T., Kessler, R.C., Finkelstein, S.N., Berndt, E.R., Davidson, J.R.T., Ballenger, J.C. and Fyer, A.J. (1999), "The Economic Burden of Anxiety Disorders in the 1990s" Journal of Clinical Psychiatry, 60:7.

Hanemann, W.M., (1994). "Valuing the Environment Through Contingent Valuation." Journal of Economic Perspectives, Vol. 8, No. 4, pp. 19-43.

Harvey, K., Burns, T., Fahy, T., Manley, C. \& Tattan, T. (2001). "Relatives Of Patients With Severe Psychotic Illness: Factors That Influence Appraisal Of Caregiving And Psychological Distress." Social Psychiatry and Psychiatric Epidemiology, 36:456-467.

Health Service Executive, National Suicide Review Group and the Department of Health and Children. (2005) Reach Out. National Strategy for Action on Suicide Prevention. Dublin: Health Service Executive.

Hirst, M. (2005). "Carer Distress: A Prospective, Population-Based Study." Social Science and Medicine, 61: $697-708$.

Hoffman, C. and Graf von der Schulenburg, J-M. (2000). "The Influence Of Economic Evaluation Studies On Decision Making A European Survey." Health Policy, 52:179-192.

Hu, T. W. (2004). "An International Review of the Economic Costs of Mental Illness." Disease Control Priorities Project Working Paper No. 31.

Irish Prison Service. (2002) Annual Report 2002. Dublin: The Stationary Office. 
Ivanov, I (2005). "Mental Health And Working Life". WHO Ministerial Conference on Mental Health Briefing paper. Copenhagen: World Health Organisation, Regional Office for Europe.

Jenkins, R., McCulloch, A., Friedli, L. and Parker, C. (2003) Developing A National Mental Health Policy. Maudsley Monographs number forty three. Psychology Press, London.

Johnston, S., Salkeld, G., Sanderson, K., Issakidis, C., Teesson, M., \& Buhrich, N. (1998) "Intensive Case Management: A Cost-Effectiveness Analysis." Australian and New Zealand Journal of Psychiatry, 32: 551559 .

Jones-Lee, M.W., (1989). The Economics of Safety and Physical Risk. Oxford: Basil Blackwell.

Joy, CB., Adams, CE. \& Rice, K. (2004).“'Crisis Intervention For People With Severe Mental Illness." The Cochrane Database of Systematic Reviews, Issue 4.

Kelly, B.D. (2004). "Mental Health Policy In Ireland 1984-2004: Theory, Overview And Future Directions." Irish Journal of Psychological Medicine; 21 (2):61-68.

Keogh, F. \& Walsh, D. (1997) Activities of Irish Psychiatric Services 1996 Dublin: Health Research Board.

Keogh, F. \& Walsh, D. (1996) Activities of Irish Psychiatric Services 1995 Dublin: Health Research Board.

Keogh, F. \& Walsh, D. (1995) Activities of Irish Psychiatric Hospitals and Units 1994 Dublin: Health Research Board.

Keogh, F. \& Walsh, D. (1995). "The Cost of Depression in Ireland." Irish Journal of Psychiatry, Spring and Autumn:10-16.

Keogh, F. \& Walsh, D. (1994) Activities of Irish Psychiatric Hospitals and Units 1993 Dublin: Health Research Board

Kessler, R. C., McGonagle, K.A., Zhao, S., Nelson, C., Hughes, B., Eshleman, S., et al (1994). "Lifetime and 12 month prevalence of DSM-III-R psychiatric disorders in the United States: Results from the National Comorbidity Survey". Archives of Geberal Psychiatry 51:8-19. 
Kind, P. and Sorenson, J. (1993) The Costs of Depression." International Clinical Psychopharmacology, 7:191-195.

Knapp, M., McDaid, D., Mossialos, E., Thornicroft, G. (2006). Mental Health Policy and practice across Europe. London: Open University Press

Knapp, M., Barrett, B., Romeo, R., McCrone, P., Byford, S., Beecham, J., Patel, A \& Simon, J. (2004). “An International Review of Cost-Effectiveness Studies for Mental Disorders". Disease Control Priorities Project Working Paper No. 36. London: Centre for the Economics of Mental Health.

Knapp, M., Chisholm, D., Astin, J., Lelliott, P. \& Audini, B. (1997). “The Cost Consequences Of Changing The Hospital-Community Balance: The Mental Health Residential Care Study." Psychological Medicine, 27:681-692

Knapp, M., Beecham, J., Koutsogeorgopoulou, V., Hallam, A., Fenyo, A., Marks, I.M., Connolly, J. Audini, B., \& Muijen, M. (1994). "Service Use And Costs Of Home-Based Versus Hospital-Based Care For People With Serious Mental Illness." British Journal of Psychiatry, 165: 195-203.

Latimer, E.A. (2001). "Economic Impacts of Supported Employment for Persons with Severe Mental IIness." Canadian Journal of Psychiatry, 46:496-505.

Latimer, E.A. (1999). "Economic Impacts Of Assertive Community Treatment: A Review Of The Literature." Canadian Journal of Psychiatry, 44:443-454

Lavaikainen, J., Lahtinen, E., and Lehtinen, V. (2001) Public Health Approach on Mental Health in Europe. Helsinki: National Research and Development Centre for Welfare and Health, STAKES. Ministry of Social Affairs and Health.

Layard, R. (2004). "Mental Health: Britain's Biggest Social Problem". Paper presented at the No. 10 Strategy Unit Seminar on Mental Health on January $20^{\text {th }}, 2005$

Lazarus, RS. \& Folkman, S. (1984). Stress, Appraisal and Coping. New York: Springer.

Leff, J. (1997). Care In The Community: Illusion Or Reality? London: Wiley. 
Lehman, A.F., Goldberg, R., Dixon, L.B., McNary, S., Postrado, L., Hackman, A., McDonnell, K. (2002). "Improving Employment Outcomes for Persons with Severe Mental Illness." Archives of General Psychiatry, 59:165-172.

Linehan, S.A., Duffy, D.M., Wright, B., Curtin, K., Monks, S. and Kennedy, H. G. (2005) "Psychiatric Morbidity In A Cross-Sectional Sample Of Male Remanded Prisoners." Irish Journal of Psychological Medicine, 22(4):128-132.

Long, J, O'Loughlin, R., O'Keefe, F. and O'Dowd, T. (2002) People Living In Tallaght And Their Health. The Adelaide Hospital Society and the Department of Community Health and Ceneral Practice, TCD.

Lowyck, B., De Hert, M., Peeters, E., Wampers, M., Gilis, P. \& Peuskens, J. (2004). "A Study Of The Family Burden Of 150 Family Members Of Schizophrenic Patients". European Psychiatry (19): 395-401.

Magliano, L., Fiorillo, A. De Rosa, C., Malangone, C. \& Maj, M. (2005). “Family Burden In Long-Term Diseases: A Comparative Study In Schizophrenia Vs. Physical Disorders". Social Science and Medicine, 61:313-322.

Marks, l., Connolly, J. \& Muijen, M. (1994). "Home Versus Hospital-Based Care For People With Serious Mental IIIness." British Journal of Psychiatry, 165:179-194.

Marshall, M., Gray, A., Green, R. (1998) "Case Management For People With Severe Mental Disorders.” Cochrane Database of Systematic Reviews, Issue 2.

Marshall, M. \& Lockwood, A. (2003). "Assertive Community Treatment For People With Severe Mental Disorders." Cochrane Review. The Cochrane Library, Issue 1.

Marshall, M. \& Lockwood, A. (1998). "Assertive Community Treatment For People With Severe Mental Disorders." The Cochrane Database of Systematic Reviews, Issue 2.

Marshall, M., Crowther, R., Almaraz-Serrano, A., Creed, F., Sledge, W., Kluiter, H., Roberts, C., Hill, E., Wiersma, D., Bond, CR., Huxley, P. \& Tyrer, P. (2001). "Systematic Reviews Of The Effectiveness Of Day Care For People With Severe Mental Disorders; (1) Acute day hospital versus admission; (2) Vocational rehabilitation; (3) Day hospital versus outpatient care." Health Technology Assessment, 5(21). 
Marshall, M., Crowther, R., Almaraz-Serrano, A., Creed, F., Sledge, W., Kluiter, H., Roberts, C., Hill, E. \& Wiersma, D. (2003) "Day Hospital Versus Admission For Acute Psychiatric Disorders." The Cochrane Database of Systematic Reviews, Issue 1.

Matschinger, H., Angermeyer, MC. (2004) “The Public's Preferences Concerning The Allocation Of Financial Resources To Health Care: Results From A Representative Population Survey In Germany”. Eur Psychiatry 19:478-482

McDaid, D. \& Thornicroft, G. (2005). "Balancing Institutional And Community-Based Care", European Observatory on Health Systems and Policies.

Downloaded from http://www.observatory.dk.

McNamee, P., Bond, J. and Buck, D. (2001) "Costs Of Dementia In England And Wales In The 21 ${ }^{\text {st }}$ Century." British Journal of Psychiatry, 179:261-266.

Mental Health Commission: Annual Report 2004. Dublin: Mental Health Commission.

Mental Health Commission: Annual Report 2002. Dublin: Mental Health Commission.

Mittelman, M. (2005). "Taking Care Of The Caregivers." Current Opinion in Psychiatry, 18:633-639.

Moller-Leimkuhler, A M. (2005) "Burden Of Relatives And Predictors Of Burden. Baseline Results From The Munich 5-Year-Follow-Up Study On Relatives Of First Hospitalized Patients With Schizophrenia Or Depression." European Archives of Psychiatry and Clinical Neuroscience, 255:223-231.

Moller-Leimkuhler, A M. (2006) “Multivariate Prediction Of Relatives' Stress Outcome One Year After First Hospitalization Of Schizophrenic And Depressed Patients." European Archives of Psychiatry and Clinical Neuroscience, 256:122-130.

Moran, R. \& Walsh, D. (1994) Activities of Irish Psychiatric Hospitals and Units 1992 Dublin: Health Research Board

Moran, R. \& Walsh, D. (1993) Activities of Irish Psychiatric Hospitals and Units 1991 Dublin: Health Research Board. 
Moran, R. \& Walsh, D (1993) Activities of Irish Psychiatric Hospitals and Units 1990 Dublin: Health Research Board.

Muijen, M., Marks, I.M., Connolly, J., Audini, \& McNamee, G. (1992). "The Daily Living Programme. Preliminary Comparison of Community Versus Hospital-Based Treatment for the Seriously Mentally III Facing Emergency Admission." British Journal of Psychiatry, 160:379-384.

National Collaborating Centre for Mental Health (2002). "Schizophrenia: The Treatment And Management Of Schizophrenia In Primary And Secondary Care." National Clinical Practice Guideline-No i, National Institute for Clinical Excellence, London.

Norton, S., Wandersman, A. \& Goldman, C.R. (1993). "Perceived Costs and Benefits of Membership in a Self-Help Group: Comparisons of Members and Nonmembers of the Alliance for the Mentally III." Community Mental Health Journal, 29(2):143-160.

O'Keane, V., Walsh, D \& Barry, S. (2005). “The Black Hole. The Funding Allocated To Adult Mental Health Services: Where Is It Actually Going?” Dublin: Irish Psychiatric Association.

O'Keane, V., Jeffers, A., Moloney, E. and Barry, S., March, 2003, "The Stark Facts". The Need For A National Mental Health Strategy As Well As Resources. Irish Psychiatric Association, Greystones.

O'Keefe, F, Long, J. and O'Dowd, T. (2002) People Living In The Dublin Docklands And Their Health. The Royal City of Dublin Hospital Trust and the Department of Community Health and General Practice, TCD.

Olsen, J. A., and C. Donaldson, (1998)."Helicopters, Hearts, and Hips: Using Willingness-to-pay to Set Priorities for Public Sector Health Care Programmes," Social Science and Medicine, Vol.46, No.1, pp 1-12.

O’Neill, C., Sinclair, H., Kelly, A \& Kennedy, H. (2002). "Interaction Of Forensic And General Psychiatric Services In Ireland: Learning The Lessons Or Repeating The Mistakes?" Irish Journal of Psychological Medicine; $19(2)$ : 48-54.

O'Shea, E et al (2001). Eliciting Preferences For Resource Allocation In Health Care. The Economic and Social Review, 32, 3, pp 217-238, 2001. 
O'Shea, E. (2000). The Costs of Caring for People with Dementia and Related Cognitive Impairments. Dublin: National Council on Ageing and Older People.

O'Shea, E., Hughes, J., Fitzpatrick, L., Dunne, E., O'Sullivan, M. and Cole, M. (1998). "An Economic Evaluation Of Inpatient Treatment Versus Day Hospital Care For Psychiatric Patients." Irish Journal of Psychological Medicine, 15 (4):127-130.

Östman, M. \& Hansson, L. (2004). "Appraisal Of Caregiving, Burden And Psychological Distress In Relatives Of Psychiatric Inpatients." European Psychiatry, 19:402-407.

Patel, A. and Knapp, M. (1998). "Costs Of Mental IIIness In England." Mental Health Research Review, 5 : 4-10.

Perlick, DA., Hohenstein, JM., Clarkin, JF., Kaczynski, R. \& Rosenheck, RA. (2005). "Use Of Mental Health And Primary Care Services By Caregivers Of Patients With Bipolar Disorder: A Preliminary Study." Bipolar Disorders, 7:126-135.

Portney, P.R., (1994). "The Contingent Valuation Debate: Why Economists Should Care." Journal of Economic Perspectives, Vol. 8, No. 4, pp. 3-17.

Rankin, J (2005). "Mental Health and Social Exclusion: Mental Health in the Mainstream". Institute for Public Policy Research

Repper, J. \& Brooker, C. (1998). "Difficulties In The Measurement Of Outcome In People Who Have Serious Mental Health Problems." Journal of Advanced Nursing, 27:75-82.

Rice, D.P. and Miller, L.S. (1998). "Health Economics And Cost Implication Of Anxiety And Other Mental Disorders In The United States." British Journal of Psychiatry, 173 (suppl. 34):4-9.

Rice D.P. and Miller, L.S. (1993) "The Economic Burden of Affective Disorders." Advances in Health Economics and Health Services Research, 14:37-53.

Roberts, E., Cumming, J. \& Nelson, K. (2005). "A Review of Economic Evaluations of Community Mental Health Care." Medical Care Research and Review, 62(5):503-543. 
Schizophrenia Ireland, (2003), Investing in Recovery. Pre-Budget 2004 Submission, Schizophrenia Ireland, Dublin

Schneider, J. (2003) "Is Supported Employment Cost Effective? A Review" The International Journal of Psychosocial Rehabilitation, 7:145-156.

Sheperd, G. \& Murray, A. (2001) "Residential care." In: Thornicroft, G. \& Szmukler, G. (eds.) Textbook of community psychiatry. Oxford: Oxford University Press.

Shiell, A. Gerard, K. and Donaldson, C. (1987). "Cost of illness studies: an aid to decision-making?" Health Policy, 8:317-23.

Simon Community information retrieved on the $7^{\text {st }}$ February 2005 from http://www.simoncommunity.com

Sledge, WH et al. (1996) "Day Hospital/Crisis Respite Care Versus Inpatient Care, Part I: Clinical Outcomes." American Journal of Psychiatry, 153:1065-1073.

Social Exclusion Unit (2004a) "Mental Health and Social Exclusion”: Office of the Deputy Prime Minister Social Exclusion Unit (2004b) "Breaking The Cycle": Office of the Deputy Prime Minister Stanley, K. \& Maxwell, D. (2004) "Fit for Purpose?" Institute for Public Policy Research Stewart, J.M., E. O'Shea, C. Donaldson \& P. Shackley, 2002. Do Ordering Effects Matter In Willingness-ToPay Studies Of Health Care? Journal of Health Economics, 784, pp. 1-15.

Stoudemire, A., Frank, R., Hedemark, N., Kamlet, M. and Blazer, D. (1986). "The Economic Burden of Depression." General Hospital Psychiatry, 8:387-394.

Tansella, M. (1986) "Community Psychiatry Without Mental Hospitals - The Italian Experience: A Review." Journal of the Royal Society of Medicine, 79:664-669.

Tarricone, R., Gerzeli, S., Montanelli, R., Frattura, L., Percudani, M and Racagni, G. (2000). "Direct And Indirect Costs Of Schizophrenia In Community Psychiatric Services In Italy. The Gisies Study." Health Policy, 51:1-18. 
The Northern Ireland Association for Mental Health in collaboration with The Sainsbury Centre for Mental Health. (date unknown) Counting the Cost. The Economic and Social Costs of Mental Illness in Northern Ireland. The Sainsbury Centre for Mental Health.

The Sainsbury Centre for Mental Health (2006). "What's It Worth?: The Social and Economic Costs of Mental Health Problems in Scotland." Scottish Association for Mental Health

The Sainsbury Centre for Mental Health (2003). "The Economic And Social Costs Of Mental Illness." The Sainsbury Centre for Mental Health Policy Paper 3.

Thornicroft, G (2006) "Tackling Discrimination". Mental Health Today

Thornicroft, G. \& Tansella, M. (2004). “Components Of A Modern Mental Health Service: A Pragmatic Balance Of Community And Hospital Care: Overview Of Systematic Evidence." British Journal of Psychiatry, 185:293-300

Thornicroft, G. \& Tansella, M. (2003). "What Are The Arguments For Community-Based Mental Health Care?" Health Evidence Network. Denmark: World Health Organisation Europe.

Thornicroft, G. \& Bebbington, P. (1989). “Deinstitutionalisation: From Hospital Closure To Service

Development." British Journal of Psychiatry, 155:739-753

Thornicroft, G., Wykes, T., Holloway, F., Johnson, S., \& Szmukler, G. (1988). "From Efficacy To Effectiveness In Community Mental Health Services." British Journal of Psychiatry, 173:423-427.

Tilson, L., McCowan, B, Ryan, M. and Barry, M. (2003). "Cost-Effectiveness Of Spironolactone In Patients With Severe Heart Failure." Irish Journal of Medical Science, 172 (2):70-72.

Trieman, N., Leff, J. \& Glover, G. (1999). "Outcome Of Long Stay Psychiatric Patients Resettled In The Community: Prospective Cohort Study." British Medical Journal, 319:13-16.

Twamley, E.W., Jeste, D.V. \& Lehman, A.F. (2003). "Vocational Rehabilitation in Schizophrenia and Other Psychotic Disorders." The Journal of Nervous and Mental Disease, 191(8): 515-523.

Tyrer, P et al (2003). "Community Mental Health Teams (Cmhts) For People With Severe Mental Illnesses And Disordered Personality." Cochrane Review. The Cochrane Library. 
Tyrer, P., Coid, J., Simmonds, S., Joseph, P. \& Marriott, S. (1998). "Community Mental Health Teams (CMHTs) For People With Severe Mental IIInesses And Disordered Personality." The Cochrane Database for Systematic Reviews, Issue 4.

Tyrer, P et al. (1995). "A Randomised Controlled Study Of Close Monitoring Of Vulnerable Psychiatric Patients." Lancet, 345:756-759.

UK700 Group. (2000) "Cost-Effectiveness Of Intensive V. Standard Case Management For Severe Psychotic Illness." British Journal of Psychiatry, 176:537-543.

Van den Berg, B., Brouwer, W., van Exel, J. \& Koopmanschap, M. (2005). "Economic Valuation Of Informal Care: The Contingent Valuation Method Applied To Informal Caregiving." Health Economics, 14:169-183.

Van der Berg, B., Brouwer, W.B. and Koopmanschap, M.A. (2004). "Economic Valuation Of Informal Care. An Overview Of Methods And Applications." European Journal of Health Economics, 5:36-45.

Van Wijngaaren, B., Schene, A.H. \& Koeter, W.J. (2004). "Family Caregiving In Depression: Impact On Caregivers' Daily Life, Distress And Help Seeking." Journal of Affective Disorders, 81:211-222.

Weisbrod, B.A., Test, M.A. \& Stein, L.I. (1980). "Alternative to Mental Hospital Treatment - Economic Benefit-Cost Analysis", Archives of Ceneral Psychiatry, 37:400-405.

Williams, J. and Corby, S. (2002). Counted In. The Report of the Assessment of Homelessness in Dublin, 2002. Dublin: The Homeless Agency.

Wolff, N., Perlick, D.A., Kaczynski, R., Calabrese, J., Nierenberg, A. \& Miklowitz, D.J. (2006). “Modeling Costs and Burden of Informal Caregiving for Persons with Bipolar Disorder." The Journal of Mental Health Policy and Economics, 9:99-110.

World Health Organisation, (2006). "Dollars, DALYs and Decisions: Economic Aspects of the Mental Health System"

World Health Organisation, (2003). HEN Report "What Are The Arguments For Community-Based Mental Health Care?"

World Health Organisation (2003) Investing In Mental Health. WHO Geneva. 
World Health Organisation (2001) The World Health Report 2001. Mental Health: New Understanding, New Hope. WHO, Geneva.

Wynne, R., \& MacAnaney, D. (2004) “Employment and Disability: Back To Work Strategies”. Dublin: European Foundation for Work and Living Conditions, 2004:128.

Ziguras, S.J., Stuart, G.W. \& Jackson, A.C. (2002). "Assessing The Evidence On Case Management." British Journal of Psychiatry, 181:17-21. 


\section{Appendix 1: Questionnaire}

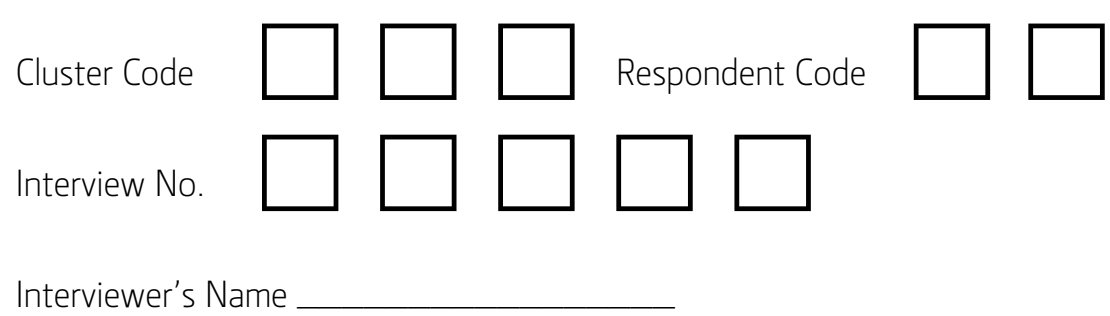

Date Time interview began (24 hour clock)

Hello, I'm from the Economic and Social Research Institute and I am collecting information on people's views on some health care programmes. I would like to carry out a survey with you, which will take about 30 minutes to complete. All the information collected will be treated in the strictest confidence and it will not be possible to identify individuals or their responses to it.

The purpose of this study is to establish the degree of importance people put on different kinds of health care programme. Such information is valuable when setting priorities in the health service.

We would like to know how much people would, hypothetically, be willing to pay for certain health care programmes. There is, of course, no question of anyone actually having to pay for these programmes. All we want to know is how people value the different programmes and the best way to do that is by asking them how much they would be willing to pay for them. For the purpose of this interview we are only concerned with three health care programmes. These are: cancer treatments, community care services for people with mental health problems and community care services for the elderly.

We would like you to think of these three programmes as if they were in competition with each other for funding. The maximum amount you would be willing to pay for a programme will be taken as a sign of how much you value that programme. If the amount you are willing to pay for one programme is greater than what you would pay for another, it will be taken to mean that you value more highly the programme you are willing to pay more for.

There are no right or wrong answers. The amount you are willing to pay could be large or small, or it could be nothing. It is your views and your opinions that we are interested in. 


\section{A. Risk Perceptions and Experience}

A.1 Have you or anyone in your close family ever had personal, first hand experience of:

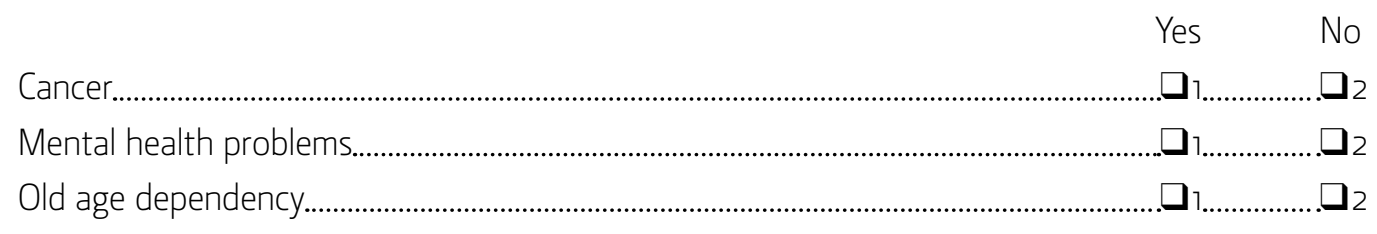

[Int: if asked what 'old age dependency' means say 'we are referring here to older adults in need of care or assistance with everyday activities'.]

A.2 How do you perceive your own risk of ever getting cancer? Is it:

$\begin{array}{cccc}\text { Much more } & \text { A little more } & \text { Average } & \text { A little less } \\ \text { than average } & \text { than average } & & \text { Much less } \\ \text { than average } & \text { thanerage }\end{array}$

$\begin{array}{lllll}a_{1} & a_{2} & a_{3} & a_{4} & \square_{5}\end{array}$

A.3 How do you perceive your own risk of ever needing home-based community mental health care services, such as community psychiatric nursing, sheltered accommodation, or day services? Is it:

\begin{tabular}{|c|c|c|c|}
\hline $\begin{array}{l}\text { Much more } \\
\text { than average }\end{array}$ & $\begin{array}{l}\text { A little more } \\
\text { than average }\end{array}$ & Average & $\begin{array}{l}\text { A little less } \\
\text { than average }\end{array}$ \\
\hline
\end{tabular}
$\square_{1}$
$\square_{2}$
$\square_{3}$
$\square_{4}$
$\square_{5}$

A.4 How do you perceive your own risk of ever needing home-based community elderly care services, such as public health nursing, home help, or day care services? Is it:

$\begin{array}{cccc}\text { Much more } & \text { A little more } & \text { Average } & \text { A little less } \\ \text { than average } & \text { than average } & & \text { Much less } \\ \text { than average } & \text { than average }\end{array}$

$\begin{array}{lllll}a_{1} & a_{2} & a_{3} & a_{4} & a_{5}\end{array}$ 


\section{B. Ranking of the Programmes}

I would now like to focus specifically on the three health programmes namely, the Cancer Programme, the Mental Health Programme and the Care Of The Elderly Programme. I would like to talk to you a little about how important you think each of these three programmes is. To begin with I would like you to first consider just the Cancer Programme and the Mental Health Programme.

Here is some information on the CANCER PROGRAMME.

Give the respondent the Card 7 (Cancer Programme) and read the card out to the respondent.

\section{Card 1: Cancer Programme}

- 200 more patients with advanced cancer could have relief from pain by radiotherapy

- This would be in addition to the 2,000 or so people who are currently getting this treatment.

- Without this treatment they would get pain-reducing medicine. However, with medicine, many patients will not have satisfactory pain relief, while others will get significant side effects in the form of tiredness and poor quality of life.

- Radiotherapy for these patients may have good pain relieving effects and lead to improved functioning and quality of life among most patients.

- The treatment will have few side effects.

- On average patients will benefit from this treatment in their last year of life. The treatment will not prolong patients' lives.

- There are patients in every age group and the average age is 60 years old. Men and women are affected in equal numbers. 
Here is some information on the MENTAL HEALTH PROGRAMME.

Give the respondent Card 2 (Mental Health Programme) and read the card out to the respondent.

\section{Card 2: Mental Health Program}

- 200 more people with mental health problems (such as depression and schizophrenia) would be able to be treated and supported in the community (some at home, some in sheltered accommodation) as a result of an expansion of community-based mental health services.

- This would help reduce the number of people in public psychiatric hospitals from the present level of approximately 3,500.

- The additional community mental health services would be in the areas of community psychiatric nursing, sheltered accommodation and day hospitals.

- The additional services would be targeted at people with severe mental health problems living in the community, either at home or in sheltered accommodation.

- The expansion of community-based facilities would improve the quality of life of people with mental health problems living independently in the community and reduce the likelihood of their admission or readmission to in-patient care.

- The people benefiting from this programme will be men and women of all ages, with an average of 45 years.

Take your time to digest all of the information.

B1. When you have decided which you think is the more important programme please tell me. You can rank the programmes first and second $(1,2)$ or you can rank them equally if you wish.

[Int: Rank the programmes 1 or 2 as appropriate or joint ' 7 ' if both are ranked equally]

Rank

Cancer Programme..

Mental Health Programme. 
Now here is some information on the CARE OF THE ELDERLY PROCRAMME.

Give the respondent Card 3 (Community Care program) and read the card out to the respondent.

\section{Card 3: Care of the Elderly Program}

- 200 more physically dependent older people would be able to remain in their own homes as a result of an expansion of community care services.

- This programme would reduce the number of people in long-stay care from the present level of approximately 20,000.

- The additional community services would be in the areas of public health nursing, home help, and day care facilities.

- The additional services would be targeted at very high dependent elderly people living at home.

- The expansion of community care facilities would improve the quality of life of dependent elderly people living at home, provide support for their carers, and reduce admissions or readmission to long-stay care for people currently on the margin between community care and residential care.

- The majority of people benefiting from this programme will be women aged 75 years and over.

RESPONDANT

Again, take your time to digest all of the information.

B. I I would like you to compare this programme with the other two in terms of their importance. When you have decided on your ranking for the three programmes please tell me. You can rank the three programmes, first, second, and third (' 1, ' ' 2 ,' ' 3 ') or you can rank some or all of them equally if you wish.

[Int: Rank the programmes ' '7', ' 2 ', or ' 3 ' as appropriate. If the respondent feels that 2 of the programmes are equally important in the first place, assign a rank of ' 7 ' to each of those and ' 3 ' to the remaining programme. If the respondent feels that 2 of the programmes are equally important in the second place, assign a rank of ' 2 ' to 2 of the programmes and ' 7 ' to the remaining programme. If all 3 programmes are felt to be equally important, rank each as ' 7 '] 
Cancer Programme.

Mental Health Programme.

Care of the Elderly Programme.

[Int: Take all cards back from the respondent and go to section D 'mental health programme' below]

\section{Willingness to Pay for an Expansion in Mental Health Programme}

Having ranked the programmes, I'm now going to ask you separately about how much you value each one. We will begin with the Mental Health Programme. As before I would like you to assume for the moment that the other two programmes are not available. The only thing I want you to consider now is the Mental Health Programme.

Give the respondent Card 2 and again read the card out to the respondent.

D.1 Would your household be willing to contribute anything in extra income tax for this expansion in community-based mental health services?

Yes No Don't Know No one in the household
pays income tax

[Int: if the respondent does not themselves pay tax but someone in the household does, tick box number 3 for Don't Know and go to the next question]

D.2 If the payment was in terms of a voluntary donation, would your household be willing to pay for this expansion in community-based mental health services?
Yes $\square$
No $\square_{2}$
Don't Know $\square_{3}$

[Int: If the respondent answered Yes to either D.1 or D.2 go to D.3a. If the respondent did not answer Yes to either D.1 or D.2 go to D.5] 
D. 3a How much is the MAXIMUM your household would be willing to contribute each year for this expansion in community-based mental health services? Please bear in mind that your contribution would reduce what you have left to spend on other things.

Show the respondent Card 4 again. Ask the respondent to select the maximum value he/she would be willing to pay and put a tick in the box for that amount.

\section{AMOUNT PER YEAR}

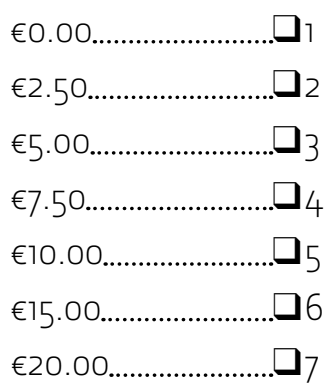

\begin{tabular}{|c|c|}
\hline $5.00 \ldots$ & 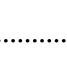 \\
\hline$€ 30.00 \ldots$ & ...... \\
\hline$€ 40.00$. & .... \\
\hline$€ 50.00$. & \\
\hline$\in 60.00$. . & \\
\hline$€ 80.00$. & \\
\hline & \\
\hline
\end{tabular}

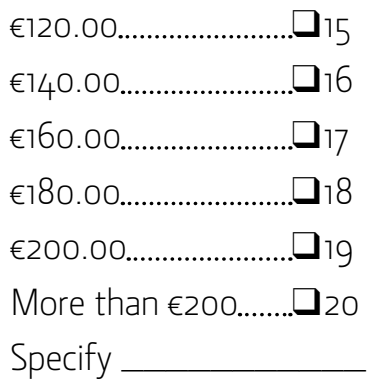

Fill in the maximum amount the respondent would be willing to pay for this expansion in this programme.

Maximum amount respondent willing to pay, $€$ Go to D.4

D.3b

[Int: Ask only if respondent is not able to give the maximum amount at D.3a above]

Look at Card 4 again and could you please tell me the amounts you are sure that you would pay and the amounts that you are sure you would not pay.

[Int: Show the respondent Card 4 again. ask them to tell you the amounts they are sure they would definitely be willing to pay and put a Tick in the boxes below for these amounts; and the amounts that they are sure they would not be willing to pay - put an X in the boxes below for these amounts] 
AMOUNT PER YEAR

\begin{tabular}{|c|c|c|}
\hline$€ 0.00 \ldots \ldots \ldots \ldots \ldots . . . .$. & $€ 25.00 \ldots \ldots \ldots \ldots \ldots \ldots \ldots . . .$. & $€ 120.00 \ldots \ldots$ \\
\hline$€ 2.50 \ldots \ldots \ldots \ldots \ldots . . . . . . . . .$. & $€ ३ 0.00 \ldots \ldots \ldots \ldots \ldots \ldots$ & $€ 140.00 \ldots \ldots \ldots$ \\
\hline$€ 5.00 \ldots \ldots \ldots \ldots \ldots \ldots$ & $€ 40.00 \ldots \ldots \ldots \ldots \ldots$ & $€ 160.00 \ldots \ldots \ldots \ldots . . .$. \\
\hline$€ 7.50 \ldots \ldots \ldots \ldots$ & 11 & $€ 180.00 \ldots \ldots \ldots \ldots \ldots$ \\
\hline$€ 10.00 \ldots \ldots \ldots \ldots \ldots \ldots$ & $€ 60.00 \ldots \ldots \ldots \ldots \ldots$ & $€ 200.00 \ldots \ldots \ldots \ldots \ldots \ldots . . . . . . . . . . .19$ \\
\hline$€ 15.00 \ldots \ldots \ldots \ldots \ldots . . . . . . . . . . . . . . .6$. & $€ 80.00 \ldots \ldots \ldots \ldots \ldots \ldots \ldots$ & More than $€ 200 \ldots \ldots . . ..]_{20}$ \\
\hline$€ 20.00 \ldots$. & $€ 100.00 \ldots$ & Specify_ \\
\hline
\end{tabular}

Fill in (the highest amount the respondent is sure they would pay) and (the lowest amount they are sure they would not pay), below.

Highest amount respondent is sure they would pay, $€$ [Highest $\boldsymbol{\sim}$ Box] Lowest amount respondent is sure they would not pay, $€$ [Lowest $\mathbf{X}$ Box]

If you had to give one value in this range, what would it be? [Record this value below].

If the respondent cannot give a value, ask them if a value in the middle of the range would be $O K$, if it is, record this value below.

[Int: the goal is to get the range where respondent can't pick exact value]

Value from the range or middle value, $€$ [Int. If zero value go to D.5]

D.4 Could you please explain the reasons why your household would be willing to contribute to this expansion?

[Int: Show the respondent Card 5 and read out all of the reasons. Tick the appropriate box(es) in Column A. If the respondent gives more than one reason in Column A, ask them which one they would regard as the most important reason and tick that box in Column B] 
Column A

Important

reasons
Column B

Most

important

reason

I, or a member of my household, might benefit

]1.

. 1

A member of my family or a friend has used the service.

a2.

$a_{2}$

Other people will benefit

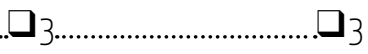

The programme will improve health .

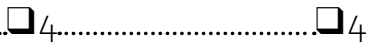

Promote more equal access to care

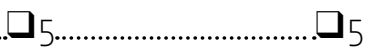

Reassuring to know care is accessible.

06.

.06

I would support technical progress in medicine

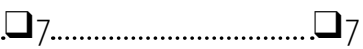

Other (Please specify)

- 8 .

[Int:Take all cards back from the respondent and go to Section E 'Care of the Elderly' below]

[Int: only ask D5 if household not willing to pay for the expansion of the service].

D. 5 Could you please tell me which one of the listed reasons best explains why you would not be willing to pay for the expansion of this service?

[Int: Show Card 6 and tick one box (the main reason)]

This programme is of no value to my household.

Other programmes are more valuable...................................................................................................

Other public sector budgets should be cut.......................................................................................

Other groups in society should pay..........................................................................................................

The users should pay...........................................................................................................................................

Health service should be more efficient........................................................................................

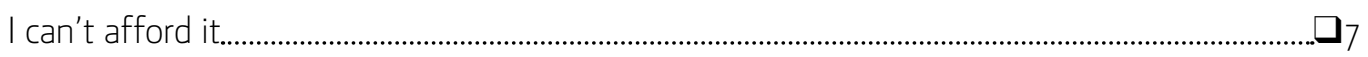

Prefer other ways of paying (private/voluntary insurance, etc.).........................................................

Other (Please specify)__

[Int: Take all cards back from the respondent and go to SECTION E 'CARE OF THE ELDERLY' below] 


\section{E. Willingness to Pay for an Expansion in Care of the Elderly Programme}

I would now like to repeat this valuation exercise with the Care of the Elderly Programme. As before I would like you to assume for the moment that the other two programmes are not available. The only thing I want you to consider now is the Care of the Elderly Programme.

Give the respondent Card 3 (Care of the Elderly Programme) and again read the card out to the respondent.

E.1 Would your household be willing to contribute anything in extra income tax for this expansion in community care services for dependent elderly people?

\begin{tabular}{|c|c|c|c|}
\hline Yes & No & Don't Know & $\begin{array}{l}\text { No one in the household } \\
\text { pays income tax }\end{array}$ \\
\hline & $\square_{2}$ & $\square_{3}$ & $\square_{4}$ \\
\hline
\end{tabular}

[Int: if the respondent does not themselves pay tax but someone in the household does, tick box number 3 for Don't Know and go to the next question]

E. 2 If the payment was in terms of a voluntary donation, would your household be willing to pay for this expansion in community care services for dependent elderly people?

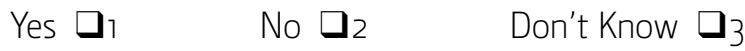

[Int: If the respondent answered Yes to either E.1 or E.2 go to E.3a. If the respondent did not answer Yes to either E.1 or E.2 go to E.5]

E.za How much is the MAXIMUM your household would be willing to contribute each year for this expansion in community care services for dependent elderly people? Please bear in mind that your contribution would reduce what you have left to spend on other things.

Show the respondent Card 4. Ask the respondent to select the MAXIMUM value he/she would be willing to pay and put a tick in the box for that amount in the table below. 
AMOUNT PER YEAR

\begin{tabular}{|c|c|c|}
\hline$€ 0.00 \ldots \ldots \ldots \ldots \ldots . . . .$. & $€ 25.00 \ldots \ldots \ldots \ldots \ldots$ & $€ 120.00 \ldots . .$. \\
\hline$€ 2.50 \ldots \ldots \ldots \ldots \ldots \ldots \ldots . . . \cdot \square_{2}$ & 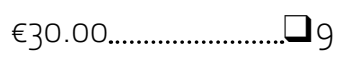 & $€ 140.00 \ldots \ldots \ldots$. \\
\hline 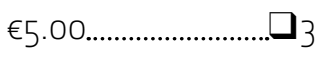 & $€ 40.00 \ldots \ldots \ldots \ldots \ldots$ & $€ 160.00 \ldots \ldots \ldots . . .$. \\
\hline$€ 7.50 \ldots \ldots \ldots \ldots . . . \cdot \square_{4}$ & 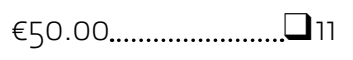 & $€ 180.00 \ldots \ldots \ldots \ldots . . . . .$. \\
\hline$€ 10.00 \ldots \ldots \ldots \ldots \ldots \ldots$ & $€ 60.00 \ldots \ldots \ldots \ldots \ldots \ldots \ldots \ldots$ & $€ 200.00 \ldots \ldots \ldots \ldots \ldots \ldots \ldots$ \\
\hline 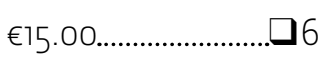 & $€ 80.00 \ldots \ldots \ldots \ldots \ldots \ldots \ldots \ldots \ldots . . . . . . . . .13$ & More than $€ 200 \ldots . . . . . . \square_{20}$ \\
\hline$€ 20.00 \ldots$. & $€ 100.00 \ldots .$. & Specify_ \\
\hline
\end{tabular}

Fill in the MAXIMUM amount the respondent would be willing to pay for this expansion in this programme.

Maximum amount respondent willing to pay, $€$ Go to E.4

[Int: If the respondent is not able to give a maximum amount at E.3a go to E3b. If the respondent is able to give a maximum amount at E.3a go to E.4. if zero value go to E.5]

E.3b [Int: Ask only if respondent is not able to give the maximum amount at E.3a above] Look at Card 4 again and could you please tell me the amounts you are sure that you would pay and the amounts that you are sure you would not pay.

[Int: Show the respondent Card 4 again. ask them to tell you the amounts they are sure they would definitely be willing to pay and put a Tick in the boxes below for these amounts; and the amounts that they are sure they would not be willing to pay - put an $X$ in the boxes below for these amounts]

AMOUNT PER YEAR

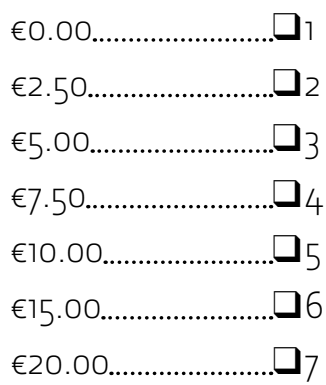

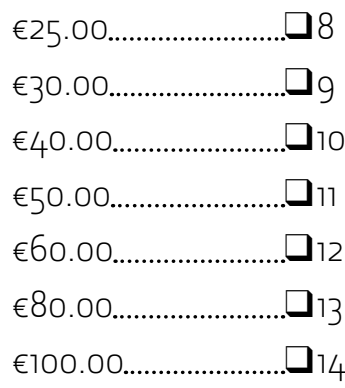

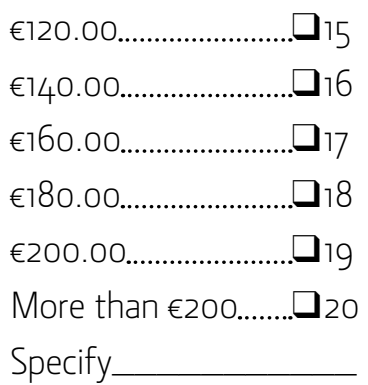


Fill in the highest amount the respondent is sure they would pay and the lowest amount they are sure they would not pay, below.

Highest amount respondent is sure they would pay, $€$ [Highest $\boldsymbol{V}$ Box] Lowest amount respondent is sure they would not pay, $€$ [Lowest $\boldsymbol{X}$ Box]

If you had to give one value in this range, what would it be? Record this value below.

If the respondent cannot give a value, ask them if a value in the middle of the range would be $O K$, if it is, record this value below.

Value from the range or middle value, $€$ (Int. If zero value go to E.5)

E.4 Could you please explain the reasons why your household would be willing to contribute to this expansion?

[Int: Show the respondent Card 5 and read out all of the reasons. Tick the appropriate box(es) in Column A. If the respondent gives more than one reason in Column A, ask them which one they would regard as the most important reason and tick that box in column B]

$\begin{array}{rr}\text { Column A } & \text { Column B } \\ \text { Important } & \text { Most } \\ \text { reasons } & \text { important } \\ & \text { reason }\end{array}$

I, or a member of my household, might benefit

(1) ... 1

A member of my family or a friend has used the service.. - 2 .

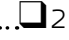

Other people will benefit - 3 .

The programme will improve health . 4

Promote more equal access to care - 5 $\cdot 3$

Reassuring to know care is accessible 06 $\pm 5$ I would support technical progress in medicine . 7 7... .06

Other (Please specify) . 8. 8

[Int: now Take all cards back from the respondent and go to SECTION C 'CANCER TREATMENTS' below ] 
[Int: only ask $E_{5}$ if respondent not willing to pay for expansion of service]

E. 5 Could you please tell me which one of the listed reasons best explains why you would not be willing to pay for the expansion of this service?

[Int: Show Card 6 and tick one box (the main reason)]

This programme is of no value to my household.

Other programmes are more valuable

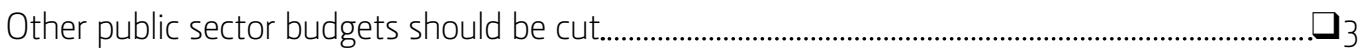

Other groups in society should pay.............................................................................................................

The users should pay........................................................................................................................

Health service should be more efficient ..............................................................................................

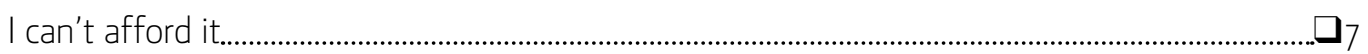

Prefer other ways of paying (private/voluntary insurance, etc.)................................................. 8

Other (Please specify)__

[Int: Take all cards back from the respondent and go to SECTION C 'CANCER TREATMENTS' below]

\section{Willingness to Pay for an Expansion in Cancer Treatments}

I would now like to repeat this valuation exercise with the Cancer Programme. Please ignore the other two programmes for the time being, the only thing I want you to consider now is the Cancer Programme.

Give the respondent Card 1 again and again read the card out to the respondent.

C. 1 Would your household be willing to contribute anything in extra income tax for this expansion in the number of CANCER TREATMENTS?

Yes No Don't know No one in the household pays income tax 
[Int: if the respondent does not themselves pay tax but someone in the household does, tick box number 3 for Don't Know and go to the next question]

C.2 If the payment was in terms of a voluntary donation, would your household be willing to pay for this expansion in the number of CANCER TREATMENTS?
Yes
No $\square_{2}$
Don't Know $\square_{3}$

[Int: If the respondent answered Yes to either $C .1$ or $C .2$ go to C.3a. If the respondent did not answer Yes to either C.1 or C.2 go to C.5]

C3a How much is the MAXIMUM your household would be willing to contribute each year for this expansion in the number of CANCER TREATMENTS? Please bear in mind that your contribution would reduce what you have left to spend on other things.

Show the respondent Card 4. Point out that the card also shows the approximate amount per week. Ask the respondent to select the MAXIMUM value he/she would be willing to pay per year and tick one box.

AMOUNT PER YEAR

\begin{tabular}{|c|c|c|}
\hline$€ 0.00 \ldots \ldots \ldots \ldots \ldots \ldots \ldots . . . \cdot \square_{1}$ & $€ 25.00 \ldots \ldots \ldots \ldots \ldots \ldots \ldots \ldots \ldots$ & $€ 120.00 \ldots \ldots \ldots . .$. \\
\hline$€ 2.50 \ldots \ldots \ldots \ldots \ldots \ldots \ldots . . . \cdot \square_{2}$ & $€ 30.00 \ldots \ldots \ldots . .$. & $€ 140.00 \ldots \ldots \ldots$ \\
\hline$€ 5.00 \ldots \ldots \ldots \ldots \ldots$ & 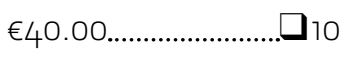 & $€ 160.00 \ldots \ldots \ldots . . .$. \\
\hline$€ 7.50 \ldots \ldots \ldots \ldots . . .$. & $€ 50.00 \ldots \ldots \ldots$ & $€ 180.00 \ldots \ldots .$. \\
\hline 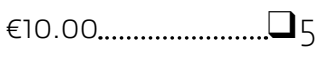 & $€ 60.00 \ldots \ldots . . .$. & $€ 200.00 \ldots \ldots$ \\
\hline$€ 15.00 \ldots \ldots \ldots \ldots \ldots \ldots$ & 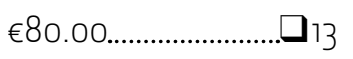 & More than $€ 200 \ldots \ldots . . . \square_{20}$ \\
\hline $20.00 \ldots \ldots \ldots . . .$. & $€ 100.00 \ldots . . . .$. & Specify_ \\
\hline
\end{tabular}

Fill in the MAXIMUM amount the respondent would be willing to pay for this expansion in this programme.

Maximum amount respondent willing to pay, $€$ Co to $\mathrm{C} .4$

[Int: If the respondent is not able to give a maximum amount at C.3a go to C.3b. If the respondent is able to give a maximum amount at C.3a go to C.4. if zero value go to C.5] 
C.3b [Int: Ask only if respondent is not able to give the maximum amount at C.3a above] Look at Card 4 again and could you please tell me the amounts you are sure that you would pay and the amounts that you are sure you would not pay.

[Int: Show the respondent Card 4 again. ask them to tell you the amounts they are sure they would definitely be willing to pay and put a Tick $\boldsymbol{V}$ in the boxes below for these amounts; and the amounts that they are sure they would not be willing to pay - put an $\boldsymbol{X}$ in the boxes below for these amounts]

AMOUNT PER YEAR

\begin{tabular}{|c|c|c|}
\hline 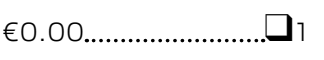 & $€ 25.00 \ldots \ldots \ldots \ldots \ldots \ldots$ & $€ 120.00 \ldots \ldots \ldots \ldots \ldots \ldots \ldots$ \\
\hline$€ 2.50 \ldots \ldots \ldots \ldots . . . .$. & $€ 30.00 \ldots \ldots \ldots . . .$. & $€ 140.00 \ldots \ldots \ldots$ \\
\hline$€ 5.00 \ldots \ldots \ldots \ldots \ldots . . . .$. & $€ 40.00 \ldots \ldots \ldots . . . .$. & $€ 160.00 \ldots \ldots \ldots . . .$. \\
\hline$€ 7.50 . \ldots \ldots \ldots \ldots \ldots \ldots . . . . .$. & $€ 50.00 \ldots \ldots$ & $€ 180.00 \ldots \ldots$. \\
\hline$€ 10.00 \ldots \ldots \ldots \ldots \ldots \ldots \ldots \ldots \ldots \ldots \ldots \ldots$ & $€ 60.00 \ldots \ldots . .$. & $€ 200.00 \ldots \ldots$ \\
\hline$€ 15.00 \ldots \ldots \ldots \ldots \ldots . . . .6$ & $€ 80.00 \ldots \ldots \ldots \ldots \ldots \ldots \ldots$ & More than $€ 200 \ldots . . . . . . D_{20}$ \\
\hline$€ 20.00 \ldots \ldots . . .$. & $€ 100.00 \ldots \ldots . .$. & Specify_ \\
\hline
\end{tabular}

[Int: Fill in the highest amount the respondent is sure they would pay and the lowest amount they are sure they would not pay, below].

Highest amount respondent is sure they would pay, $€$ [Highest $\boldsymbol{\sim}$ Box] Lowest amount respondent is sure they would not pay, $€$ [Lowest $\boldsymbol{X}$ Box]

If you had to give one value in this range, what would it be? [INT:Record this value below].

[INT:If the respondent cannot give a value, ask them if a value in the middle of the range would be $O K$, if it is, record this value below.

Value from the range or middle value, $€$ [Int. If zero value go to C.5] 
C.4 Could you please explain the reasons why your household would be willing to contribute to this expansion?

[Int: Show the respondent Card 5 and read out all of the reasons. Tick the appropriate box(es) in Column A. If the respondent gives more than one reason in Column A, ask them which one they would regard as the most important reason and tick that box in column B]

$\begin{array}{rr}\text { Column A } & \text { Column B } \\ \text { Important } & \text { Most } \\ \text { reasons } & \text { important } \\ & \text { reason }\end{array}$

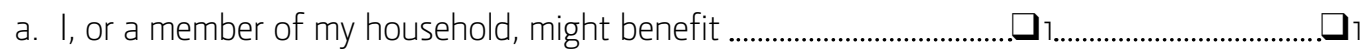

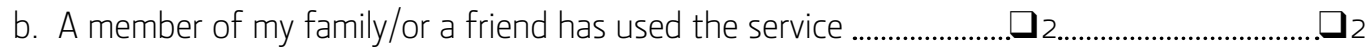

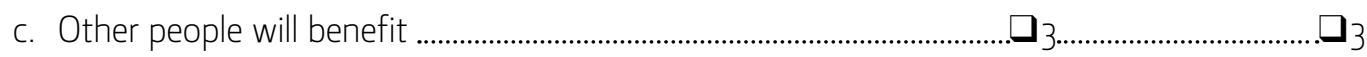

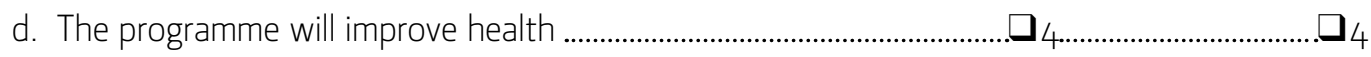

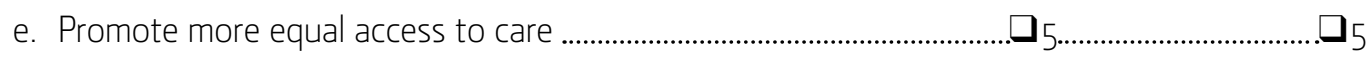

f. Reassuring to know care is accessible ........................................................................... 6 6

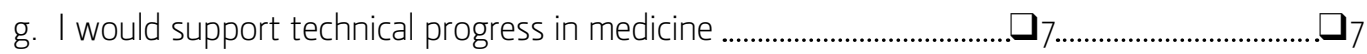

h. Other (Please specify) ....................................................................... $\square$ 8

[Int: now take all cards back from the respondent and go to $F_{7}$ below]

[Int: only ask $C_{5}$ if household not willing to pay for the expansion of the service].

C. 5 Could you please tell me which one of the listed reasons best explains why you would not be willing to pay for the expansion of this service?

[Int: Show Card 6 and tick one box (the main reason)]

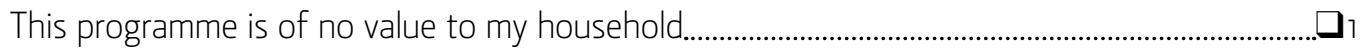

Other programmes are more valuable.......................................................................................................

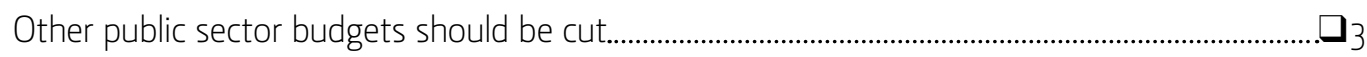

Other groups in society should pay................................................................................................

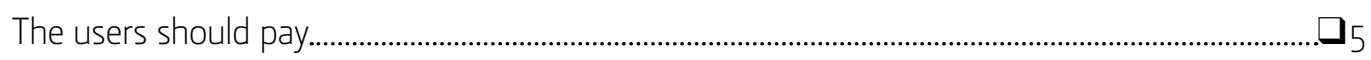

Health service should be more efficient................................................................................................

I can't afford it....................................................................................................................

Prefer other ways of paying (private/voluntary insurance, etc.)......................................................... 88

Other (Please specify)__ 
[Int: Take all cards back from the respondent and go to f7]

\section{F. Difficulties with the Questions}

F.1 Did you find it difficult to answer these questions on how much you would be willing to pay for the expansion of each of the three health programmes?

Yes .......... 1 (Go to F.2) No............ 2 (Go to G.1)

F.2 Why did you find it difficult?

[Int: Record as fully as possible on a verbatim basis]

\section{G. [For the Interviewer]}

[Int: Answer the interviewers' question below and then go to H.1]

How would you assess the respondent's degree of interest in the survey, on a 1-5 scale where ' 1 ' means not at all interested and ' 5 ' means extremely interested. Please tick the box which you feel best describes the level of interest shown by the respondent to the survey.

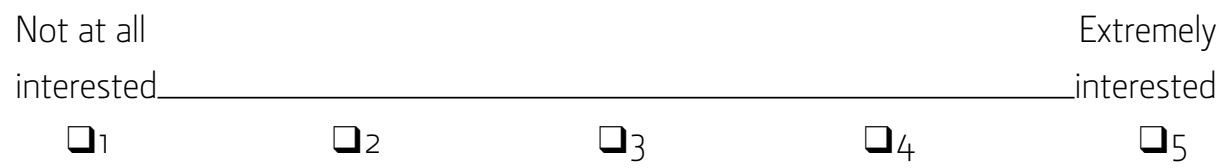

\section{H. Demograpic Details}

So that we can analyse the responses we get from different people, I would now like to ask you a few questions about yourself and your household 
H.1

(Int: record the respondent's sex]

Male …............... $\beth_{1} \quad$ Female ……............

H.2a How many persons (including yourself) live in your household?

H.2b Of these, how many (including yourself if relevant) are aged 65 years or more?

H.2C How many (including yourself if relevant) are aged between 16 and 64 years?

H.2d How many are aged less than 16 years?

[Int: Record the respondent's answers above, if none for any category do not leave blank, write none or o] [Int: Check that the total at $\left(\mathrm{H}_{2} \mathrm{a}\right)=\left(\mathrm{H}_{2} \mathrm{~b}\right)+\left(\mathrm{H}_{2} \mathrm{C}\right)+\left(\mathrm{H}_{2} \mathrm{~d}\right)$

H.3 What is your marital status:

$\begin{array}{ll}\text { Married.............................. } & \text { Divorced/Separated............ } \square_{4} \\ \text { Living with partner........... } & \text { Never Married/Single........... } \square_{5} \\ \text { Widowed........................ } & \end{array}$

H.4 What is your date of birth?

(Day) (Month) (Year)

H. 5 What is the highest level of education that you attained? [Int: Tick one box]

None. Leaving Cert or equivalent . 7

Incomplete Primar........................................... Third Level incomplete.. .08

Complete Primary. Certificate or diploma. 99

Some Second Level. University primary degree or equivalent....... $\square_{10}$ Group Cert or equivalent. $\square_{5}$ University higher degree or equivalent...

Junior/Intermediate Cert or equivalent... $\square_{11}$ 
H. 6 What is [was] your employment status?

\begin{tabular}{|c|c|c|}
\hline alf-employed.. & $\square_{1}$ & Retired/Pensioners..... \\
\hline Paid Employee. & $\nabla_{2}$ & Student.... \\
\hline lome Duties..... & $\nabla_{3}$ & II/Disabled... \\
\hline Unemployed... & $a_{4}$ & Other (Please specify)... \\
\hline
\end{tabular}

H.7a What is [was] your occupation? Please describe as fully as possible the nature of the work you do?

[Int: If the respondent is a farmer please record the acreage farmed] [Int: If not working but worked in the past, ask about usual former occupation]

H.7b How would you classify yourself in terms of your occupation?

[Int: or former occupation if worked in the past]

Self-employed (not farmer)........................... $\square_{1} \quad$ Skilled manual worker..................................

Farmer (self-employed)................................... Un 2 Unskilled manual worker............................... 6

Professional/Senior managerial.................... $\square_{3} \quad$ Never worked................................................

Other non-manual worker.................................

Other (Please specify)............................................

H.8a Are you the main earner in this household?

$$
\text { Yes........... } 1 \text { (Go to H.9) No............ } 2 \text { Go to H.8b) }
$$

$\mathrm{H} .8 \mathrm{~b}$ What is [was] the occupation of the main earner in the household? Please describe as fully as possible the nature of the work he/she does?

[Int: If the respondent is a farmer please record the acreage farmed]

[Int: Ask if not working now but worked in the past] 
H.8c How would you classify the main earner in the household in terms of his/her occupation [or former occupation]?

\begin{tabular}{|c|c|}
\hline Self-employed (not farmer).. & Skilled manual worker... \\
\hline Farmer (self-employed)............. & Unskilled manual worker.. \\
\hline Professional/Senior managerial....... & Never worked... \\
\hline Dther non-manual worker...................... & Don't know.... \\
\hline & Dther (Please specify). \\
\hline
\end{tabular}

H.9 Could I ask you about the approximate level of net household income. This means the total income, after tax, PRSI and other statutory deductions, of all members of the household. It includes all types of income: income from employment, social welfare payments, rents, interest, pensions, etc. We would just like to know which of twelve broad groups the total income of your household falls into. The groups are shown on this card. Perhaps you would like to look at it and tell me into which of the 12 groups (A to $\mathrm{M}$ ) your household falls. I would like to assure you once again that all information you give me is entirely confidential.

[Int: Show the respondent Card 7]

\section{Net Household Income}

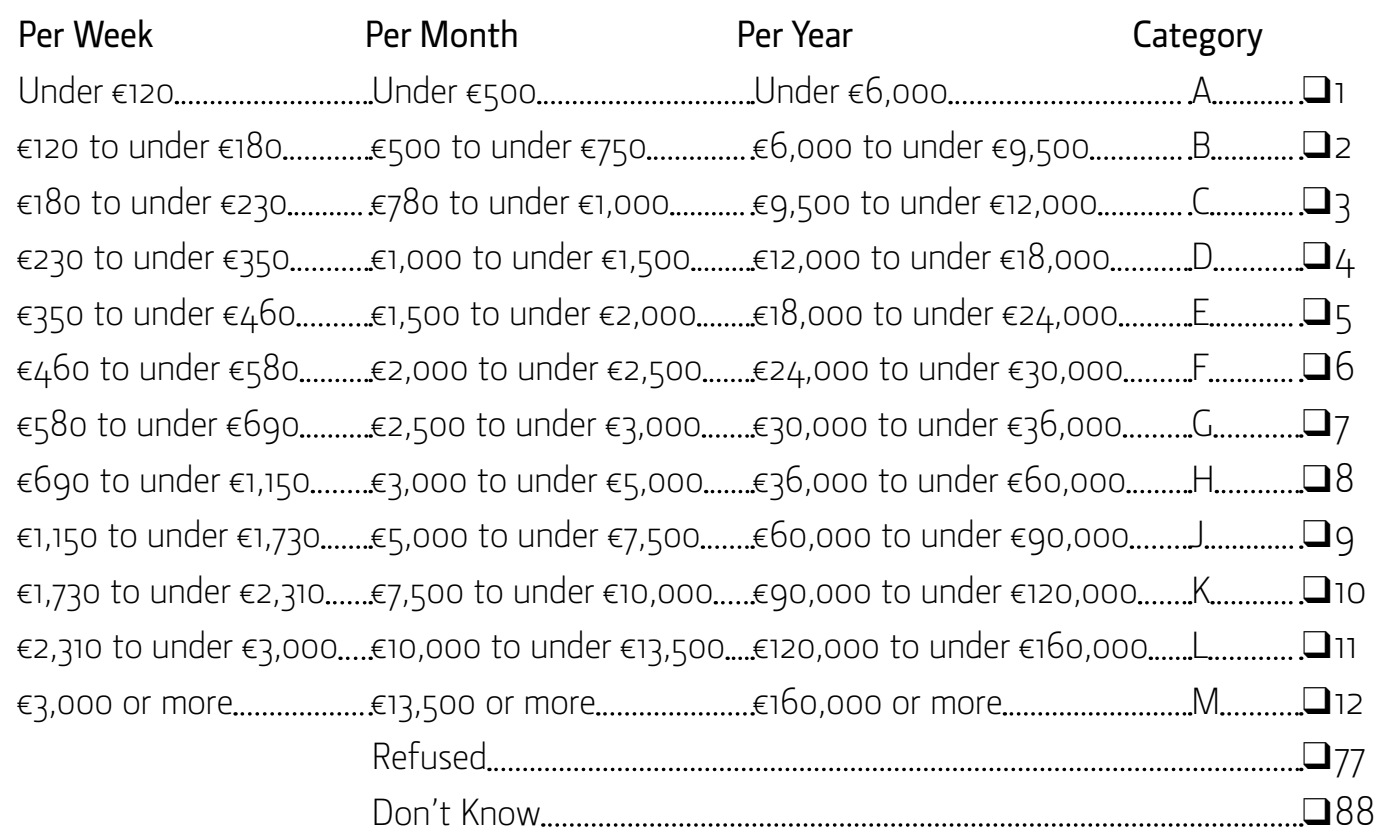


H. 9 If your NET household income is less than $€ 180$ per week, could you tell me whether or not this was approximately in the range of:

Under $€ 65$ per week

. $1 \quad € 95-€ 124$ per week

. 2 €125-€179 per week.

H.10 Taking your age into account, how would you describe your health?

$\begin{array}{ccccc}\text { Excellent } & \text { Cood } & \begin{array}{c}\text { Neither Good } \\ \text { Nor Bad }\end{array} & \text { Poor } & \text { Very Poor } \\ \square_{1} & \square_{2} & \square_{3} & \square_{4} & \square_{5}\end{array}$

H.11 In the last 12 months how many times have you consulted, or been visited at home, by a doctor? Please do not include visits on behalf of someone else such as a child. [Int: This includes both general practitioners and hospital-based consultants]

$\begin{array}{cccc}\text { Never } & \text { Once } & 2-5 \text { times } & 6 \text { times or more } \\ \square_{1} & \square_{2} & \square_{3} & \square_{4}\end{array}$

H.12 Are you covered by a Medical Card, either in your own name or through someone else's card?

Holder of a Medical Card

Covered on someone else's Medical Card.................

Not covered by a Medical Card

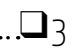

H.13 Are you (also) medically insured (through VHI, BUPA, or any other health insurance company) either in your own name or through another family member?

Yes, in own name.

Yes, through family cover.

Not medically insured.

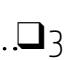

H.14 Do you smoke daily, occasionally or never?

Daily.......... 1 Occasionally........... $]_{2} \rightarrow(\text { Go to H.16) Never........... }]_{3} \rightarrow($ Go to H.16) 
H.15 If you smoke daily how many cigarettes would you smoke in a day?

Number of cigarettes smoked by respondent on a daily basis:

H.16 In general how often would you say that you take an alcoholic drink?

\begin{tabular}{|c|c|}
\hline Every day.......................... & About once a month............... \\
\hline A few times per week & Less than once a month.................................... 6 \\
\hline Once a week & 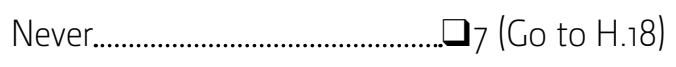 \\
\hline
\end{tabular}

H.17 When you have a drink how much would you usually drink?

[Int: If the respondent answered that they drink every day, ask the question in relation to what they drink on a daily basis, if they answered that they drink a few times a week or weekly, ask the question in relation to what they drink on a weekly basis and if they answered that they drink monthly or a few times a month, ask the question on the basis of what they would drink in a month and if they drink less than once a month, ask the question on the basis of what they would drink during the year]

Pints Glasses of spirits Classes of wine Other (Specify)

$\mathrm{H} .18$ If more resources were available for health care and prevention, in your opinion, which three of the areas on this card should be expanded? [Int: Show the respondent Card 8 and tick three boxes]

\section{Resources for Health Care or prevention of...}

\begin{tabular}{|c|c|}
\hline Motor vehicle accidents................................. & Cancers........ \\
\hline Heart diseases.......... & Diabetes........... \\
\hline 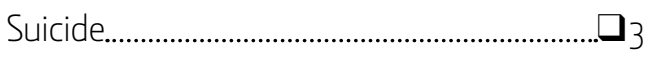 & Mental health.... \\
\hline Community care for the elderly.......................... $\square_{4}$ & Smoking... \\
\hline Residential care for the elderly...................... & Alcoholism... \\
\hline Children's domestic accidents.......................... 6 6 & Drug Treatment.... \\
\hline Obstetric care.................................................... & Back pain.................. \\
\hline & Other (Pleas \\
\hline
\end{tabular}


Time interview ended

(24 hour clock)

Thank you very much for your participation 


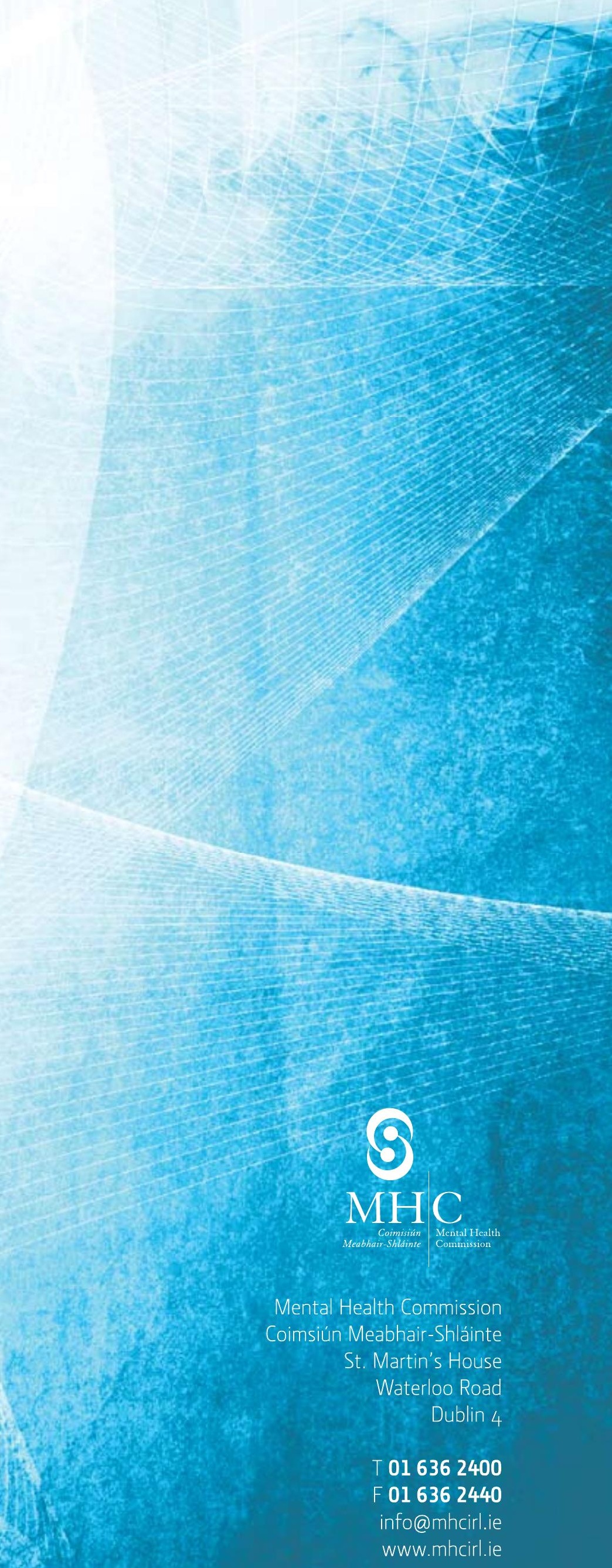

